\title{
Review \\ Advances in Electrochemical Detection Electrodes for As(III)
}

\author{
Haibing $\mathrm{Hu}{ }^{1, *(\mathbb{D})}$, Baozhu Xie ${ }^{1}$, Yangtian $\mathrm{Lu}^{1}$ and Jianxiong $\mathrm{Zhu}^{2, *}$
}

1 Academy of Opto-Electric Technology, Special Display and Imaging Technology Innovation Center of Anhui Province, National Engineering Laboratory of Special Display Technology, State Key Laboratory of Advanced Display Technology, Collaborative Innovation Center of Advanced Display Technology, Anhui Key Laboratory of Advanced Imaging and Display Technology, Opto-Electric Display Industry Innovation Center, Anhui Province Key Laboratory of Measuring Theory and Precision Instrument, School of Instrument Science and Optoelectronics Engineering, Hefei University of Technology, Hefei 230009, China; xie_bz@163.com (B.X.); hfut_lyt@163.com (Y.L.)

2 School of Mechanical Engineering, Southeast University, Nanjing 211189, China

* $\quad$ Correspondence: huhb@hfut.edu.cn (H.H.); mezhujx@seu.edu.cn (J.Z.); Tel.: +86-1811-097-2015 (H.H.)

\section{check for}

updates

Citation: Hu, H.; Xie, B.; Lu, Y.; Zhu, J. Advances in Electrochemical Detection Electrodes for $\mathrm{As}(\mathrm{III})$. Nanomaterials 2022, 12, 781. https:// doi.org/10.3390/nano12050781

Academic Editor: Lyubov G. Bulusheva

Received: 27 January 2022

Accepted: 17 February 2022

Published: 25 February 2022

Publisher's Note: MDPI stays neutral with regard to jurisdictional claims in published maps and institutional affiliations.

Copyright: (c) 2022 by the authors. Licensee MDPI, Basel, Switzerland. This article is an open access article distributed under the terms and conditions of the Creative Commons Attribution (CC BY) license (https:// creativecommons.org/licenses/by/ $4.0 /)$.

\begin{abstract}
Arsenic is extremely abundant in the Earth's crust and is one of the most common environmental pollutants in nature. In the natural water environment and surface soil, arsenic exists mainly in the form of trivalent arsenite (As(III)) and pentavalent arsenate (As(V)) ions, and its toxicity can be a serious threat to human health. In order to manage the increasingly serious arsenic pollution in the living environment and maintain a healthy and beautiful ecosystem for human beings, it is urgent to conduct research on an efficient sensing method suitable for the detection of As(III) ions. Electrochemical sensing has the advantages of simple instrumentation, high sensitivity, good selectivity, portability, and the ability to be analyzed on site. This paper reviews various electrode systems developed in recent years based on nanomaterials such as noble metals, bimetals, other metals and their compounds, carbon nano, and biomolecules, with a focus on electrodes modified with noble metal and metal compound nanomaterials, and evaluates their performance for the detection of arsenic. They have great potential for achieving the rapid detection of arsenic due to their excellent sensitivity and strong interference immunity. In addition, this paper discusses the relatively rare application of silicon and its compounds as well as novel polymers in achieving arsenic detection, which provides new ideas for investigating novel nanomaterial sensing. We hope that this review will further advance the research progress of high-performance arsenic sensors based on novel nanomaterials.
\end{abstract}

Keywords: As(III) detection; electrochemical sensing; nanosensing; biosensing

\section{Introduction}

In China and the rest of the world, environmental pollution has always been an urgent problem that threatens the living environment and health of human beings. A variety of forms of environmental pollution exist at the same time, including soil, air, radioactive elements, water pollution, and so on. Among the most direct and obvious causes of harm to human beings, the heavy metal pollution of water environments, the toxicity of heavy metal-like arsenic (As) ions, and the degree of difficulty in detecting and removing them constitutes one of the most important forms of environmental pollution. Arsenic is an element that is widely distributed in soil, minerals, the aquatic environment, and the atmosphere. In terms of arsenic abundance, it ranks 20th in the Earth's crust, 14th in seawater, and 12th in human systems when comparing all elements [1]. Widespread in nature, arsenic and its compounds are mobile in the environment and, when dissolved in the water species of arsenic, contamination will even enter the biosphere through the food chain. As early as the 1970s, in a study by the U.S. National Pesticide Monitoring Program targeting the detection of mercury, arsenic, lead, cadmium, and selenium residues in fish, the results show that more than $95 \%$ of the combined samples have detectable residues 
of all metals. This number is increasing year by year [2]. In natural water bodies, arsenic is usually present as arsenite $(\mathrm{As}(\mathrm{III}))$, arsenate $(\mathrm{As}(\mathrm{V}))$, monomethylarsenic acid (MMA), and dimethylarsenic acid (DMA). Inorganic forms of arsenite (As(III)) and arsenate ( $\mathrm{As}(\mathrm{V}))$ have stronger circulation and are more likely to be enriched in the food chain, which is the main form of arsenic present in nature and has a great impact on human survival.

Heavy metals are a very important class of carcinogens, especially nickel, chromium, and arsenic, which are recognized as human carcinogens [3]. Radon and arsenic exposure were recognized as major risk factors in a cohort of Chinese tin miners with lung cancer [4]. Additionally, in China, Y J Lu et al. studied mineral dust deposition in the lungs of tin miners in Yunnan Province, and data obtained in lung tissue provided evidence for arsenic as a cause of lung cancer [5]. Exposure to inorganic arsenic in drinking water has the potential to cause changes in left ventricular geometry and cardiomegaly in adult males [6]. There are many ways for humans and animals to be exposed to arsenic (mainly through drinking water and the accumulation of arsenic in the food chain). Long-term exposure to arsenic ions may lead to a series of physiological diseases, including neurological, physiological, reproductive, kidney, liver, and even genetic conditions [7]. There is serious arsenic contamination of water and soil in many countries around the world, including China, and there was a large-scale arsenic ion poisoning incident in Bangladesh $[8,9]$.

It is on account of these characteristics of arsenic that the detection of trace amounts of arsenic is very important. As early as the nineteenth century, John Bostock realized the importance of detecting traces of arsenic and observed different methods of doing so [10]. In 1901, S Delepine applied arsenic detection technology to life, detecting arsenic in beer and brewing materials [11]. In the following years, various techniques were applied to arsenic detection, and these techniques are divided into two main categories according to the instruments used: one is the use of traditional instrumentation techniques, including atomic absorption spectrometry, atomic emission spectrometry, inductively coupled plasma mass spectrometry, etc. The second is the use of new sensor methods, mainly biosensor methods, electrochemical detection, and the ultraviolet-visible spectroscopy (UV-Vis), colorimetric method, etc. In this paper, electrochemical detection methods will be introduced. Electrochemical detection has a series of advantages such as simple instrumentation, simple operation, high sensitivity, high selectivity, being easy to carry, and being easy to use for rapid detection. Electrochemical detection methods are an effective alternative to traditional ion detection methods.

\section{Principles of Electrochemical Detection of As(III)}

Probably one of the oldest measurement techniques, the electrochemical method, is an analytical method based on electrochemical principles and founded on the electrochemical properties of a substance in solution, which implies the transfer of charge between the electrode and the liquid or solid phase [12]. During the detection, the solution to be tested is usually used as part of a chemical cell, which reacts to the concentration of the substance being detected by means of the electrical parameters of the chemical cell. Compared with other arsenic detection methods, electrochemical detection is considered to be user-friendly and achieves a more desirable detection result, while the detection process is simple and cost effective. After a long period of development, electrochemical detection techniques to detect arsenic have become more mature, and there are many commonly methods based on various electrical signals used in the detection of heavy metals. Electrochemical techniques are divided into amperometric, voltammetric, potentiometric, impedance measurements, coulometric, and electrochemiluminescent techniques [13]. The general apparatus for electrochemical detection is shown in Figure 1 and usually consists of an electrolytic cell in which the heavy metal ions or other classes of heavy metal ions to be detected act as the electrolyte. A chemical reaction occurs in the cell, partly at the working electrode, resulting in a change in the electrical parameters that establish a link with the concentration of the target element for the purpose of quantitative analysis. 


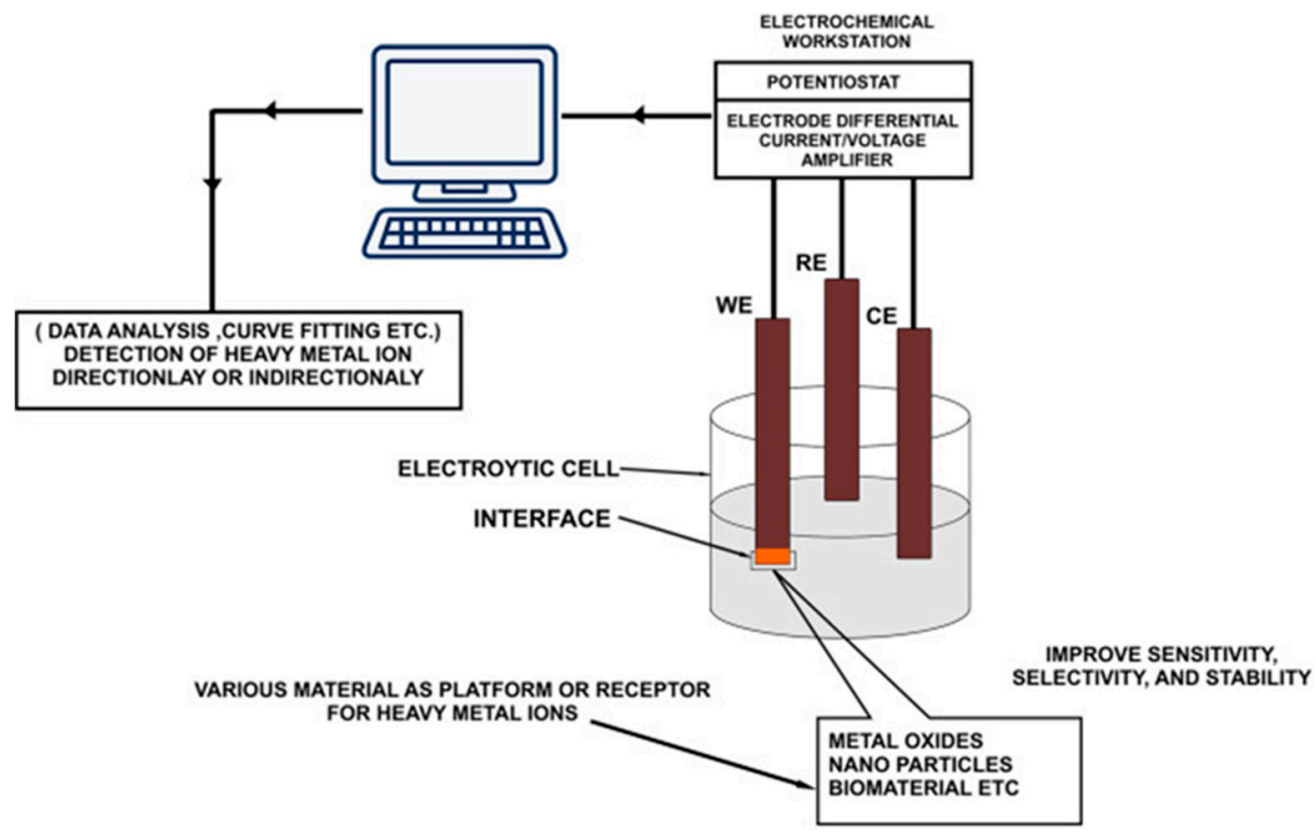

Figure 1. General apparatus for electrochemical detection of arsenic. (Reprinted with permission from [13], Copyright 2017, Elsevier B.V.)

Voltammetry is considered the most versatile of the arsenic ion assays and has been further advanced with the development of potential and current modulation techniques, such as differential pulse voltammetry (DPV), square-wave voltammetry (SWV), stripping chronopotentiometry (SCP), etc. Voltammetry is based on the voltage-current time relationship generated in a three-electrode cell; the position of the peak is reflective of the specific chemical, and the density of the peak is related to the concentration of the substance being detected. The combination of electrode modification and pre-concentration techniques further increases the selectivity and sensitivity of voltammetry.

\section{Electrochemical Detection Electrodes for As(III)}

During decades of research, electrodes have often been modified in order to improve the sensitivity and selectivity of the electrochemical detection of ions. In the beginning, the excellent electrical properties of precious metals (e.g., gold and silver) were taken into account and a large number of electrodes made of precious metals were used for electrochemical detection. Later, there were considerations of cost constraints, reducing the amount of precious metals, and modifying the working electrodes with precious metals and their nanoparticles to achieve the same detection results. To further reduce costs, a range of materials including carbon nanomaterials, non-precious metal oxides, and bimetallic nanoparticles have been used for detection, again well below the WHO (World Health Organization) detection limit of $10 \mathrm{ppb}$. Additionally, in today's interdisciplinary world, there are many biotechnologies used for electrochemical detection, with examples of bioreceptors such as DNA or proteins being used for modified electrodes.

\subsection{Precious Metal Electrodes and Precious-Metal-Modified Electrodes}

The excellent electrical properties of precious metals with good conductivity make them the preferred choice for electrode materials and their modifications in electrochemical detection. They show distinct advantages over the conventional macroelectrodes, such as increased mass transport, decreased influence of the solution resistance, low detection limit, and better signal-to-noise ratio [14]. In addition, precious metal particles can easily be deposited onto the electrode surface by electrochemical means, thus modifying the electrode and improving its overall surface properties. 


\subsubsection{Gold Electrodes and Gold-Modified Electrodes}

Gold electrodes in various forms and gold-modified materials have long been a popular topic in electrochemical detection. Agnese Giacomino et al. achieved a low detection limit of $0.060 \mathrm{ppb}$ in the range of $1-15 \mathrm{ppb}$ for the determination of As(III) by anodic dissolution voltammetry using a lateral gold electrode [15]. The electrochemical behavior of gold electrodes is closely related to their crystal orientation, and single-crystal $\mathrm{Au}(111)$ electrodes with clean, well-defined, and ordered surfaces can provide a more defined electrochemical behavior for As detection and are suitable for studying deposition mechanisms. Mohammad Rezaur Rahman et al. reported a simple method for the fabrication of $\mathrm{Au}$ (111)-like poly-gold electrodes, achieving a low detection limit of $0.28 \mathrm{ppb}$ by squarewave anodic solvation voltammetry (SWASV) [16]. In addition, there are different sizes and forms of gold electrodes, including solid-disc gold electrodes [17], thin-film gold electrodes on glass carbon electrodes [18], graphite electrodes [19], platinum electrodes [20], microfilament gold electrodes [21], etc. Lijuan $\mathrm{Bu}$ et al. proposed the first method to electrically generate $\mathrm{H}_{2}$ to reduce $\mathrm{As}(\mathrm{III})$ and improve $\mathrm{As}(0)$ preconcentration on a gold disc electrode for the determination of As(III) by anodic stripping voltammetry, which improved the sensitivity of As(III) detection and achieved a detection limit of $1.0 \mathrm{nM}$ or $0.075 \mathrm{ppb}$ [22]. Gold wire microelectrodes are also a common class of gold electrodes and ChiZhou was able to detect $\mathrm{As}(\mathrm{III})$ down to $2.6 \mathrm{ppb}$ in $0.5 \mathrm{M} \mathrm{H}_{2} \mathrm{SO}_{4}$ by square-wave anodic dissolution voltammetry using electrochemically etched gold wire microelectrodes [23]. S. Laschi et al. tested a disposable gold screen-printed working electrode for arsenic detection in aqueous solutions using square-wave anodic dissolution voltammetry (SWASV) and achieved a detection limit of $2.5 \mathrm{ppb}$ after $60 \mathrm{~s}$ of deposition [24]. A self-made nanoporous gold microelectrode by Darío Xavier Orellana Jaramillo et al. had a high sensitivity of $29.75 \mu \mathrm{A}\left(\mu \mathrm{g} \mathrm{L}^{-1}\right)^{-1} \mathrm{~cm}^{-2}$ and a low detection limit of $0.62 \mathrm{ppb}$ [25]. More comparisons of different gold-based electrodes are given in Table 1.

Table 1. Comparison of gold electrodes.

\begin{tabular}{|c|c|c|c|c|c|}
\hline Electrode & Method & Sensitivity $(\mu \mathrm{A} / \mathrm{ppb})$ & Linear Range(ppb) & LOD (ppb) & Reference \\
\hline composite gold electrode & DPASV & & & 0.32 & [26] \\
\hline $\begin{array}{l}\text { gold side disk } \\
\text { rotating electrode }\end{array}$ & DPASV & & $5-80$ & & [27] \\
\hline gold screen-printed electrode & SWASV & 0.03 & $0-200$ & 2.5 & {$[24]$} \\
\hline gold film & $\mathrm{SCP}^{1}$ & & & 0.022 & [28] \\
\hline gold nanoelectrode ensembles & SWASV & 3.14 & & 0.02 & [29] \\
\hline gold nanofilm & $\mathrm{LSV}^{2}$ & & $0.2-375$ & 0.04 & [17] \\
\hline $\begin{array}{l}\mathrm{Au}(111) \text {-like polycrystalline } \\
\text { gold electrode }\end{array}$ & SWASV & $0.097 \mu \mathrm{A} \mathrm{ppb}{ }^{-1} \mathrm{~cm}^{-2}$ & $0-1123.8$ & 0.28 & [16] \\
\hline $\begin{array}{l}\text { vibrating gold } \\
\text { microwire electrode }\end{array}$ & DPASV & $0.014 \mu \mathrm{Appb}^{-1} \mathrm{~mm}^{-1} \mathrm{~V}^{-1}$ & $0.07-3.0$ & 0.07 & [21] \\
\hline lateral gold electrode & ASV & 9.15 & $0.1-15$ & 0.06 & [15] \\
\hline MEA-modified Au electrode & DPASV & 0.0366 & $0.2-300$ & 0.02 & [30] \\
\hline Au-MEE & LSASV & & $1-10$ & 0.09 & [31] \\
\hline Au disc electrode & ASV & 18.69 & $0.75-299.68$ & 0.075 & [22] \\
\hline $\begin{array}{l}\text { nanoporous gold } \\
\text { microelectrode }\end{array}$ & LSV & $1.74 \times 10^{-4}$ & $1.50-14,984$ & 1.50 & [32] \\
\hline two gold electrodes & ASV & & $0.0374-0.7492$ & 0.0097 & [33] \\
\hline Au-wire electrode & $\mathrm{ASCP}^{3}$ & & & 0.42 & [34] \\
\hline
\end{tabular}


Table 1. Cont.

\begin{tabular}{|c|c|c|c|c|c|}
\hline Electrode & Method & Sensitivity $(\mu \mathrm{A} / \mathrm{ppb})$ & Linear Range(ppb) & LOD (ppb) & Reference \\
\hline porous gold electrode & SWV & & $0.1-14$ & 0.1 & [35] \\
\hline gold electrode & ASV & & $0-5000$ & 850 & [36] \\
\hline $\begin{array}{l}\text { nanoporous gold } \\
\text { microelectrode }\end{array}$ & SWASV & $29.75 \mu \mathrm{A} \mathrm{ppb}{ }^{-1} \mathrm{~cm}^{-2}$ & $\begin{array}{c}2-30 \text { and } \\
10-200\end{array}$ & 0.62 & [25] \\
\hline gold wire microelectrode & ASV & $6.8 \mu \mathrm{A} \mathrm{ppb}^{-1} \mathrm{~cm}^{-2}$ & & 2.6 & [23] \\
\hline $\begin{array}{l}\text { arsenite-selective ionophore } \\
\text { film-Au }\end{array}$ & ASV & & 10-100 & 1.10 & [37] \\
\hline gold nanotextured electrode & ASV & $39.54 \mu \mathrm{A} \mathrm{ppb}^{-1} \mathrm{~cm}^{-2}$ & $0.1-9$ & 0.1 & [38] \\
\hline gold nanostar & SWSV $^{4}$ & & $2.5-764.2$ & 0.8 & [39] \\
\hline
\end{tabular}

Additionally, due to the detection cost of using gold as an electrode, there has been increasing amounts of research on gold nanoparticle-modified conventional macroscopic electrodes, such as modified graphite electrodes [19], glassy carbon electrodes [40], screenprinted electrodes [41], gold electrodes [17], solid carbon paste electrodes [42] or borondoped diamond electrodes [43], etc. Forsberg et al. tested three different materials (platinum, mercury, and gold) for modified electrodes [44], using anodic solvation voltammetry (ASV) and differential pulse anodic solvation voltammetry (DPASV), and found that the gold-modified electrodes were the most sensitive to the electrical signal generated by arsenic oxidation (which is one of the reasons why gold nanomaterials became the first material for modified electrodes). In addition to various forms of nanogold, other materials of composite-modified electrodes for the electrochemical detection of arsenic are a hot topic of research.

Supunnee Duangthong et al. developed a flow injection differential pulsed anodic dissolution voltammetry (FI-DPASV) method for the detection of arsenic, using a gold filmmodified glassy carbon electrode as the working electrode and optimizing the parameters to achieve a low detection limit of $0.81 \mathrm{ppb}$ in the linear interval 1.0-30 ppb for As(III) [45]. Syeda Sara Hassan et al. synthesized gold nanoflower structures by heating a mixture of ibuprofen and gold chloride $\left(\mathrm{HAuCl}_{4}\right)$ at a constant temperature for about $30 \mathrm{~min}$. The SEM images are shown in Figure 2. Ibu-AuPNFs modified screen-printed electrodes, followed by Nafion as a binder and stabilizer, were used in the $0.1-1800 \mathrm{ppb}$ range, observed for As(III) with a linear calibration plot with a lower limit of detection of $0.018 \mathrm{ppb}$ [46]. Tran Ngoc Huan proposed a three-dimensional (3D) gold ( $\mathrm{Au}$ ) nanodendritic network porous structure constructed by a simple electrochemical synthesis method, the SEM images of which in different views are shown in Figure 3, allowing for the more sensitive detection of As(III) due to its larger surface area [47]. Dao Anh Quang successfully synthesized and stabilized gold nanorods (GNR) using cetyltrimethylammonium bromide (GNR-CTAB) and poly(sodium-4-styrenesulfonate) (GNR-PSS); the TEM image and the diameter and length distribution of the synthesized nanorods are shown in Figure 4. The GNR-modified glassy carbon electrode showed an excellent response with a limit of detection (LOD) of $0.72 \mathrm{ppb}$ and a linear concentration of As(III) between 0.90 and $38.99 \mathrm{ppb}$ [48]. Dingnan Lu et al. reported a square-wave anodic dissolution voltammetry (SWASV) method using a new gold nanostar-modified screen-printed electrode (AuNS/SPCE) as the working electrode; the TEM image of the gold nanostar is shown in Figure 5. Electrochemical impedance spectroscopy tests showed that the charge transfer resistance of AuNS/SPCE $(0.8 \mathrm{k} \Omega)$ was significantly lower compared with bare SPCE $(2.4 \mathrm{k} \Omega)$, achieving a sensitivity of $0.2213 \mu \mathrm{A} / \mathrm{ppb}$ in the linear detection interval of 0-100 ppb for As(III) detection [49]. 


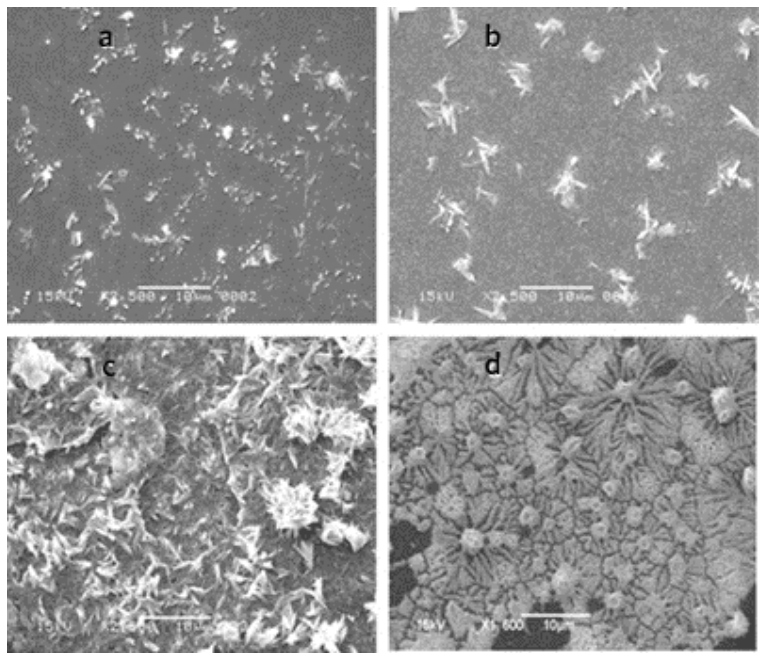

Figure 2. SEM images of Ibu-NSs at (a) 1, (b) 10, (c) 20, and (d) $30 \mathrm{~min}$ of heating time. (Reprinted with permission from [46], Copyright 2012, Elsevier B.V.)
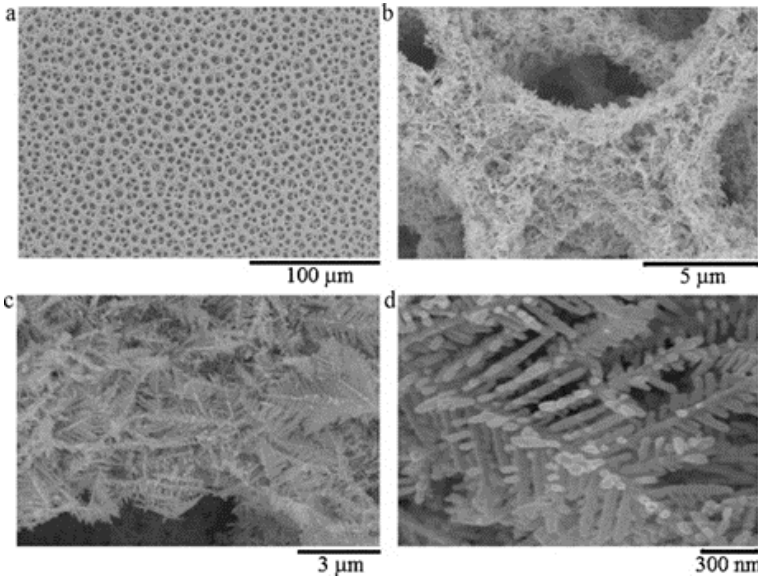

Figure 3. SEM images of porous structures of 3D Au nanodendritic networks with four different fields ((a) $100 \mu \mathrm{m}$, (b) $5 \mu \mathrm{m}$, (c) $3 \mu \mathrm{m}$, and (d) $300 \mathrm{~nm}$ ) of view. (Reprinted with permission from [47], Copyright 2011, Elsevier B.V.)
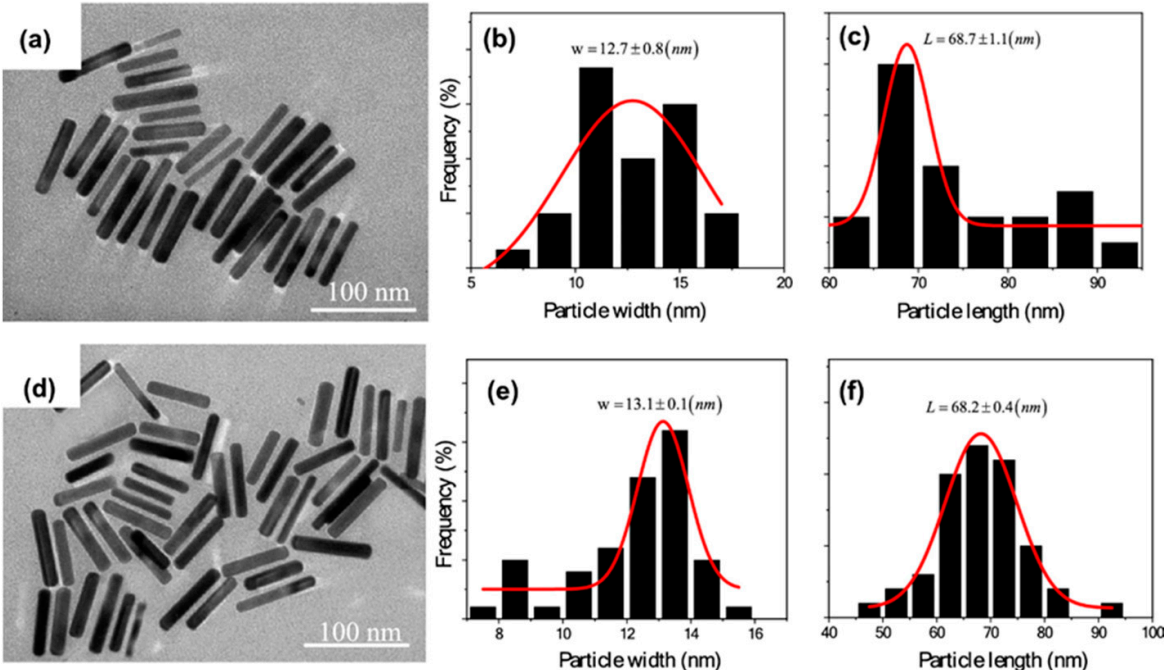

Figure 4. TEM images, diameter, and length distribution of GNR-CTAB (a-c) and GNR-PSS (d-f). (Reprinted with permission from [48], Copyright 2022, Springer Nature Switzerland AG.) 


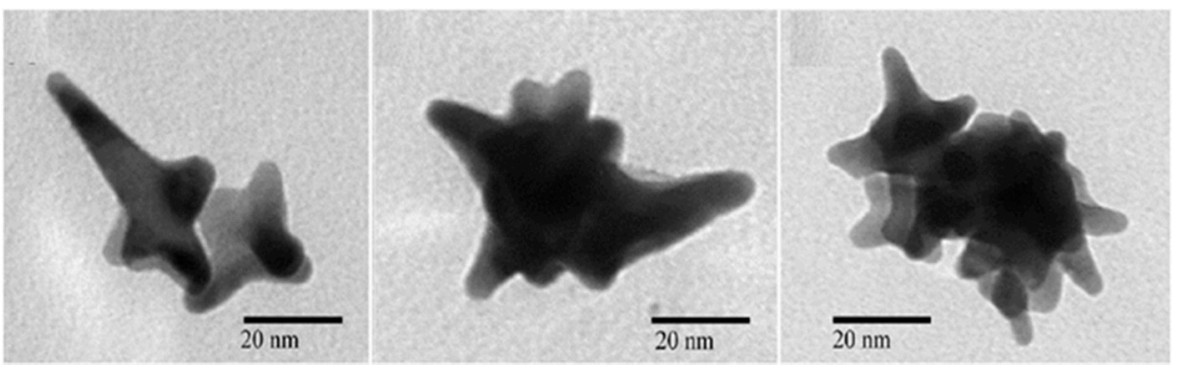

Figure 5. Representative TEM images of AuNS. (Reprinted with permission from [49], Copyright 2022, Springer Nature Switzerland AG.)

Among the many gold nanomaterials, gold nanoparticles and composites of gold nanoparticles on various materials are the absolute favorites in the field of electrochemical detection.

Anamarija Stanković et al. modified glassy carbon electrodes with gold nanoparticles and crystalline violet [50]. The electron impedance spectroscopy results show that the electron transfer resistance of the nanogold crystalline violet film was lower than that of the bare glassy carbon electrode, thus enhancing the electron transfer kinetics. The sensitivity of the modified electrode for the detection of As(III) was $5.6 \mathrm{~A} / \mu \mathrm{M} \mathrm{cm}^{2}$, the detection limit was $0.8 \mu \mathrm{M}$, and it had a good linear response in the range of 2.0-22.0 $\mu \mathrm{M}$. Connor Sullivan et al. used a screen-printed electrode modified with nanogold to detect As(III) in commercial apple juice by square-wave dissolution voltammetry. The sensitivity of the method was $0.1007 \mu \mathrm{A} \mathrm{ppb}^{-1}$ and the detection limit was $16.73 \mu \mathrm{g} \mathrm{L}^{-1}$. The results of voltammetry were compared with those of graphite furnace atomic absorption spectrometry, with no systematic deviation and an $\mathrm{R}^{2}$ of 0.939 [51]. In recent years, electro-membrane extraction (EME) and anodic stripping voltammetry (ASV) combined with gold nanoparticle-modified glassy carbon electrodes (AuNPs/GCE) have also been used to detect As (III) in water, with a detection limit of $0.18 \mu \mathrm{g} \mathrm{L}^{-1}$ for this method [52]. The application of electromagnetic radiation before electrochemical determination improves the selectivity and cleaning ability of the sample, which can increase the lifetime of the working electrode and reduce surface passivation.

A simple and easy method for synthesizing bentonite (bt) clay-supported gold nanoparticles (AuNPs) composites has been reported [53], and the test plots are shown in Figure 6. The AuNPs were successfully synthesized and doped into bt clay, as shown by spectroscopic, microscopic and electrochemical methods, and the synthesized Au-bt material was used to modify the glassy carbon electrode (GC). The GC/Au-bt electrode was used to detect As(III) in neutral solution by cyclic voltammetry. The GC/Au-bt electrode showed a wide linear range with good reproducibility and stability in As(III) solutions in the range of $1-1700 \mu \mathrm{M}$. The detection limit was $0.1 \mu \mathrm{M}$ with high sensitivity. In addition, it had good selectivity for the determination of $\mathrm{As}$ (III) in the presence of $\mathrm{Cu}$ (II) and other interfering ions, providing an effective new route for the measurement of As(III) under neutral conditions. Qian Tang et al. prepared Au-PANI-Fe-CNFs composites by forming polyaniline (PANI) nanosheet arrays on Fe-CNFs substrates followed by the self-deposition of Au nanoparticles; the process is shown in Figure 7, using the composite-modified glassy carbon electrode as a sensing platform for As(III) measurements [54]. Polyaniline showed a uniform array structure on the surface of carbon fibers (CNFs), and the presence of Fe in CNFs promoted the formation of polyaniline nanosheets and the adsorption of As(III) in the subsequent sensing process. The detection of As(III) in water has good electrochemical performance, and the SWASV response plot is shown in Figure 8. The electrode has a wide linear range (5-400 ppb) and high sensitivity with a detection limit of $0.5 \mathrm{ppb}$, which provides a new route for the electrochemical analysis of arsenic in water. 


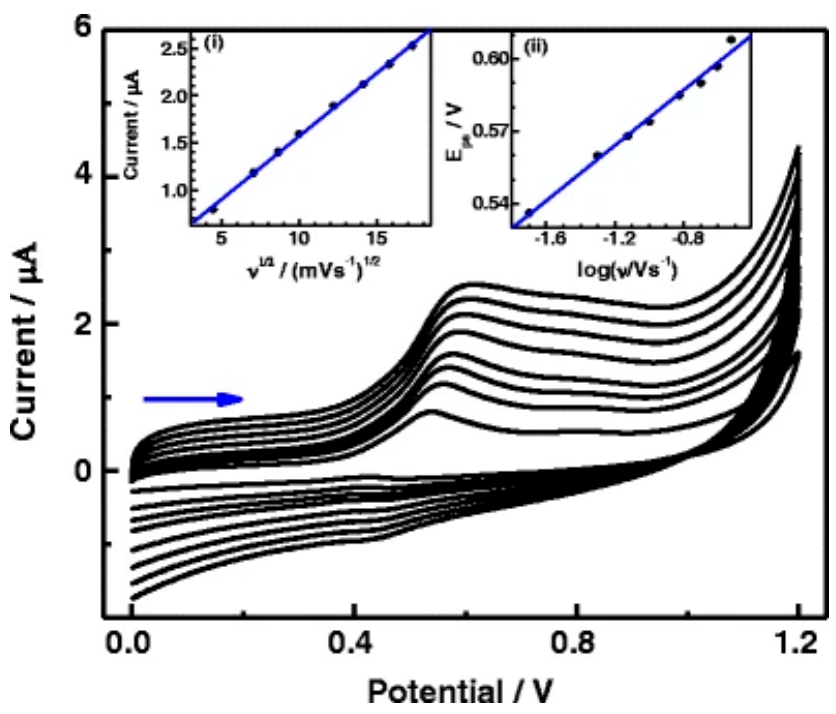

Figure 6. Cyclic voltammetric response of GC/Au-bt to $100.0 \mu \mathrm{M}$ As(III) oxidation at different scan rates. Inset (i) shows the plot of the oxidation peak currents against the square root of scan rates and inset (ii) shows the plot of the oxidation peak potential against the log of scan rate. (Reprinted with permission from [53], Copyright 2016, Springer Nature).

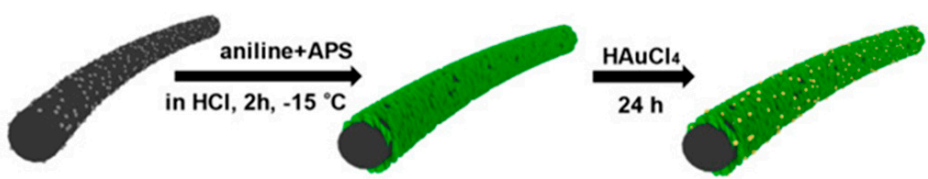

Fe-CNF

PANI-Fe-CNF

Au-PANI-Fe-CNF

Figure 7. Schematic diagram of the preparation process of Au-PANI-Fe-CNFs. (Reprinted with permission from [54], Copyright 2020, Elsevier B.V.)
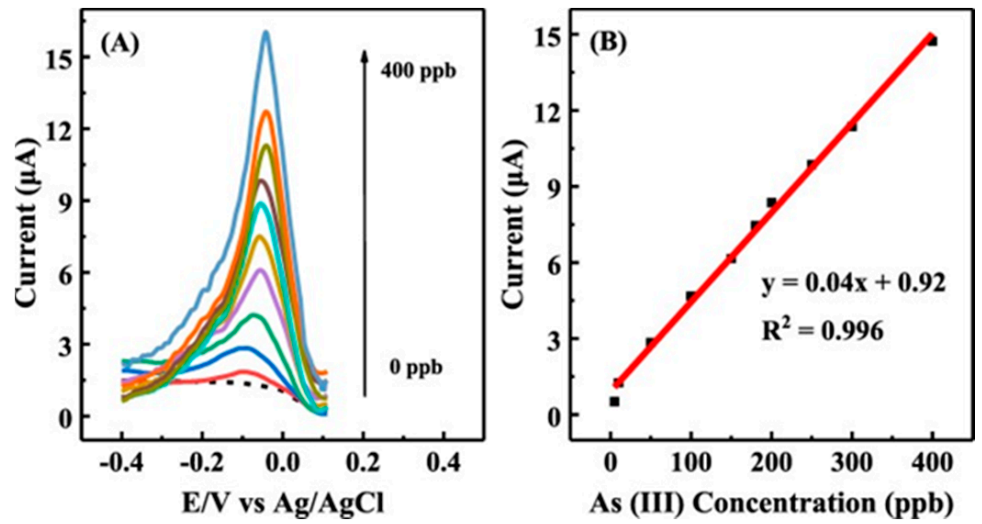

Figure 8. (A) SWASV response of different concentrations of As(III) on Au-PANI-Fe-CNFs/GCE. (B) Linear calibration curve of peak current versus As(III) concentration (0-400 ppb). (Reprinted with permission from [54], Copyright 2020, Elsevier B.V.)

Besides composites of gold nanomaterials with carbon materials, metal oxide nanomaterials and certain polymers have also received much attention. More pairs of gold nanomaterial-modified electrodes are shown in Table 2. 
Table 2. Gold-trimmed electrodes.

\begin{tabular}{|c|c|c|c|c|c|}
\hline Electrode & Method & Sensitivity $(\mu \mathrm{A} / \mathrm{ppb})$ & Linear Range (ppb) & LOD (ppb) & Reference \\
\hline Au-ITO & LSV & & & 5 & [55] \\
\hline AuNPs & ASV & $0.400 \mu \mathrm{A} \cdot \mathrm{V} \mathrm{ppb}^{-1}$ & $0.5-15$ & 0.25 & [40] \\
\hline AuNPs-PANI & SWV & & & 0.4 & [56] \\
\hline $\begin{array}{l}\text { Au-coated boron-doped } \\
\text { diamond thin-film }\end{array}$ & DPASV & & $0.01-40$ & 0.005 & [57] \\
\hline $\mathrm{AuCNT}$ & ASV & 26.49 & & 0.1 & [58] \\
\hline $\begin{array}{l}\text { 3DAu nanodendrite } \\
\text { network porous structure }\end{array}$ & DPSV & & $0.1-70$ & 0.1 & [47] \\
\hline $\mathrm{AuNPs} / \mathrm{Fe}_{3} \mathrm{O}_{4}$ & SWASV & 13.55 & $0.01-1$ & 0.00097 & [59] \\
\hline Nafion-Ibu-AuNSs & $\mathrm{CV}$ & & $0.1-1800$ & 0.018 & [46] \\
\hline citrate stabilized AuNPs & SWV & & $0.05-1$ and $1-15$ & 0.025 & {$[60]$} \\
\hline PDDA-AuNPs & DPV & 0.017 & $0-7492$ & 4.36 & [61] \\
\hline NF (Au nano) & SWV & 0.32 & $0.1-12.0$ & 0.047 & {$[62]$} \\
\hline ERGO-AuNPs & ASV & 0.16 & $0.75-374.6$ & 0.20 & {$[63]$} \\
\hline AuNP-SPE & LSAdSV $^{1}$ & 0.014 & $0.75-749.2$ & & [64] \\
\hline $\mathrm{Au} / \mathrm{Te}$ & SWASV & 6.35 & & 0.0026 & [65] \\
\hline $3 \mathrm{D}$ porous $\mathrm{Au} / \mathrm{TiO}_{2}$ & SWASV & 0.064 & $7.49-599.36$ & 3.00 & [66] \\
\hline CB-AuNPs/SPE & ASV & 0.63 & $2-30$ & 0.4 & [67] \\
\hline $\mathrm{MnO}_{\mathrm{x}}$-AuNPs & LS-ASV & $2.73 \mu \mathrm{A} \mathrm{ppb}{ }^{-1} \mathrm{~cm}^{-2}$ & $0.5-80$ & 0.057 & [68] \\
\hline AuNP & DPASV & & $4-1498$ & 0.9 & {$[42]$} \\
\hline TTCN-AuNPs & $\mathrm{CV}$ & & $0.0019-2.55$ & 0.0006 & [69] \\
\hline gold film & FI-DPASV & & $1.0-30$ & 0.81 & [45] \\
\hline AuNPs & EME $^{2}-\mathrm{ASV}$ & & $0.5-10$ and $10-600$ & 0.18 & [52] \\
\hline AuNPs-C films & ASV & 0.026 & $1-100$ & 0.55 & {$[70]$} \\
\hline EG-AuNPs & SWASV & & & 0.58 & {$[71]$} \\
\hline AuNPs-bt & CV & & $74.92-127,364$ & 7.49 & [53] \\
\hline $\mathrm{Au} @ \mathrm{Fe}_{3} \mathrm{O}_{4}$-RTIL & SWASV & $\begin{array}{l}458.66 \mu \mathrm{A} \mathrm{ppb}^{-1} \mathrm{~cm}^{-2} \\
/ 86.89 \mu \mathrm{Appb}^{-1} \mathrm{~cm}^{-2}\end{array}$ & 0.1-1/1-10 & 0.0022 & [72] \\
\hline np-Au & SWASV & 0.60 & $0.5-15$ & 0.0315 & [73] \\
\hline $\begin{array}{c}\mathrm{MnFe}_{2} \mathrm{O}_{4} / \mathrm{Au} \text { hybrid } \\
\text { nanospheres }\end{array}$ & SWASV & 0.315 & & 3.37 & {$[74]$} \\
\hline $\mathrm{AuNpC} \mu \mathrm{F}$ & DPV & & & 0.9 & [75] \\
\hline GCE-AuNPs & SWASV & & $10-12,000$ & 0.15 & [76] \\
\hline AuNPs-PCWEs & $\begin{array}{c}\text { AS- } \\
\text { chronoamperometry }\end{array}$ & 0.083 & & 2.2 & [77] \\
\hline AuNPs-RGO & ASV & 0.092 & $1-20$ & 0.13 & [78] \\
\hline AuNPs-PpyNW & $\mathrm{I}-\mathrm{V}$ & 0.0029 and 0.0585 & $\begin{array}{l}7.49-599.36 \text { and } \\
749.21-5244.51\end{array}$ & 23.97 & [79] \\
\hline $\mathrm{Au} / \mathrm{SiO}_{2}$ & SWV & & $0.1-40$ & 0.07 & [80] \\
\hline $\mathrm{ZrF}-8 \mathrm{CAu}$ & $\mathrm{CV}$ & & $5-700$ & 1 & [81] \\
\hline 3D-rGO/AuNPs & EIS & & $3.8 \times 10^{-7}-3.0 \times 10^{-4}$ & $1.4 \times 10^{-7}$ & [82] \\
\hline SPE/CNF-CHIT@Au nano & FIA-ECD & 0.2181 & $100-100,000$ & 11.4 & [83] \\
\hline
\end{tabular}


Table 2. Cont.

\begin{tabular}{|c|c|c|c|c|c|}
\hline Electrode & Method & Sensitivity $(\mu \mathrm{A} / \mathrm{ppb})$ & Linear Range (ppb) & LOD (ppb) & Reference \\
\hline AuNP/BDD & SWASV & & $100-1500$ & 20 & [84] \\
\hline $\mathrm{AuNPs} / \mathrm{CeO}_{2}-\mathrm{ZrO}_{2}$ & SWASV & 0.976 & $0.5-15$ & 0.137 & [85] \\
\hline AuNPs-SPCE & ASV & 0.11 & $30-150$ & 8.9 & [41] \\
\hline $\begin{array}{c}\text { Buckypaper modified } \\
\text { by GNP }\end{array}$ & LSASV & & $0.75-750$ & 0.75 & [86] \\
\hline AuNP-Au film & ASLSV & $0.027 \mu \mathrm{A} \mathrm{ppb}{ }^{-1} \mathrm{~cm}^{-2}$ & $1-150$ & 0.42 & [87] \\
\hline eAuNP-SPE & DPASV & & $0.5-20$ & 0.22 & [88] \\
\hline gold film-plastic & DPSV & & $10-500$ & 5 & [89] \\
\hline rGO-Au nano & SWASV & & $1.0-50.0$ & 0.08 & [90] \\
\hline $\mathrm{AuNPs} / \mathrm{gC}_{3} \mathrm{~N}_{4}$ & LSASV & 3.07 & $0.375-74.921$ & 0.22 & [91] \\
\hline 3D NPG-ITO & DPASV & 9.837 & $0.1-50$ & 0.054 & [92] \\
\hline SiNPs/AuNPs & LSASV & & $10-100$ & 5.6 & [93] \\
\hline MCPTH-AuNPs & $\mathrm{CV}$ & & & 1 & [94] \\
\hline AuNS/SPCE & SWASV & 0.2213 & $0-100$ & 0.8 & [49] \\
\hline $\begin{array}{l}\text { gold nanoparticles and } \\
\text { crystal violet }\end{array}$ & DPV & $0.075 \mu \mathrm{A} \mathrm{ppb}^{-1} \mathrm{~cm}^{-2}$ & $149.84-1648.24$ & 59.94 & {$[50]$} \\
\hline gold nanostar & SWV & 0.101 & $0-100$ & 2.9 & [95] \\
\hline Au-PANI-Fe-CNF & SWASV & 0.04 & $5-400$ & 0.5 & [54] \\
\hline $\begin{array}{l}\text { quasi-hexagonal } \\
\text { gold nano }\end{array}$ & DPASV & & $0.075-30$ & 0.11 & [96] \\
\hline GNR & DPASV & & $0.90-38.99$ & 0.72 & [48] \\
\hline AuNP-rLA-Lcyst & SWV-ASV & 0.1 & $3-25$ & 3 & [97] \\
\hline $\mathrm{AuNPs}-\mathrm{Co}_{3} \mathrm{O}_{4}$ & SWASV & $12.1 / 3.7$ & $0.1-1 / 1-20$ & $0.09 / 0.79$ & [98] \\
\hline $\begin{array}{c}\mathrm{GO} / \mathrm{Fe}_{3} \mathrm{O}_{4} @ \\
\mathrm{PMDA} / \mathrm{AuNPs}\end{array}$ & SWASV & & $5-500$ & 0.15 & [99] \\
\hline AuNPs & SWSV & 0.1007 & & 16.73 & [51] \\
\hline Au nano/Fe-MOF & SWASV & 4.708 & $2-30$ & 0.0085 & [100] \\
\hline GC-AuNP-ArOx & $\mathrm{CV}$ & 46.05 & $0.75-749.21$ & 0.37 & [101] \\
\hline
\end{tabular}

${ }^{1}$ Linear sweep adsorptive stripping voltammetry; ${ }^{2}$ electromembrane extraction.

\subsubsection{Platinum Electrodes and Platinum-Modified Electrodes}

In addition to gold, there are other precious metals used in the electrochemical detection of arsenic. Platinum wires are not only used as counter electrodes in many electrochemical detection systems, but there are also many working electrodes made of platinum or modified with platinum nanoparticles. Tung Son Vinh Nguyen et al. determined the As(III) ion concentration in water samples by the anodic solvation voltammetry (ASV) technique using a Nafion film-modified platinum electrode and obtained a wide linear range from $0 \mathrm{ppb}$ to $40 \mathrm{ppb}$ with a detection limit below $10 \mathrm{ppb}$ [102]. $\mathrm{He} \mathrm{Xu}$, on the other hand, used a Pt nanotube array electrode, the SEM in cross-sectional view of which is shown in Figure 9, achieving a low detection limit of $0.1 \mathrm{ppb}$. Electrochemical experiments demonstrated that platinum-nanotube array electrodes (PtNTAEs) exhibited better performance for As(III) analysis than Pt nanoparticle-coated GCE (Pt nano/GCE) or Pt foil electrodes [103]. In addition, the modification of other electrodes with Pt nanoparticles and their composites is also a promising approach [104-108]; the detection limit is mostly below $10 \mathrm{ppb}$. Of interest is a Pt single-atom-anchored catalyst on $\mathrm{MoS}_{2}\left(\mathrm{Pt}_{1} / \mathrm{MoS}_{2}\right)$ developed by Pei-Hua L et al. to catalyze the determination of $\mathrm{As}(\mathrm{III})$. $\mathrm{Pt}_{1} / \mathrm{MoS}_{2}$ of $4 \%$ exhibited 
excellent stability and interference resistance, with a sensitivity of up to $3.31 \mu \mathrm{A} / \mathrm{ppb}$ for the detection of As(III) under near-neutral conditions, due to the Pt single atoms activated close to $\mathrm{S}$ atoms, greatly enhancing the catalytic activity of S atoms in the $\mathrm{MoS}_{2}$ plane [109]. Dong-Dong Han et al. demonstrated a size-dependent effect of 2-5 nm Pt nanoparticles on the electrochemical behavior of arsenic (As(III)), with a decrease in sensitivity as the size of Pt nanoparticles increased from $2.3 \mathrm{~nm}$ to $5.5 \mathrm{~nm}$ [110].

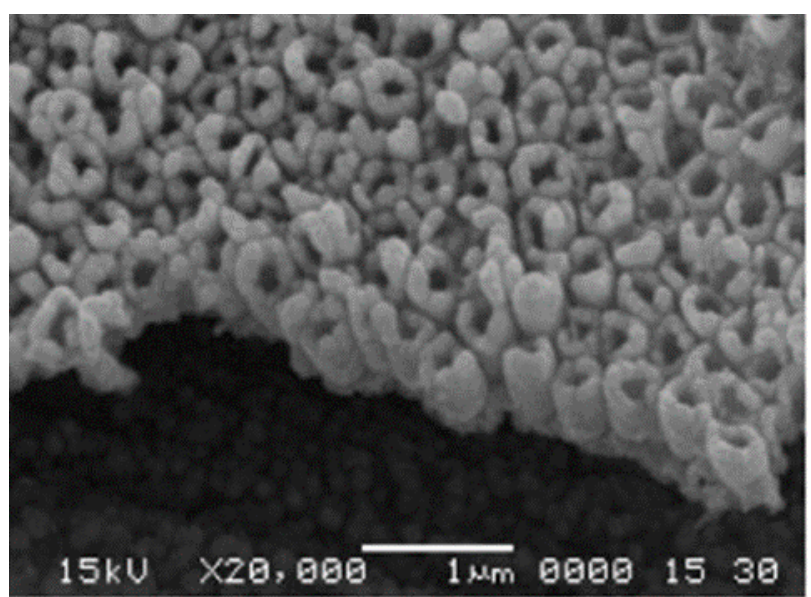

Figure 9. SEM image of cross-sectional view of PtNTAEs. (Reprinted with permission from [103], Copyright 2008, Elsevier B.V.)

\subsubsection{Silver Electrodes and Silver-Modified Electrodes}

Several papers have reported on the silver-based electrochemical sensing of arsenic. Among them, María del C. Aguirre used a silver wire electrode (SWE) for the electrochemical detection of arsenite with a minimum detection limit of $0.09 \mathrm{ppb}$, indicating that SWE can be used for the detection of trace arsenic in alkaline and neutral media [111]. Baudelaire Matangouo Sonkoue generated silver nanocolloids by the chemical reduction of silver salts using citrate in aqueous solution and used a gold electrode modified with silver nanoparticles as the working electrode in linear sweep voltammetry for the detection of arsenic ions. Under optimal conditions, calibration curves were plotted over a concentration range of $0.05-0.2 \mu \mathrm{M}$ and the limit of detection was estimated to be $13.8 \mathrm{nM}$ [112]. In addition, composites of silver nanomaterials with chitosan and graphene are also of interest for the electrochemical detection of arsenic. Silver nanoparticles (AgNPs) with chitosan (CT)-modified glassy carbon electrode (GCE) prepared by S. Prakash were used for the detection of As(III) by differential-pulse anodic dissolution voltammetry (DPASV), which has high sensitivity for the detection of As(III) in water due to the unique threedimensional network and powerful adsorption capacity, and the designed nanostructured electrode has a wide linearity range (10-100 ppb), high sensitivity $\left(0.309 \mu \mathrm{A} \mathrm{ppb}^{-1}\right)$ and a detection limit of 1.20 ppb (16.2 nM) [113]. Riyaz Ahmad Dar used cyclic voltammetry and anodic dissolution voltammetry measurements to evaluate the electrochemical properties of $\beta$-cyclodextrin-stabilized AgNPs-GO/GCE for As (III) detection with an approximately threefold increase in peak current compared with GO films alone, showing a wide linear range (13.33-375.19 $\mathrm{nM})$ and high sensitivity $\left(180.5 \mu \mathrm{A} \mu \mathrm{M}^{-1}\right)$, including a $0.24 \mathrm{nM}$ detection limit [114]. Shao-Hua Wen et al. described the multimodal determination of arsenite (As(III)) in environmental samples by the stimulated response of multi-ligand functionalized silver nanoparticles (Ag NPs) in the electrochemical determination with GSH/DTT/Asn-Ag NPs as the signal probe of the redox electrochemical As(III) sensor. The As(III) concentration increased, the peak currents of Ag NPs in the DPV response curves were recorded, and the calibration curves showed good linearity of peak current intensity with As(III) concentration in the range of $0.01-40 \mathrm{ppb}$, with detection limits as low as 5.2 ppt [115]. 


\subsubsection{Other Precious-Metal-Modified Electrodes}

Agustiany studied the preparation of stable iridium-modified boron-doped diamond electrodes by electrodeposition, and As(III) was detected by cyclic voltammetry [116]. The electrode showed a linear curve in the concentration range of $1-100 \mu \mathrm{M}$ with a detection limit of $4.64 \mu \mathrm{M}$ and good stability and reproducibility, with a relative standard deviation of $2.6 \%$ under the optimal conditions of a $\mathrm{pH} 3$ phosphate buffer and a scanning speed of $50 \mathrm{mV} / \mathrm{s}$. In addition, the electrode showed good linearity $\left(\mathrm{R}^{2}=0.998\right)$ and sensitivity for the measurement of As(III) in both tap water and lake water samples. The test plots are shown in Figure 10. Erfan Mafakheri electrodeposited iridium oxide $\left(\mathrm{IrO}_{2}\right)$ nanotubes in polycarbonate (PC) stencils to form $\mathrm{IrO}_{2}$ nanotubes with a uniform diameter of $110 \pm 10 \mathrm{~nm}$, an estimated length of 1-3 $\mu \mathrm{m}$, and $\mathrm{IrO}_{2}$ nanotube-modified glassy carbon electrodes for the detection of As(III) [117].

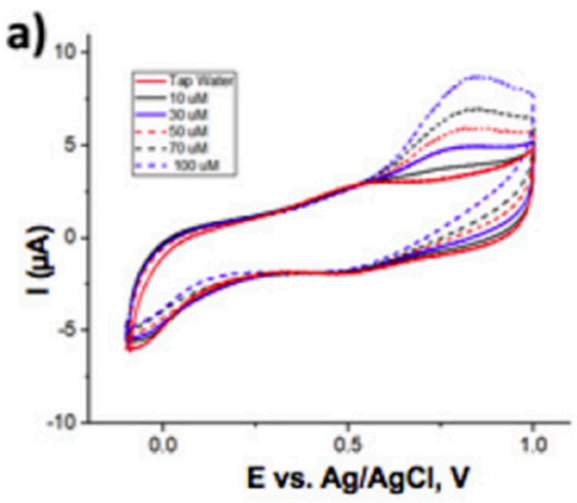

b)
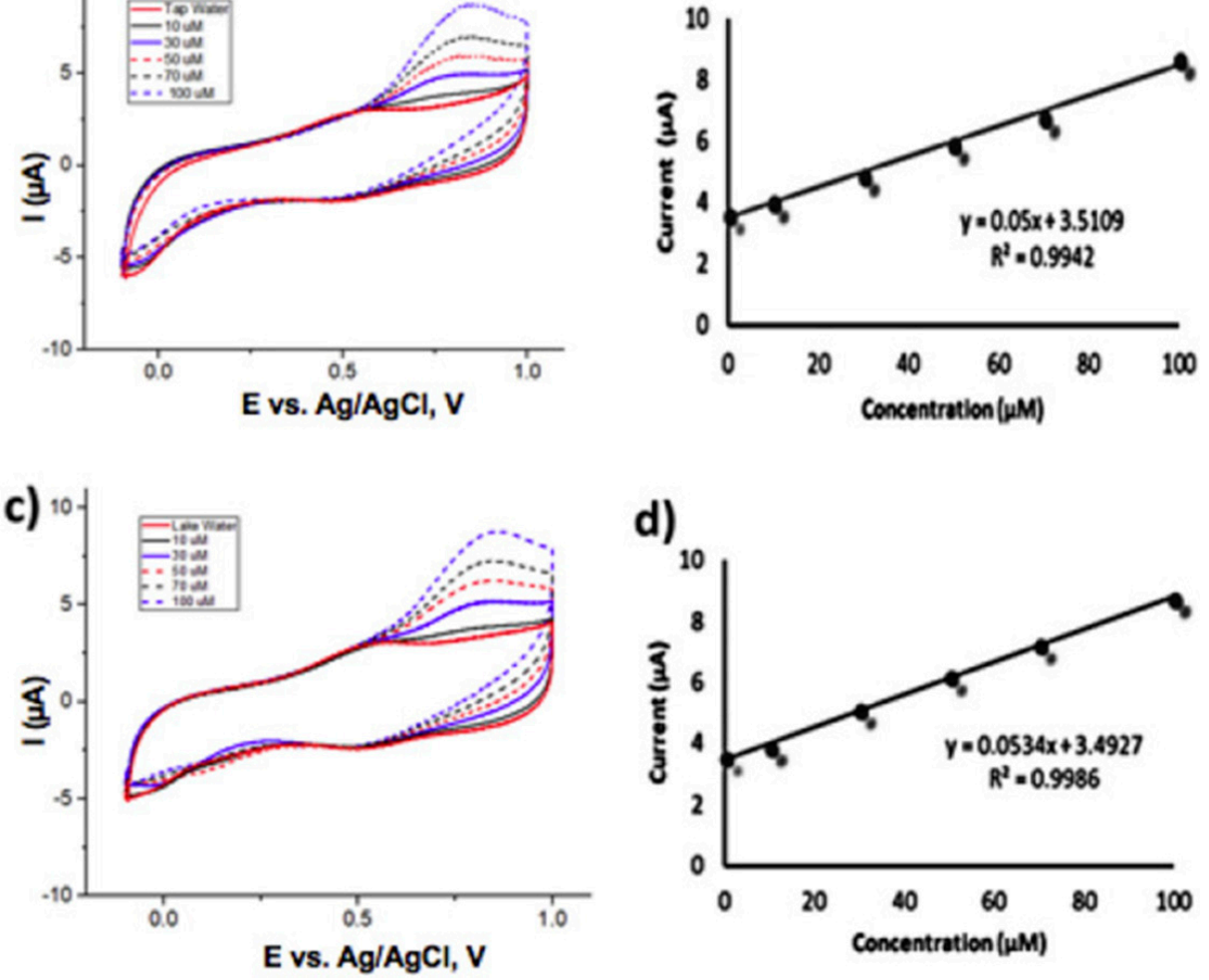

Figure 10. Cyclic voltammetry responses of different spike concentrations of arsenic (III) in (a) tap water and (c) lake water samples; scan rate $50 \mathrm{mV} / \mathrm{s}$ at Ir-BDD prepared using complete step deposition. (b) and (d) depict the dependence of current responses on arsenic (III) concentrations. (Reprinted with permission from [116], Copyright 2020, Elsevier B.V.)

R Gupta et al. deposited metallic ruthenium nanoparticles (RuNPs) on a glassy carbon electrode (GC) with a modified electrode with arsenite selectivity, schematically shown in Figure 11, for the detection of arsenite in water [118]. The differential pulse voltammetry (DPV) based on RuNPs /GC can determine the concentration of arsenite within minutes with a detection limit of $0.1 \mathrm{ppb}$, a reproducibility of $5.4 \%$, and a sensitivity of $2.38 \mathrm{nA} \mathrm{ppb}^{-1}$. RuNPs can be anchored on different chemical platforms such as graphene, electrodes, $\mathrm{Fe}_{3} \mathrm{O}_{4}$, etc. to design robust and reusable electrochemical sensors for the detection of arsenite in various aqueous solutions. 

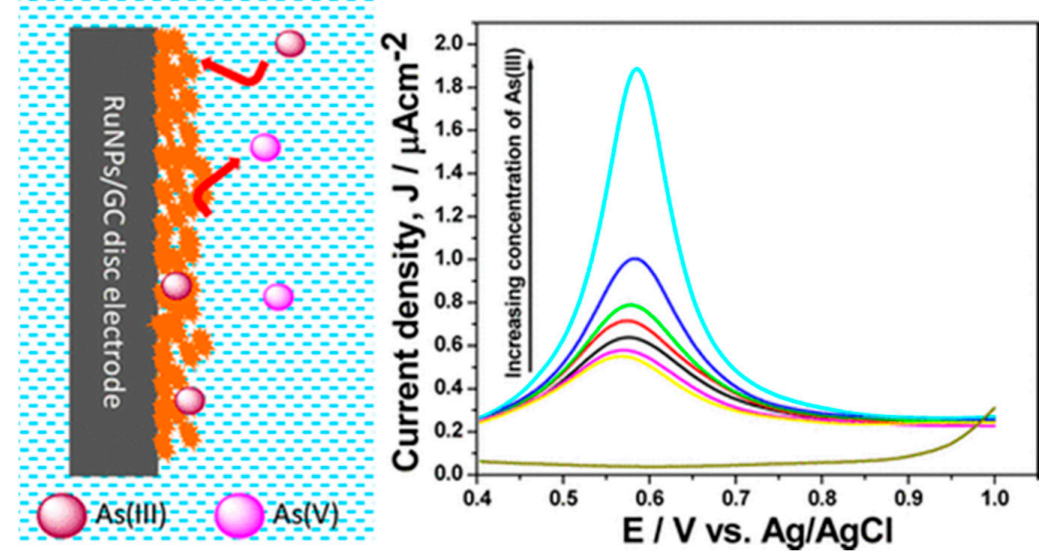

Figure 11. Schematic diagram of RuNPs/GC-based As electrochemical detection. (Reprinted with permission from [118], Copyright 2016, American Chemical Society.)

Sthitaprajna Dash investigated the electrodeposition of nanodendritic Pd on poly(3,4ethylenedioxythiophene) (PEDOT)-modified Pd nanodendritic electrodes for the electroanalysis of $\mathrm{As}(\mathrm{III})$ in $1 \mathrm{M} \mathrm{HCl}$ solution. A wide detection range of up to $10 \mu \mathrm{M}$ and a low detection limit of $7 \mathrm{nM}(0.52 \mathrm{ppb})$ can be achieved with a pre-deposition time of $120 \mathrm{~s}$ under optimal conditions [119]. Md. Mahbubul Alam electrochemically immobilized Pd nanoparticles on Pt surface in the presence of sodium dodecyl sulfate (SDS) molecules. and its FE-SEM image is shown in Figure 12. The LOD of As(III) was determined to be $0.2 \mathrm{ppb}$ using a Pt-Pd $\mathrm{sds}_{\mathrm{s}}$ sensor [120]. In addition, other noble-metal-modified electrode comparisons are presented in Table 3.

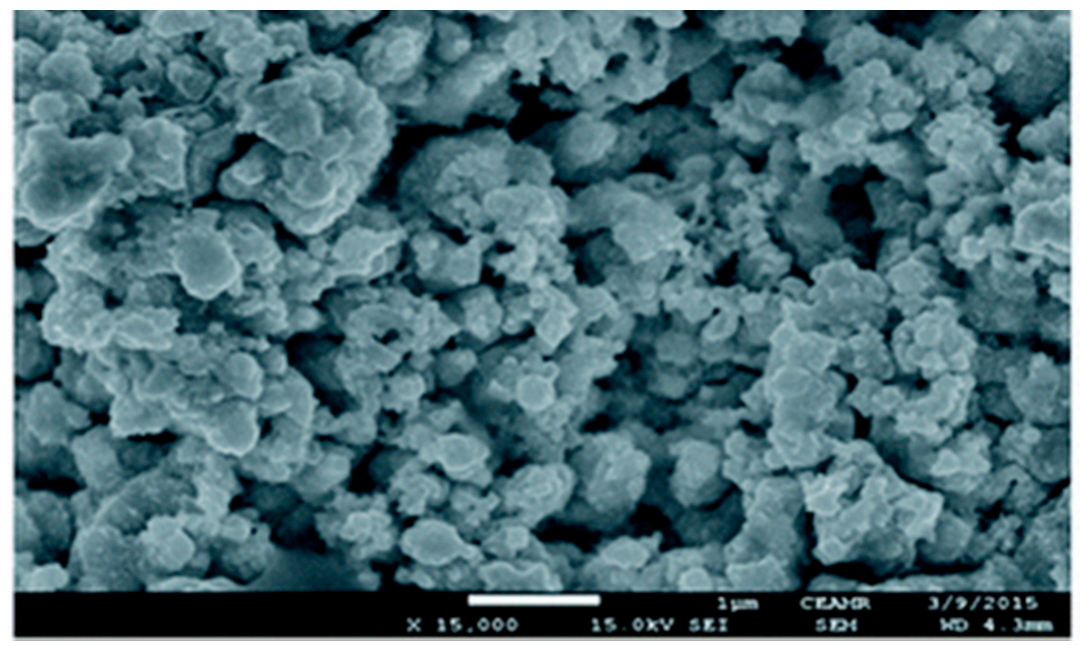

Figure 12. FE-SEM image of Pd particles deposited on Pt surface. (Reprinted with permission from [120], Copyright 2018, The Royal Society of Chemistry.)

Table 3. Other precious-metal-modified electrodes.

\begin{tabular}{|c|c|c|c|c|c|}
\hline Electrode & Method & Sensitivity $(\mu \mathrm{A} / \mathrm{ppb})$ & Linear Range (ppb) & LOD (ppb) & Reference \\
\hline Pt nano & ASV & $2.94 \times 10^{-3}$ & $74.92-3746.08$ & 2.1 & [121] \\
\hline Pt nano & SWV & & $0-100$ & 0.5 & [107] \\
\hline PtNTAEs & LSV & 0.011 & $749.21-14,984.32$ & 0.1 & [103] \\
\hline $\mathrm{Pt}$ nano/CNTs & LSV & $9.34 \times 10^{-3}$ & $374.61-74,921.6$ & 0.12 & [104] \\
\hline Pt nano & $\mathrm{CV}$ & & & 5.68 & [122] \\
\hline
\end{tabular}


Table 3. Cont.

\begin{tabular}{|c|c|c|c|c|c|}
\hline Electrode & Method & Sensitivity $(\mu \mathrm{A} / \mathrm{ppb})$ & Linear Range (ppb) & LOD (ppb) & Reference \\
\hline Gr-nPt & SWASV & & $0.75-7.49$ & 0.082 & [106] \\
\hline Pt nano $(2.3 \mathrm{~nm})$ & SWASV & 0.356 & $0-1000$ & & [110] \\
\hline Nafion/Pt & ASV & 0.036 & $0-40$ & $<10$ & [102] \\
\hline Pt nano & ASV & & $0-100$ & 16.50 & [105] \\
\hline $\mathrm{Pt}_{1} / \mathrm{MoS}_{2}$ & SWASV & 3.31 & $0.5-8$ & 0.05 & [109] \\
\hline Pt nano & ASV & $6.3 \times 10^{-7}{\mathrm{C} \mu \mathrm{M}^{-1}}^{-1}$ & $3.75-74.92$ & 4 & [123] \\
\hline SWE & LSASV & & & 0.09 & [111] \\
\hline AgNPs/CT & DPASV & & $10-100$ & 1.20 & [113] \\
\hline AgNPs-GO & ASV & 2.41 & $1-28.11$ & 0.018 & [114] \\
\hline Ag-GCE & SWASV & 0.98 & $10-60$ & 4.2 & [124] \\
\hline Ag-SPCE & SWASV & 0.6 & $10-80$ & 8.4 & [124] \\
\hline AgNPs & DPASV & & $3.75-14.98$ & 1.03 & [112] \\
\hline $\begin{array}{c}\text { GSH/DTT/Asn-Ag } \\
\text { NPs }\end{array}$ & DPV & & $0.01-40$ & $5.2 \times 10^{-3}$ & [115] \\
\hline IrOx-BDD & chronoamperometry & 0.056 & $1.50-3746.08$ & 0.15 & [125] \\
\hline Ir-BDD & $\mathrm{CV}$ & $1.24 \times 10^{-3} \mu \mathrm{A} \mathrm{ppb}^{-1} \mathrm{~cm}^{-2}$ & & 1.5 & [126] \\
\hline $\mathrm{IrO}_{2}$ nanotubes & DPV & & $0-5993.73$ & 7.49 & [117] \\
\hline $\mathrm{Au}-\mathrm{IrM}$ & SWASV & $3.19 \times 10^{-4} / 2.64 \times 10^{-3}$ & $0.75-3.75 / 0.07-0.75$ & 0.037 & [127] \\
\hline Ir-BDD & $\mathrm{CV}$ & $7.47 \times 10^{-4} \mu \mathrm{A} \mathrm{ppb}^{-1} \mathrm{~cm}^{-2}$ & $74.92-7492.16$ & 347.63 & [116] \\
\hline $\mathrm{Ru}$ NPs & DPV & $2.38 \times 10^{-3}$ & & 0.1 & [118] \\
\hline$\left[\mathrm{Ru}(\mathrm{bpy})_{3}\right]^{2+}-\mathrm{GO}$ & DPV & 0.32 & $7.49-14.98$ & 0.015 & [128] \\
\hline Ru(II)-tris(bipy)-GO & $\mathrm{CV}$ & $1.42 \mu \mathrm{A} \mathrm{ppb}^{-1} \mathrm{~cm}^{-2}$ & $3.75-59.93$ & 2.25 & [129] \\
\hline Pd-PEDOT & DPASV & $19.78 \mu \mathrm{A} \mathrm{ppb}^{-1} \mathrm{~cm}^{-2}$ & $0-749.21$ & 0.52 & [119] \\
\hline $\mathrm{Pt}-\mathrm{Pd}_{\mathrm{sds}}$ & SWV & & $74.92-16,857.36$ & 0.2 & [120] \\
\hline
\end{tabular}

\subsection{Bimetallic Particle-Modified Electrodes}

Precious metal nanomaterials are good for electrode modification, but the cost of modifying electrodes with gold is very high, so people choose to use gold composites for detection, in addition to deriving other bimetallic particles, in order to ensure the detection sensitivity and, at the same time, control the cost of detection. The bimetallic nanomaterials containing gold are $\mathrm{Au}-\mathrm{Pd}, \mathrm{Au}-\mathrm{Pt}, \mathrm{Au}-\mathrm{Ag}, \mathrm{Au}-\mathrm{Cu}$, etc. In addition, Fe has an excellent performance in arsenic ion detection, so it has also been studied in Fe-based bimetallic particle-modified electrodes, where bimetallic FePt, FeAu, FePd, and AuPt nanoparticles (NPs) are electrochemically deposited on $\mathrm{Si}(100)$ substrates and their electrochemical properties are investigated for As(III) detection. Trace amounts of As(III) can be determined by anodic stripping voltammetry at neutral $\mathrm{pH}$. The synergistic effect with Fe alloying leads to the better performance of Fe precious metal NPs ( $\mathrm{Au}, \mathrm{Pt}$ and $\mathrm{Pd}$ ) than pristine precious metal NPs (without Fe alloying). Detection limits and linear ranges were obtained for FePt, $\mathrm{FeAu}$, and FePd NPs. The best performance was obtained for FePt NPs with a detection limit of $0.8 \mathrm{ppb}$ and a sensitivity of $0.42 \mu \mathrm{Appb}^{-1}$. The selectivity of the sensor was also tested in the presence of large amounts of $\mathrm{Cu}$ (II), the most detrimental interfering ion for As detection. Thus, bimetallic NPs are expected to be an effective and high-performance electrochemical sensor for the detection of ultra-trace amounts of arsenic [130]. More electrodes modified with bimetallic materials and their detection performance are summarized in Table 4. 
Table 4. Bimetallic modified electrodes.

\begin{tabular}{|c|c|c|c|c|c|}
\hline Electrode & Method & Sensitivity $(\mu \mathrm{A} / \mathrm{ppb})$ & Linear Range (ppb) & LOD (ppb) & Reference \\
\hline Au-Pd NPs & SWV & & $1-25$ & 0.25 & [131] \\
\hline Au-Pd NPs & SWASV & 3.9 & & 0.024 & [132] \\
\hline $\mathrm{Au} / \mathrm{Te}$ crystals & SWASV & 6.35 & $0.1-10$ & 0.0026 & [65] \\
\hline $\mathrm{Au}-\mathrm{Pt} \mathrm{NPs}$ & LSASV & & $0.37-224.76$ & 0.28 & [133] \\
\hline $\mathrm{Au}-\mathrm{Cu}$ & SWASV & $1.63 \mu \mathrm{A} \mathrm{ppb}{ }^{-1} \mathrm{~cm}^{-2}$ & & 2.09 & [134] \\
\hline Au-PtNPs/PANI & SWASV & 0.23 & $2.47-14.98$ & 1.48 & [135] \\
\hline C-AuNPs & SWV & & $0.5-100$ & 0.092 & [136] \\
\hline $\mathrm{Ag}-\mathrm{Au}$ & $\mathrm{CV} / \mathrm{DPV}$ & & $0.01-10$ & $0.003 \times 10^{-3}$ & [137] \\
\hline $\mathrm{Fe}_{3} \mathrm{O}_{4}-\mathrm{Au}$ & SWASV & 122 & $1-100$ & 0.22 & [138] \\
\hline $\mathrm{FePt}$ & SWV & 0.42 & $1-5$ & 0.8 & [130] \\
\hline $\mathrm{Pt}-\mathrm{Fe}$ & ASV & 0.064 & & 0.75 & [139] \\
\hline
\end{tabular}

\subsubsection{Gold-Platinum Bimetallic Modified Electrodes}

A novel and easy-to-use nanohybrid platform suitable for the electrochemical detection of As(III) was prepared based on gold and platinum bimetallic nanoparticles (Au-Pt NPs) and the conducting polymer polyaniline [135]. Good detection limits were obtained by square-wave anodic dissolution voltammetry using modified screen-printed electrodes. The SWASV of 0-15 ppb (As(III) concentration) was recorded (Figure 13a) and this sensor was found to have good linearity in the range of 33-200 nM concentration of As(III) ions, with an LOD up to $19.7 \mathrm{nM}$, as shown in its calibration plot (Figure 13b).

\subsubsection{Gold-Copper Bimetallic Modified Electrode}

Recently, a simple hydrothermal method for the preparation of $\mathrm{Au}$ and $\mathrm{Cu}$ bimetallic nanoparticles of different compositions has been proposed [134]. The electrochemical performance of Au-Cu bimetallic nanoparticles in the determination of As(III) particle concentration was investigated using the square-wave anodic dissolution voltammetry SWASV method, and the SWASV response for As(III) detection in different concentration ranges is shown in Figure 14, where the $\mathrm{Cu}$ content in Au-Cu bimetallic nanoparticles is crucial for the detection efficacy. Compared with gold nanoparticles and gold electrodes, $\mathrm{Au}-\mathrm{Cu}$ bimetallic nanoparticles exhibited better electrochemical performance with a lower detection limit (2.09 ppb) and higher sensitivity $\left(1.63 \mu \mathrm{A} \mathrm{ppb}^{-1} \mathrm{~cm}^{-2}\right)$. In addition, the Au$\mathrm{Cu}$ bimetallic nanoparticles also exhibited superb anti-interference performance for the detection of As(III).

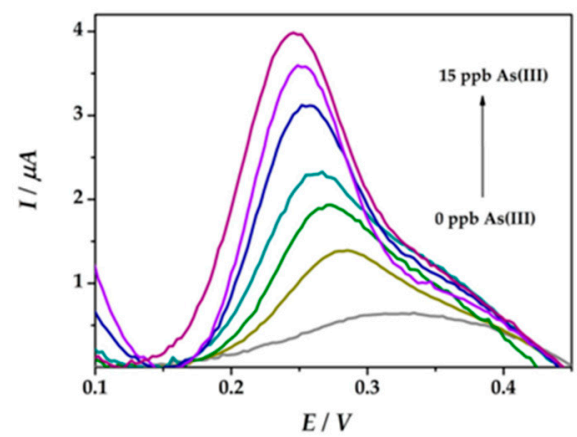

(a)

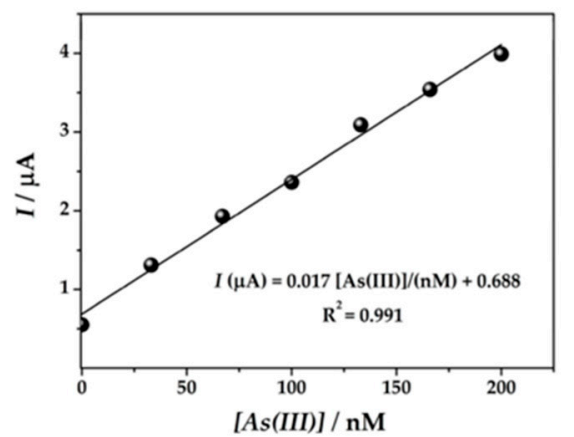

(b)

Figure 13. (a) SWASV curves obtained at the Au-PtNPs/SPCE platform. (b) Corresponding calibration plots (Reprinted with permission from [135]). 
a)

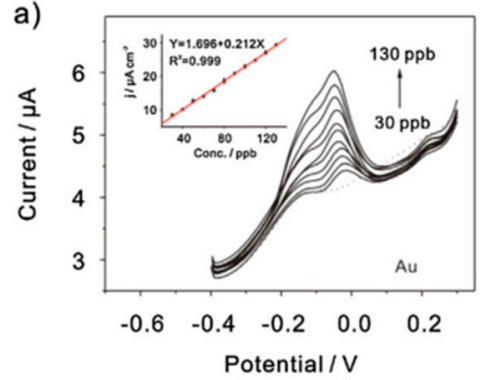

c)

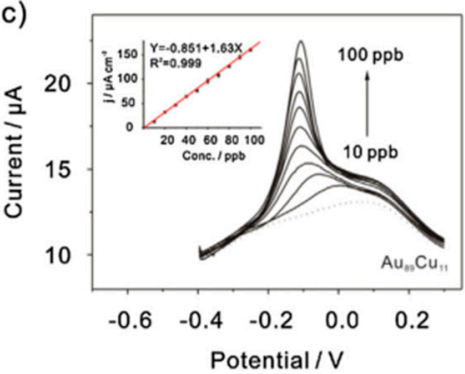

b)

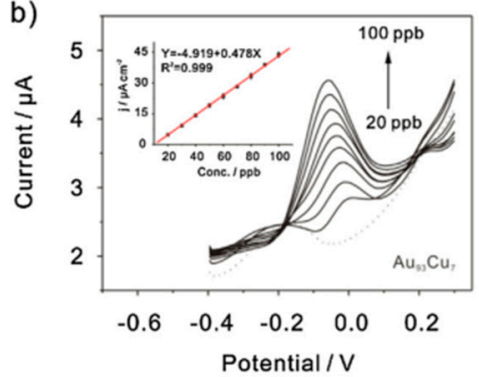

d)

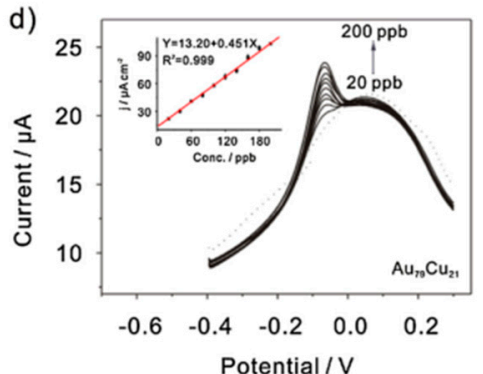

Figure 14. SWASV response of (a) $\mathrm{Au}$, (b) $\mathrm{Au}_{93} \mathrm{Cu}_{7}$, (c) $\mathrm{Au}_{89} \mathrm{Cu}_{11}$, and (d) $\mathrm{Au}_{79} \mathrm{Cu}_{21}$ bimetallic nanoparticle-modified GCE for As(III) detection at different concentration ranges. (Reprinted with permission from [134], Copyright 2016, Elsevier B.V.)

\subsubsection{Silver-Gold Bimetallic Modified Electrode}

Reetu Yadav reported a sensor with silver-gold alloy nanoparticles (i.e., silver and gold alloy nanoparticles) modified with glassy carbon electrode and loaded with aptamer [137]. The bimetallic nanoparticles have a large surface area for adhesion with the aptamer, and thus have a large number of binding sites. The detection method uses cyclic voltammetry and differential pulse voltammetry, the electrode is used for the determination of $\mathrm{As}^{3+}$ in actual water samples, and the curve is linear when the $\mathrm{As}^{3+}$ concentration is $0.01-10 \mu \mathrm{g} / \mathrm{L}$, with a detection limit of $0.003 \times 10^{-3} \mu \mathrm{g} / \mathrm{L}$. The sensor has good repeatability, stability, and selectivity, and can be applied to the detection of arsenic ion concentration in real water samples.

\subsection{Other Metals and Their Compound-Modified Electrodes \\ 3.3.1. Fe and Its Compound-Modified Electrodes}

In the three-electrode-based electrochemical detection, the adsorption ability of the electrode surface on the target element plays a crucial role in the electrochemical detection performance, and the oxide nanoparticles of Fe become a hot spot for electrochemical detection due to their high adsorption ability and magnetic properties [140]. Pooja Devi et al. reported a chemically reduced $\mathrm{rGO} / \mathrm{Fe}_{3} \mathrm{O}_{4}$ nanocomposite-modified glassy carbon electrode, which achieved a low detection limit of $0.12 \mathrm{ppb}$ by square-wave anodic dissolution voltammetry [141]. Haibing $\mathrm{Hu}^{\prime}$ s team prepared $\mathrm{Fe}_{3} \mathrm{O}_{4}$ nanomaterials using a co-precipitation method, resulting in a $\mathrm{Fe}_{3} \mathrm{O}_{4}$ particle size of about $20 \mathrm{~nm}$, which was then compounded with reduced graphene oxide. Under the optimized experimental conditions, the $\mathrm{Fe}_{3} \mathrm{O}_{4}$ rGO-modified glassy carbon electrode showed higher sensitivity $(2.15 \mu \mathrm{A} / \mathrm{ppb})$ for arsenic and achieved low detection limits [142]. The $\mathrm{rGO} / \mathrm{Fe}_{3} \mathrm{O}_{4}$ nanocomposite has been shown to be a potential electrochemical and bioelectrochemical sensing material for the simultaneous detection of ascorbic acid, dopamine and uric acid, as well as for the electrocatalytic determination of nitrite. Akajionu Benjamin Chimezie et al. used differential pulsed anodic solvation voltammetry (DPASV) on a screen-printed electrode modified with reduced oxidation. An electrochemical sensor for the determination of As(III) in water resources was developed on the surface of graphene-magnetic nanocomposite ( $\mathrm{rGO}-\mathrm{Fe}_{3} \mathrm{O}_{4} / \mathrm{SPEC}$ ) using differential pulsed anodic dissolution voltammetry (DPASV) [143]. The schematic diagram is shown in Figure 15. The electrode has a detection limit of $0.1 \mu \mathrm{g} / \mathrm{L}$ for As(III) in 
drinking water. The sensor has a wide operating range $\left(2-300 \mu \mathrm{g} \mathrm{L}^{-1}\right)$, good repeatability, reproducibility and stability, and is virtually unaffected by common interfering ions.

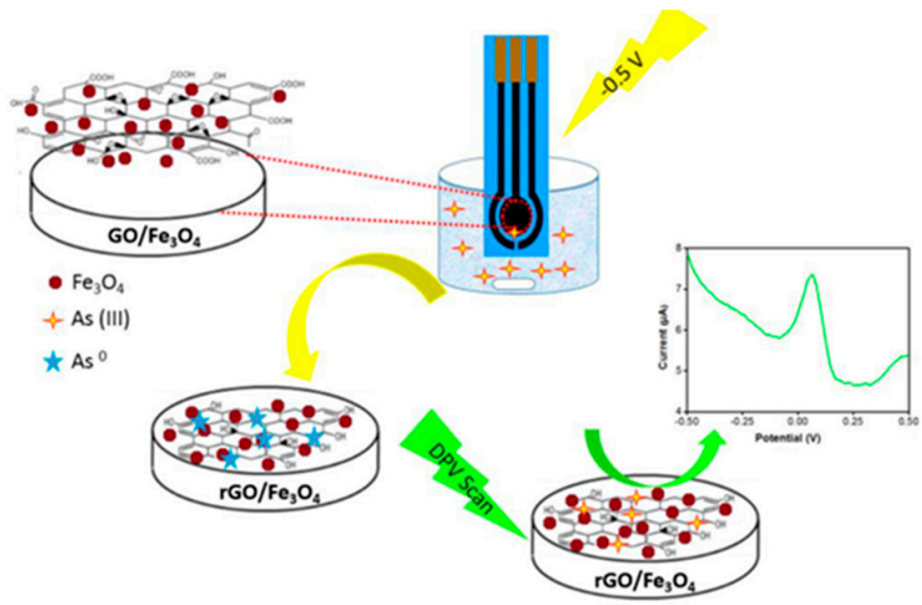

Figure 15. Schematic diagram of $\mathrm{rGO}-\mathrm{Fe}_{3} \mathrm{O}_{4}$ /SPEC-based electrochemical analysis of arsenic ions. (Reprinted with permission from [143], Copyright 2017, Elsevier B.V.)

Hong Cui et al. modified the glassy carbon electrode with a composite of magnetic $\mathrm{Fe}_{3} \mathrm{O}_{4}$ nanoparticles and gold nanoparticles, and the detection limit was $0.00097 \mathrm{ppb}$ under optimal conditions [59]. Chao Gao et al. proposed an $\mathrm{Fe}_{3} \mathrm{O}_{4}$-RTIL (room temperature ionic liquid) composite-modified screen-printed carbon electrode (SPCE) in order to achieve ultra-low detection limits while reducing the dependence on precious metal gold, and obtained an ultra-low detection limit of $8 \times 10^{-4}$ ppb by square-wave anodic solvation voltammetry (SWASV) while achieving a high sensitivity of $4.91 \mu \mathrm{A} \mathrm{ppb}{ }^{-1}$ [144]. Other ferrites also have great potential for electrochemical detection. Shaofeng Zhou et al. reported $\mathrm{Au}$ nanoparticle-decorated mesoporous $\mathrm{MnFe}_{2} \mathrm{O}_{4}$ nanocrystal clusters for the detection of As(III) in water samples by square-wave anodic dissolution voltammetry (SWASV) with good reproducibility, stability and reproducibility, as well as interference resistance [74]. In a recent study, Hong-QiHuang et al. proposed a successful electrochemical sensor driven by noble metal-free layered porous $\mathrm{Fe}_{3} \mathrm{O}_{4} / \mathrm{Co}_{3} \mathrm{~S}_{4}$ nanosheets for As(III) analysis, and obtained a considerable sensitivity of $4.359 \mu \mathrm{A} / \mathrm{ppb}$ for the electrochemical detection of As(III) in 0.1 M HAc-NaAc ( $\mathrm{pH}$ 6.0) by square-wave anodic dissolution voltammetry (SWASV). The improved electrochemical performance of As(III) is attributed to its nanoporous structure, the presence of oxygen vacancies and the strong synergistic coupling effect between $\mathrm{Fe}_{3} \mathrm{O}_{4}$ and $\mathrm{Co}_{3} \mathrm{~S}_{4}$ species [145].

\subsubsection{Manganese and Cerium Oxide-Modified Electrodes}

Due to the synergistic effect, $\mathrm{Mn}_{2} \mathrm{O}_{3} / \mathrm{CeO}_{2}$ nanocubes have a high adsorption capacity for $\mathrm{As}(\mathrm{III})$, so its detection sensitivity is higher than any kind of oxide. Combined with the sensing properties of gold ( $\mathrm{Au}$ ) for $\mathrm{As}(\mathrm{III})$, a sensing material based on $\mathrm{Mn}_{2} \mathrm{O}_{3} / \mathrm{CeO}_{2}$ nanocubes modified with gold electrode was fabricated [146], as shown in Figure 16. Under the optimized conditions, the sensitivity of the sensor was $0.0414 \mathrm{~mA} \mathrm{ppb}^{-1}$ and the limit of detection (LOD) was 3.35 ppb with good stability and reproducibility, and the electrode had good selectivity for the presence of common interfering ions.

Manganese oxide $\left(\mathrm{MnO}_{2}\right)$ can be used as an active electrode material due to its good redox properties, porosity, low cost, and large specific surface area. In addition, the electrocatalytic properties of the composites can be further improved through synergistic effects by immobilizing metal oxides on the surface of polyhydroxytyramine (POT) and graphene oxide (rGO) composites. Sathish Kumar Ponnaiah et al. used a novel manganese dioxide/polyhydroxytyramine/reduced graphene oxide nanocomposite $\left(\mathrm{MnO}_{2} / \mathrm{POT} / \mathrm{rGO} /\right.$ GCE) to fabricate sensing electrodes with a wide linear range (0.01-0.900 ppb) and minimum 
detection limit (42.0 ppt), and excellent selectivity, stability and reproducibility [147]. The process schematic is shown in Figure 17.

\section{A) Adsorption}

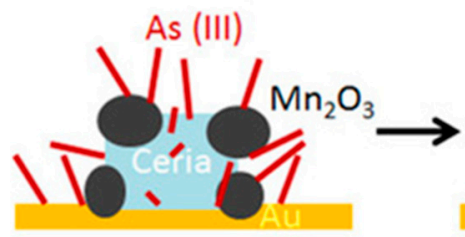

Au sub.
B) Pre-concentration

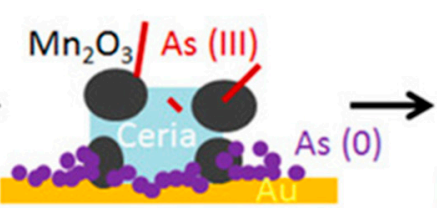

$\mathrm{Mn}_{2} \mathrm{O}_{3}$
As (III)

\section{C) Stripping}

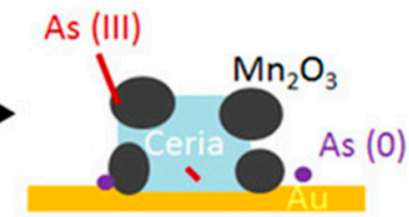

- As (0)

Figure 16. Schematic diagram of electrochemical analysis of arsenic on $\mathrm{Mn}_{2} \mathrm{O}_{3} / \mathrm{CeO}_{2} /$ gold electrode. (A) Adsorption, (B) pre-concentration, (C) stripping. (Reprinted with permission from [146], Copyright 2018, Wiley-VCH Verlag GmbH \& Co. KGaA, Weinheim.)

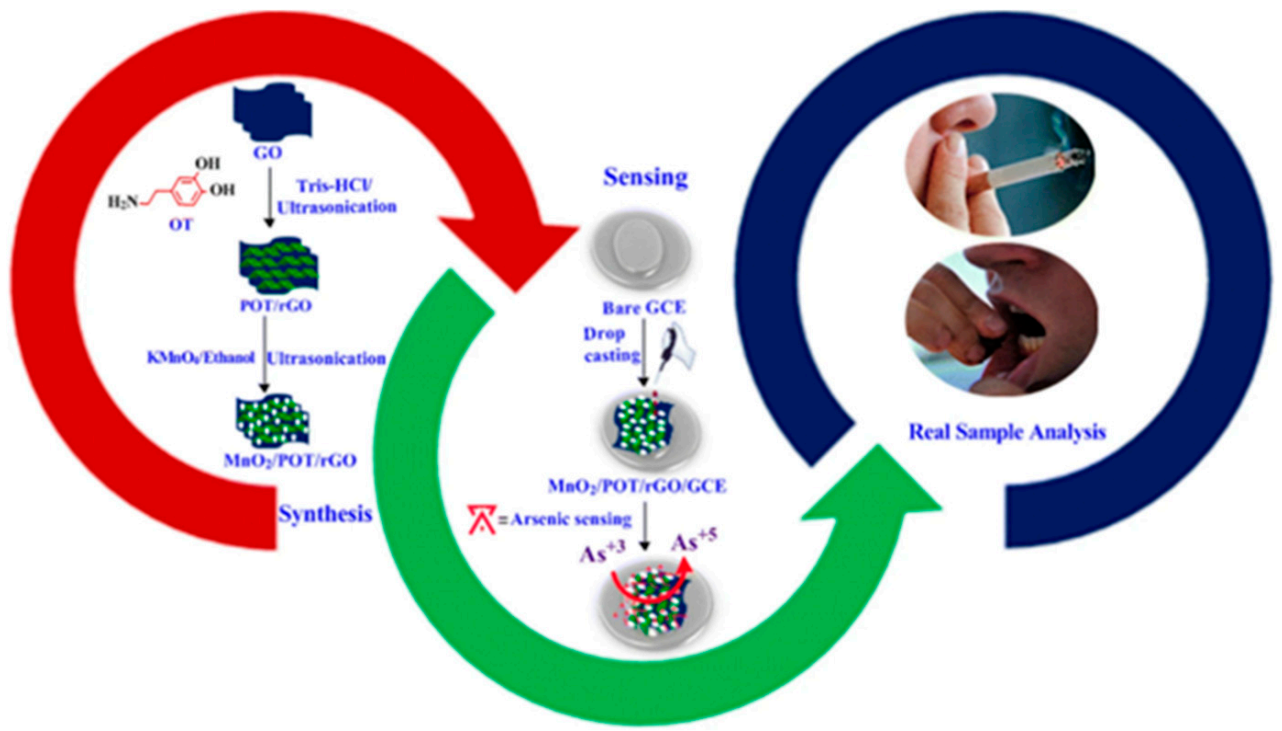

Figure 17. Synthesis of $\mathrm{MnO}_{2} / \mathrm{POT} / \mathrm{rGO}$ nanocomposites and arsenic detection process. (Reprinted with permission from [147], Copyright 2020, Springer Nature Switzerland AG.)

\subsubsection{Cobalt Oxide-Modified Electrodes}

An electrochemical sensor based on cobalt oxide nanoparticles was developed by Abdollah Salimi et al. Cobalt oxide (CoOx) nanoparticles were prepared from an aqueous buffer solution of $\mathrm{CoCl}_{2}$ using cyclic voltammetry and deposited on the surface of a glassy carbon electrode. Then, As(III) was detected by cyclic voltammetry, and a detection limit of $11 \mathrm{nM}$ was achieved. The authors concluded that immobilizing cobalt oxide nanoparticles on the surface of GC electrode seems to be an efficient method to develop a new class of sensitive, stable and reproducible electrochemical sensors for As(III) [148]. ChunYang Li combined the excellent catalytic properties of AuNPs with the high adsorption capacity of $\mathrm{Co}_{3} \mathrm{O}_{4}$ nanomaterials to construct an ultra-sensitive electrochemical sensor for electrochemical analysis of As(III) by homogeneously assembling gold nanoparticles on porous cobalt oxide $\left(\mathrm{Co}_{3} \mathrm{O}_{4}\right)$ microsheets to form nanocomposites [98]. The experimental results show that the AuNPs $/ \mathrm{Co}_{3} \mathrm{O}_{4}$ nanocomposite-modified SPCE achieved an ultra-high sensitivity of $12.1 \pm 0.2 \mu \mathrm{A} \mathrm{ppb}^{-1}$ and a detection limit of $0.09 \mathrm{ppb}$ for As(III) using the SWASV method. This excellent electrochemical performance was attributed to the high adsorption capacity of the porous $\mathrm{Co}_{3} \mathrm{O}_{4}$ microporous sheet and AuNPs for the favorable electrocatalysis of As(III) reduction. In addition, the method also exhibits good anti-interference performance in the presence of other metal ions $(\mathrm{Cu}(\mathrm{II}), \mathrm{Pb}(\mathrm{II}), \mathrm{Cd}(\mathrm{II})$, 
etc.) with good stability and reproducibility. Most importantly, the electrochemical sensor has been successfully applied to the electroanalysis of As(III) in water and human serum samples, which provides a new approach to design sensitive and stable electrochemical sensors. The schematic diagram of the electrochemical analysis is shown in Figure 18 below.

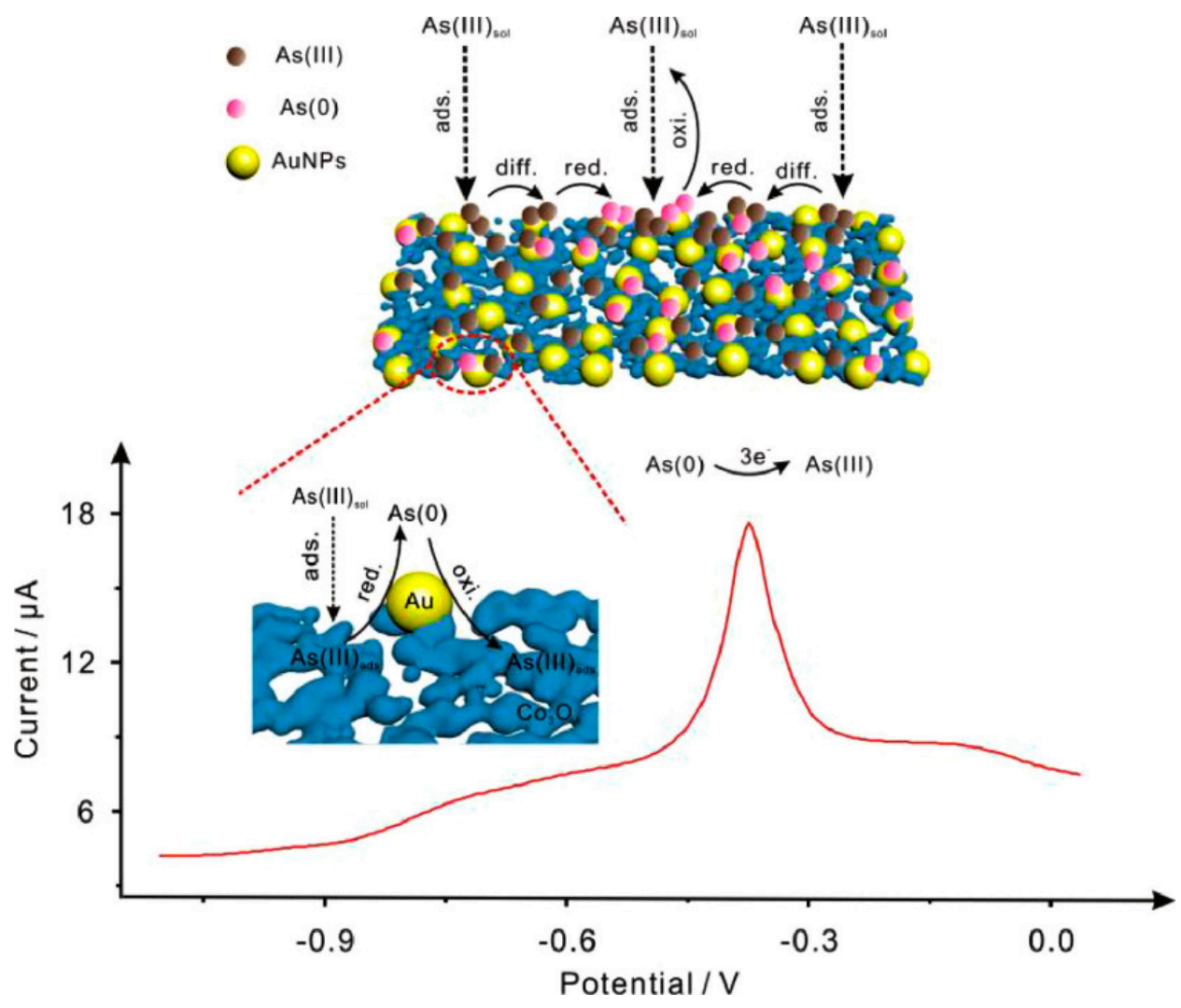

Figure 18. Electrochemical analysis of arsenic ions in solution based on AuNPs $/ \mathrm{Co}_{3} \mathrm{O}_{4} / \mathrm{SPCE}$. (Reprinted with permission from [98], Copyright 2020, Elsevier Ltd.)

\subsubsection{Tin Oxide-Modified Electrodes}

Tin oxide $\left(\mathrm{SnO}_{2}\right)$ has become the material of choice for arsenic $\left(\mathrm{As}^{3+}\right)$ redox sensing due to its high catalytic activity, environmental performance, wide band gap (3.64 eV) and high specific surface area (nanoscale) [149]. Tian-JiaJiang et al. reported an ultrathin $\mathrm{SnO}_{2}$ nanosheet for the modification of gold electrodes, resulting in enhanced adsorption capacity on the gold electrode surface [150]. Gaurav Bhanjana et al. synthesized $\mathrm{SnO}_{2}$ nanopins (particle size 60-80 $\mathrm{nm}$ ) by the chemical precipitation method, characterized their elemental, topological, morphological and structural features, and then coated these nanopins on the surface of pencil cores (containing graphite/carbon $(C)$ ) to serve as working electrodes to prepare nanomaterial sensors for the detection of arsenic ions [151]. By the electrochemical determination of arsenic in real samples, the sensor has a detection limit of $10 \mathrm{ppb}$, a linear range of $50-500 \mathrm{ppb}$, and a sensitivity of $28.13 \mu \mathrm{A} \mathrm{ppb}^{-1} \mathrm{~cm}^{-2}$. The experimental results provide a feasible method for the field detection of $\mathrm{As}^{3+}$ in environmental samples such as food, beverages, industrial samples, and wastewater. The modified electrode current response relationship under certain conditions is shown in Figures 19 and 20. 

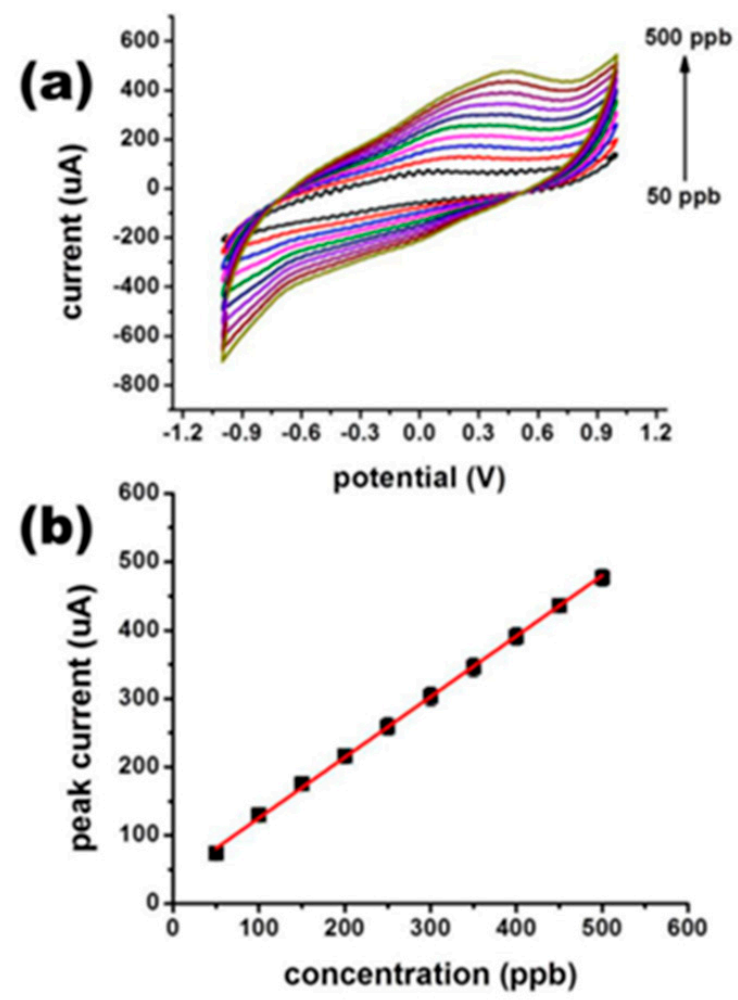

Figure 19. (a) Current response to different concentrations of arsenic; (b) oxidation peak current and concentration linear calibration curve. (Reprinted with permission from [151], Copyright 2018, Elsevier B.V.)
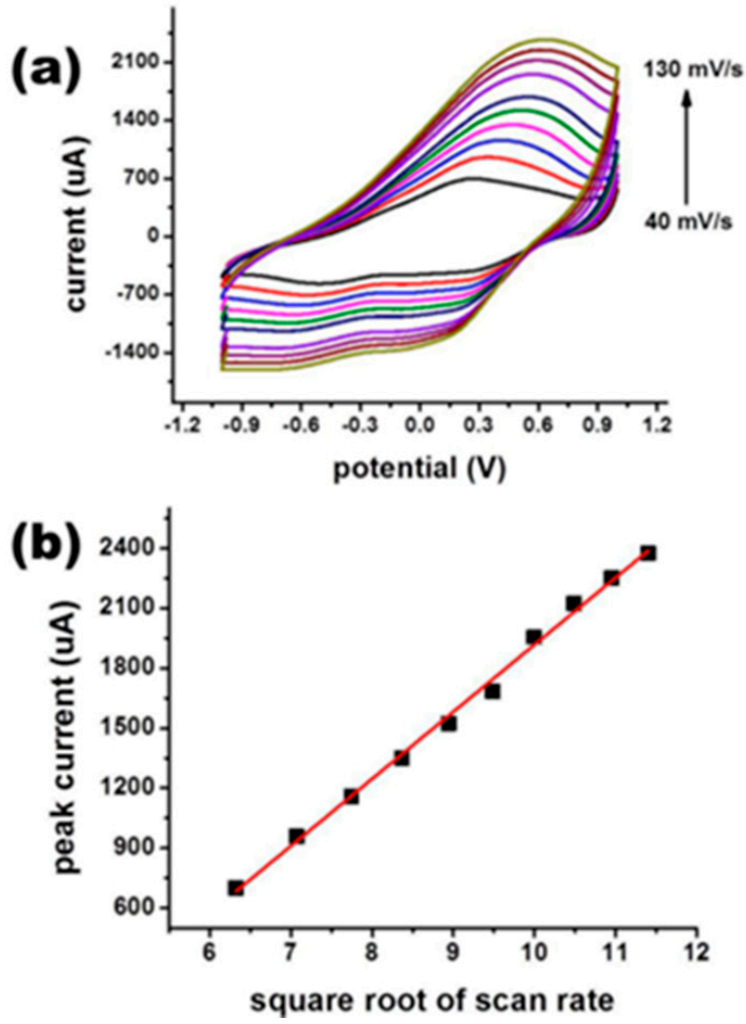

Figure 20. (a) Current response at different scan rates; (b) oxidation peak current and scan rate linear calibration curve (Reprinted with permission from [151], Copyright 2018, Elsevier B.V.) 


\subsubsection{Strontium Compound-Modified Electrodes}

A. Karthika et al. reported a glassy carbon electrode modified with strontium titanium trioxide $\left(\mathrm{SrTiO}_{3}\right)$ and $\beta$-cyclodextrin $(\beta-\mathrm{CD})$-based nanocomposite, for the determination of toxic As(III) ions in water and serum samples [152]. The prepared $\mathrm{SrTiO}_{3} / \beta-\mathrm{CD}$ nanocomposite-modified glassy carbon electrode has a high specific surface area and a sensitive electrochemical response. After testing, the oxidation peak current of As(III) increased linearly with the concentration in the concentration range of $10-140 \mu \mathrm{M}$ of $\mathrm{As}(\mathrm{III})$ particles, and the detection limit was $0.02 \mu \mathrm{M}$. The electrode is stable, sensitive and reproducible for the detection of $\mathrm{As}(\mathrm{III})$ in water and serum.

\subsubsection{Bismuth Compound-Modified Electrode}

Thabile Ndlovu electrodeposited a bismuth film onto an exfoliated graphite (EG) electrode at a potential of $-600 \mathrm{mV}$. The modification of EG resulted in an increase in the electroactive surface area of the electrode, and square-wave anodic dissolution voltammetry using the modified electrode (EG-Bi) in As(III) solution was able to detect 5 ppb of As(III) and was insensitive to many interfering cations except $\mathrm{Cu}$ (II) [153]. Potlako J. Mafa also electrodeposited bismuth nanoparticles onto graphite electrodes and used square-wave anodic solvation voltammetry (SWASV) to co-detect heavy metal ions in water samples with a detection limit of $0.014 \mathrm{ppb}$ for As(III) under optimized experimental conditions [154]. In addition to bismuth nanoparticles, Lignesh Durai reported a novel and facile hydrothermal synthesis of bismuth vanadate $\left(\mathrm{BiVO}_{4}\right)$ nanoflakes for the trace detection of arsenic in biological samples by the electrodeposition of a screen-printed carbon electrode (SPCE) coated with polyaniline (PANI), with the As(III) sensing mechanism as shown in Figure 21. The sensor can detect $\mathrm{As}^{3+}$ ions by the differential pulse dissolution voltammetry (DPASV) technique with a significantly low limit of detection (LOD) of $0.0072 \mathrm{ppb}$ and a sensitivity of $6.06 \mu \mathrm{A} \mathrm{ppb}^{-1} \mathrm{~cm}^{-2}$ with a linear range of $0.01-300 \mathrm{ppb}$ [155].

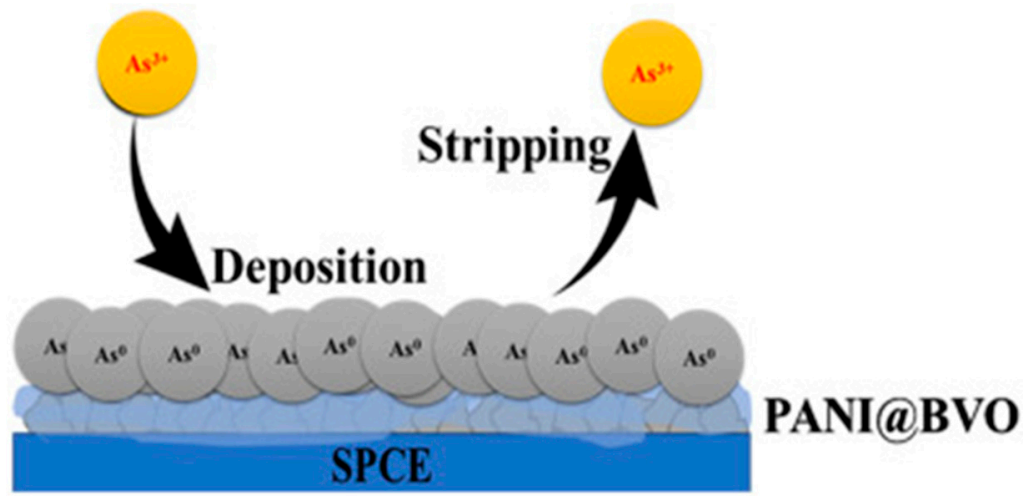

Figure 21. DPASV sensing mechanism of PANI@BiVO 4 /SPCE for $\mathrm{As}^{3+}$ ions. (Reprinted with permission from [155], Copyright 2020, Elsevier B.V.)

\subsubsection{Zirconium Compound-Modified Electrodes}

Gaurav Bhanjana used gold electrodes modified with zirconia nanocubes synthesized by a facile hydrothermal route, and electrochemical sensing of arsenic was achieved by cyclic voltammetry (CV) and chronoamperometry with a sensitivity of $550 \mathrm{nA} \mathrm{cm}{ }^{-2} \mathrm{ppb}^{-1}$ and a detection limit of $5 \mathrm{ppb}$ (linear range of 5-60 ppb, response time below $2 \mathrm{~s}$ ). The synthesized nanoparticles are nanocubes, and from the $\mathrm{CV}$ plots under different conditions (Figure 22) it can be seen that the peak oxidation current is more pronounced for zirconia nanocube-modified electrodes than for zirconia nanoparticle-modified electrodes, which are used as effective electrocatalysts in the direct redox sensing of arsenic [156]. In addition, zirconia composites were used for the electrochemical detection of arsenic. MengYang used AuNPs $/ \mathrm{CeO}_{2}-\mathrm{ZrO}_{2}$ nanocomposite-modified glassy carbon electrodes (GCE) to fabricate a sensing interface for the sensitive and accurate analysis of As(III) in 
near groundwater $\mathrm{pH}$ values, and square-wave anodic dissolution voltammetry (SWASV) was used to determine $\mathrm{As}(\mathrm{III})$ in real water samples. Thanks to the strong adsorption capacity of $\mathrm{CeO}_{2}-\mathrm{ZrO}_{2}$, the electroanalytical sensitivity and theoretical detection limit of $\mathrm{As}(\mathrm{III})$ were $0.976 \mu \mathrm{A} \mathrm{ppb}^{-1}$ and $0.137 \mathrm{ppb}$, respectively, at the optimal parameters. In addition, the method has good anti-interference performance [85]. The performance analysis of different electrodes modified with metals other than noble metals and their compounds for the electrochemical detection of arsenic is given in Table 5.
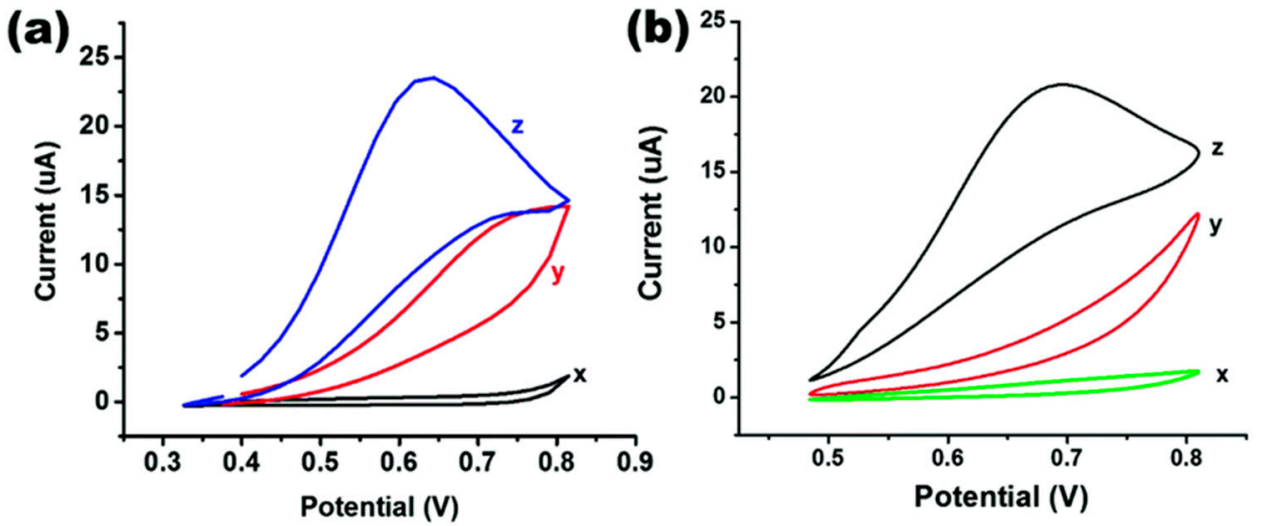

Figure 22. (a) CV curves of $50 \mathrm{ppm}$ arsenic(III) ion standard under varying conditions for zirconia nanocubes, $\mathrm{x}$ : blank (black line), y: bare gold electrode (red line), and z: after fabrication (blue line); (b) CV curves of $50 \mathrm{ppm}$ arsenic(III) ion standard under varying conditions for zirconia nanoparticles: $\mathrm{x}$ : blank (green line), y: bare gold electrode (red line), and z: after fabrication (black line). (Reprinted with permission from [156], Copyright 2016, Royal Society of Chemistry.)

Table 5. Other metal- and compound-modified electrodes.

\begin{tabular}{|c|c|c|c|c|c|}
\hline Electrode & Method & Sensitivity $(\mu \mathrm{A} / \mathrm{ppb})$ & Linear Range (ppb) & LOD (ppb) & Reference \\
\hline $\mathrm{Au} \mathrm{NPs} / \mathrm{Fe}_{3} \mathrm{O}_{4}$ & SWV & 13.55 & $0.01-1$ & 0.00097 & [59] \\
\hline $\mathrm{Fe}-\mathrm{CB} / \mathrm{PE}$ & ASV & & $0.4-20$ & 0.16 & [157] \\
\hline $\mathrm{Fe}_{3} \mathrm{O}_{4}-\mathrm{RTIL}$ & SWASV & 4.91 & $1-10$ & 0.0008 & [144] \\
\hline Chitosan- $\mathrm{Fe}(\mathrm{OH})_{3}$ & ASV & 8.39 & $2-100$ & 0.072 & [158] \\
\hline $\mathrm{Au} @ \mathrm{Fe}_{3} \mathrm{O}_{4}-\mathrm{RTIL}$ & SWASV & $58.66 \mu \mathrm{A} \mathrm{ppb}^{-1} \mathrm{~cm}^{-2}$ & $0.1-1$ & 0.0022 & [72] \\
\hline $\mathrm{rGO} / \mathrm{Fe}_{3} \mathrm{O}_{4}$ & & 1.922 & $2-20$ & 0.3 & [159] \\
\hline $\mathrm{rGO}-\mathrm{Fe}_{3} \mathrm{O}_{4}$ & DPASV & & $2-300$ & 0.10 & [143] \\
\hline $\mathrm{rGO} / \mathrm{Fe}_{3} \mathrm{O}_{4}$ & SWASV & 0.281 & & 0.12 & [141] \\
\hline $\begin{array}{c}\mathrm{Fe}-\mathrm{MOF} \\
@ \mathrm{mFe}_{3} \mathrm{O}_{4} @ \mathrm{mC}\end{array}$ & EIS & & $7.49 \times 10^{-4}-0.75$ & $5.04 \times 10^{-4}$ & [160] \\
\hline $\mathrm{Fe} \mathrm{Pc} / \mathrm{Si}-\mathrm{NP}$ & DPASV & 0.20 & & 3.66 & [161] \\
\hline CoPc/Si-NP & DPASV & 0.18 & & 4.39 & [161] \\
\hline $\mathrm{Au} / \mathrm{Fe}_{3} \mathrm{O}_{4}$ & SWASV & 9.43 & $0.1-10$ & 0.0215 & [162] \\
\hline$\alpha-\mathrm{FeOOH}$ & $\mathrm{CV}$ & & $0.75-1498.43$ & 0.37 & [163] \\
\hline $\mathrm{Fe}_{2} \mathrm{~V}_{4} \mathrm{O}_{13}$-polypyrrole & DPASV & & $0-500$ & 0.3 & [164] \\
\hline $\begin{array}{l}\mathrm{Fe}_{3} \mathrm{O}_{4}-\mathrm{Ag} / \mathrm{Au} \\
\text { HNSs-rGONs }\end{array}$ & $\mathrm{CV}$ & 52 & $0.1-20$ & 0.01 & [165] \\
\hline $\begin{array}{l}\text { CN-wrapped IL-modified } \\
\text { ZF-Ms (CN@ZF-Ms-IL) }\end{array}$ & SWASV & 41.08 & $1-60$ & 0.0006 & [166] \\
\hline $\mathrm{Fe}_{3} \mathrm{O}_{4}-\mathrm{rGO}$ & SWV & 2.15 & $1-20$ & 1.19 & [142] \\
\hline
\end{tabular}


Table 5. Cont.

\begin{tabular}{|c|c|c|c|c|c|}
\hline Electrode & Method & Sensitivity $(\mu \mathrm{A} / \mathrm{ppb})$ & Linear Range (ppb) & LOD (ppb) & Reference \\
\hline $\mathrm{GO} / \mathrm{Fe}_{3} \mathrm{O}_{4} @ \mathrm{PMDA} / \mathrm{AuNPs}$ & SWSV & & $0.5-750$ & 0.15 & [99] \\
\hline $\mathrm{Fe}_{3} \mathrm{O}_{4}-\mathrm{Au}-\mathrm{IL}$ & SWASV & 122 & $1-100$ & 0.22 & {$[138]$} \\
\hline $\mathrm{Fe}_{3} \mathrm{O}_{4} / \mathrm{Co}_{3} \mathrm{~S}_{4}$ & SWASV & 4.359 & $1.0-10.0$ & 0.691 & [145] \\
\hline $\mathrm{MnO}_{\mathrm{x}} / \mathrm{AuNPs}$ & LS-ASV & $2.73 \mu \mathrm{A} \mathrm{ppb}{ }^{-1} \mathrm{~cm}^{-2}$ & $0.5-80$ & 0.057 & {$[68]$} \\
\hline $\mathrm{MnFe}_{2} \mathrm{O}_{4} \mathrm{NCs}$ & SWASV & 0.295 & & 1.95 & {$[167]$} \\
\hline $\mathrm{rGO} / \mathrm{MnO}_{2}$ & SWASV & 0.175 & $0.1-50$ & 0.05 & {$[168]$} \\
\hline $\mathrm{AuNPs} / \alpha-\mathrm{MnO}_{2}$ & SWASV & 0.828 & $1-10$ & 0.019 & [169] \\
\hline $\begin{array}{c}\mathrm{MnFe}_{2} \mathrm{O}_{4} / \mathrm{Au} \text { hybrid } \\
\text { nanospheres }\end{array}$ & SWASV & 0.315 & & 3.37 & [74] \\
\hline $\mathrm{Mn}_{2} \mathrm{O}_{3} / \mathrm{CeO}_{2}$ & SWASV & 0.0414 & & 3.35 & {$[146]$} \\
\hline Nafion/ $\alpha-\mathrm{MnO} @ P D A$ & SWASV & 0.13 & $10-150$ & 3.2 & [170] \\
\hline $\mathrm{MnO}_{2} / \mathrm{POT} / \mathrm{rGO}$ & DPV & 0.00163 & $0.01-0.9$ & 0.042 & [147] \\
\hline Bi-NPs & SWV & & & 5 & {$[153]$} \\
\hline EG-Bi & SWASV & & & 0.014 & {$[154]$} \\
\hline PANI@BiVO 4 & DPASV & $6.06 \mu \mathrm{A} \mathrm{ppb}{ }^{-1} \mathrm{~cm}^{-2}$ & $0.01-300$ & 0.0072 & [155] \\
\hline F-doped CdO thin films & $\mathrm{CV}$ & $5.747 \times 10^{-3}$ & $4.55-41$ & 0.00455 & {$[171]$} \\
\hline $\mathrm{CoOx}$ & $\mathrm{CV}$ & $1.49 \times 10^{-3}$ & & 0.82 & {$[148]$} \\
\hline Co-rGO & ASV & & & 0.31 & {$[172]$} \\
\hline $\mathrm{AuNPs}-\mathrm{Co}_{3} \mathrm{O}_{4}$ & SWASV & $12.1 / 3.7$ & $0.1-1 / 1-20$ & $0.09 / 0.79$ & {$[98]$} \\
\hline $\mathrm{Fe}_{3} \mathrm{O}_{4} / \mathrm{Co}_{3} \mathrm{~S}_{4}$ & SWASV & 4.359 & $1.0-10.0$ & 0.691 & {$[145]$} \\
\hline $\mathrm{In}_{0.38} \mathrm{Ga}_{0.62} \mathrm{~N} / \mathrm{Si}(111)$ & SWV & & $10-50$ & 9.27 & [173] \\
\hline $\mathrm{Pt}_{1} / \mathrm{MoS}_{2}$ & SWASV & 3.31 & $0.5-8$ & 0.05 & [109] \\
\hline $\mathrm{PbO}_{2} / \mathrm{rGO}$ & & & & 0.75 & {$[174]$} \\
\hline Au-ITO & ASV & & & 5 & {$[175]$} \\
\hline $\mathrm{SnO}_{2}$ nanosheets & SWASV & 0.058 & $5-300$ & 4.6 & [150] \\
\hline Nafion/SnO $\mathrm{S}_{2}$ nanoneedles & $\mathrm{CV}$ & $28.13 \mu \mathrm{A} \mathrm{ppb}{ }^{-1} \mathrm{~cm}^{-2}$ & $50-500$ & 10 & [151] \\
\hline 3D NPG-ITO & DPASV & 9.837 & $0.1-50$ & 0.054 & {$[92]$} \\
\hline Gemini-ITO & SWV & & $1-100$ & 0.88 & [176] \\
\hline $\mathrm{SrTiO}_{3} / \beta-\mathrm{CD}$ & Amperometry & $0.0053 \mu \mathrm{A} \mu \mathrm{M} \mathrm{cm}^{-2}$ & $749.21-10,489.02$ & 1.50 & [152] \\
\hline $\mathrm{CP}-\mathrm{ThO}_{2} \mathrm{NP}$ & DPASV & 0.54 & $3-180$ & 0.1 & [177] \\
\hline $3 \mathrm{D}$ porous $\mathrm{Au} / \mathrm{TiO}_{2}$ & SWASV & 0.064 & $7.49-599.36$ & 3.00 & {$[66]$} \\
\hline $\mathrm{TiO}_{2}-\mathrm{GSE}$ & LSV & 1.10 & $10-80$ & 10 & {$[178]$} \\
\hline $\mathrm{ZrO}_{2}$-nanocubes & $\mathrm{CV}$ & & $5-60$ & 5 & [156] \\
\hline $\mathrm{ZrF}-8 \mathrm{CAu}$ & $\mathrm{CV}$ & & $5-700$ & 1 & {$[81]$} \\
\hline $\begin{array}{c}\text { Zr-G-PGE } \\
(\mathrm{As}(\mathrm{V}))\end{array}$ & DPV & 1.36 & $0.10-40.0$ & 0.12 & {$[179]$} \\
\hline $\mathrm{AuNPs} / \mathrm{CeO}_{2}-\mathrm{ZrO}_{2}$ & SWASV & 0.976 & $0.5-15$ & 0.137 & [85] \\
\hline
\end{tabular}

\subsection{Carbon Nanomaterial-Modified Electrodes}

In electrochemical sensing, carbon-based electrodes such as glassy carbon electrodes, screen-printed carbon electrodes and graphite-carbon paste electrodes are widely used for arsenic ion detection. In addition, due to the unique electronic properties of carbon-based 
nanomaterials, carbon nanomaterials have proven to be very suitable for the modification of working electrodes in the electrochemical detection of arsenic. Carbon nanomaterials include single-walled carbon nanotubes (SWNT), multi-walled carbon nanotubes (MWNT), graphene, nanodiamond, fullerene, and graphene quantum dots. The most widely studied carbon nano-derivatives in electrochemical sensing are carbon nanotubes and graphene [180]. The performance analysis of different carbon nanomaterials and their composite-modified electrodes for the electrochemical detection of arsenic is statistically presented in Table 6.

Table 6. Carbon material-modified electrode.

\begin{tabular}{|c|c|c|c|c|c|}
\hline Electrode & Method & Sensitivity $(\mu \mathrm{A} / \mathrm{ppb})$ & Linear Range (ppb) & LOD (ppb) & Reference \\
\hline ERGO-AuNPs & ASV & 0.16 & $0.75-374.61$ & 0.20 & {$[63]$} \\
\hline Gr-nPt & SWASV & & $0.75-7.5$ & 0.082 & [106] \\
\hline $\mathrm{Au} / \mathrm{GO} /$ Leucine/Nafion & $\mathrm{CV}$ & $0.03 \mu \mathrm{A} \mathrm{ppb} \mathrm{cm}^{-1}$ & & 500 & [181] \\
\hline $\mathrm{NH}_{2}-\mathrm{GO}$ & SWASV & $130.631 \mu \mathrm{A} \mathrm{ppb}{ }^{-1} \mathrm{~cm}^{-2}$ & & 0.162 & [182] \\
\hline 3D-rGO/AuNPs & EIS & & $3.8 \times 10^{-7}-3.0 \times 10^{-4}$ & $1.4 \times 10^{-7}$ & [82] \\
\hline$\left[\mathrm{Ru}(\mathrm{bpy})_{3}\right]^{2+}-\mathrm{GO}$ & DPV & & $6.00-1123.83$ & 1.57 & [183] \\
\hline $\mathrm{Ru}(\mathrm{II})$-tris(bipy)-GO & $\mathrm{CV}$ & $1.42 \mu \mathrm{A} \mathrm{ppb} \mathrm{cm}^{-1}$ & $3.75-59.94$ & 2.25 & [129] \\
\hline $\mathrm{TTCA} / \mathrm{rGO}$ & SWASV & & $0-10$ & 0.054 & [184] \\
\hline $\mathrm{Gr} / \mathrm{MOF}$ & DPASV & & $0.2-25$ & 0.06 & [185] \\
\hline RM-rGO & SWASV & 2.49 & & 0.07 & [186] \\
\hline SPGE & DPAV & & $0.0-5.0$ & 0.28 & [187] \\
\hline Au-PANI-Fe-CNF & SWASV & 0.04 & $5-400$ & 0.5 & [54] \\
\hline SH-SWCNTs & LSV & 1.33 & & 0.008 & [188] \\
\hline DNA-SWCNT & LSV & 0.17 & $0-33.6$ & 0.05 & [189] \\
\hline Pt nano/CNTs & LSV & $9.34 \times 10^{-3}$ & $374.61-74,921.6$ & 0.12 & [104] \\
\hline CNTs/Leucine/Nafion & $\mathrm{CV}$ & 0.27 & $0.37-149.84$ & 0.12 & [190] \\
\hline CNTs/Nafion/Glutamine & & 1.33 & $0.075-37.835$ & 2.72 & [191] \\
\hline CNTs-GNPs & LSASV & 135 & & 0.5 & [192] \\
\hline ssDNA/SWCNTs & DPV & & $0.5-10$ & 0.5 & [193] \\
\hline Eu-MGO/Au@MWCNT & SWSV & & $0.99-100.0$ & 0.27 & [194] \\
\hline $\begin{array}{c}\text { Buckypaper modified } \\
\text { by GNP }\end{array}$ & LSASV & & $0.75-750$ & 0.75 & [86] \\
\hline CQDs/f-MWCNTs/GO & DPV & & $7.49 \times 10^{-3}-0.82$ & 0.037 & [195] \\
\hline MMWCNTs-D-NH 2 & SWASV & 0.5613 & $1.0-50.0$ & 0.46 & [196] \\
\hline
\end{tabular}

\subsubsection{Carbon Nanotube-Based Detection of Arsenic Ions}

Carbon nanotubes (CNT) are an excellent support structure due to their large effective detection surface, fast electron transfer rate compared with bulk carbon electrodes, high electrocatalytic activity and low electrode contamination, which can further help to improve electrochemical analysis performance by immobilizing other chemical species, such as metal NPs and organic molecules [14]. The main features of carbon nanotubes in electrochemical sensors are a fast response and low detection limits.

$\mathrm{He} \mathrm{Xu}$ et al. chose to form a composite with carbon nanotubes for the electrochemical detection of arsenic using Pt nanoparticles, as shown by the TEM image of the composite (Figure 23), where Pt nanoparticles are clearly decorated on carbon nanotubes, reflecting a higher electroactive area than the Pt nanoparticle modification alone [104]. Yaxiong Liu et al. 
proposed a single-layer low-resistance single-walled carbon nanotube-modified glassy carbon electrode for the electrochemical detection of arsenic with non-covalent $\mathrm{SH}$ groups sensitive to As(III), achieving an ultra-low detection limit of $0.008 \mathrm{ppb}$ [188]. In addition to compounding with metal particles, carbon nanotubes can also be combined with biomolecules and with DNA. Yaxiong Liu's team developed a layer-by-layer assembly of DNA-functionalized single-walled carbon nanotubes that achieves a detection limit of $0.05 \mathrm{ppb}$ in a near-physiological environment and can be reused multiple times [189]. Subramanian Nellaiappan et al., on the other hand, proposed a gold nanoparticle/carbon nanofiber/chitosan chemically modified carbon screen-printed electrode by simultaneously combining carbon nanofibers with metal particle biomolecules, achieving comparable results to inductively coupled plasma-emission spectroscopy [83].

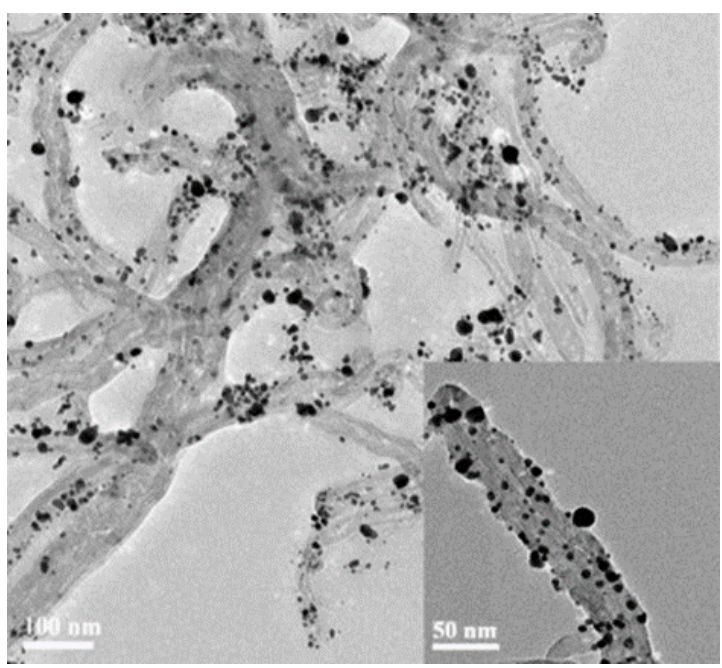

Figure 23. TEM photograph of $\mathrm{Pt}$ nano/CNTs synthesized by microwave irradiation; the inset is a higher magnification image of Pt/CNTs nanocomposite. (Reprinted with permission from [104], Copyright 2008, Elsevier B.V.)

\subsubsection{Graphene-Based Detection of Arsenic Ions}

Graphene is a new material in which carbon atoms are tightly packed into a single twodimensional honeycomb lattice structure. This material has excellent properties, with high strength and good toughness, and good electrical conductivity, and can be used directly as a modification material for electrodes. In addition, graphene has a characteristic that is very favorable for loading other materials, which is that it has many smooth folds, so there will be many graphene and other material composites to modify the electrode, so that the characteristics of the loading material can be more obvious.

Haibing $\mathrm{Hu}^{\prime}$ s team performed the electrochemical characterization of bare glassy carbon electrode, $\mathrm{rGO}, \mathrm{Fe}_{3} \mathrm{O}_{4}$, and $\mathrm{Fe}_{3} \mathrm{O}_{4}$-rGO nanocomposite-modified glassy carbon electrode in a specific detection solution in the preparation of $\mathrm{Fe}_{3} \mathrm{O}_{4}$-rGO nanocomposite, and found that the electrochemical performance of glassy carbon electrode modified by rGO or $\mathrm{Fe}_{3} \mathrm{O}_{4}$ only was not as good as that of bare glassy carbon electrode, although it was better than that of bare glassy carbon electrode, while the electrochemical performance of glassy carbon electrode modified by both composites was very good, which indicated that the large surface area provided by rGO caused the $\mathrm{Fe}_{3} \mathrm{O}_{4}$ particles to adhere well to the surface [142]. In addition to metal oxides, graphene can also form composites with metals [185], multi-walled carbon nanotubes [195], precious metals [114], and biomolecules [197], among others.

Carbon nanoparticles and other carbon-based nanomaterials have been used for signal enhancement in electrochemical sensors and biosensors due to their advantageous specific surface area. An electrochemical sensor based on carbon nanoparticles (CNPs) and gold nanoparticles (AuNPs) comprising an immobilized platform for As(III) detection in water 
was reported in 2019 [136]. The carbon-gold nanoplatform was prepared by drop coating CNPs on a glassy carbon electrode (GCE), followed by the electrodeposition of AuNPs on the CNPs-modified electrode under certain conditions. The sensor has a detection limit of $0.092 \mathrm{ppb}$ and exhibits insensitivity to the interference of $\mathrm{Cd}^{2+}, \mathrm{Cu}^{2+}$, and $\mathrm{Hg}^{2+}$, providing an interference reduction method for the electrochemical detection of arsenic.

\subsection{Biomolecule-Modified Electrodes}

\subsubsection{Arsenic Detection Based on DNA-Modified Electrodes}

DNA in DNA-based biosensors provides biologically recognizable components with three modes of interaction [198], namely electrostatic interactions with negatively charged phosphates, binding interactions with minor and major grooves of the DNA double helix, and embedding between natural DNA stacked base pairs.

An advanced DNA biosensor was reported by J. Labuda et al. [199]. Using the Co(III) complex with 1,10-phenanthroline, $\left[\mathrm{Co}(\text { phen })_{3}\right]^{3+}$, as an electrochemical DNA marker and the $\mathrm{Ru}(\mathrm{II})$ complex with bipyridyne, $\left[\mathrm{Ru}(\text { bipy })_{3}\right]^{2+}$, as a DNA oxidation catalyst, calf thymus DNA (CT-DNA) immobilized on the surface of a screen-printed electrode (SPE) was placed in aqueous solutions of different concentrations of As(III), As(V), dimethylarsenic acid, phenylarsenic and p-arsenic acid. Although this system was reported to have a poor detection limit $(75 \mathrm{mg} / \mathrm{L})$, it showed a successful correlation between DNA-labeling signals and As(III) levels. Liu and Wei exploited the high electrical conductivity of carbon nanotubes (CNTs) to construct electrochemical biosensors and explored the concept of the direct oxidation of $\mathrm{As}(0)$ to $\mathrm{As}(\mathrm{III})$ on DNA-functionalized single-walled CNT-modified glassy carbon electrodes [189]. The developed biosensor was operationally stable over a wide $\mathrm{pH}$ range with a detection limit $(\mathrm{S} / \mathrm{N}=3)$ of $0.05 \mu \mathrm{g} \mathrm{L}{ }^{-1}$ at $\mathrm{pH} 7.0$. and demonstrated the ability to be reused 16 times. Shaohua Wen described a voltammetric method for the determination of arsenite (As(III)) based on the specific binding of As(III) to probe DNA (SBP DNA; single-stranded DNA) and the electrochemical indicator methylene blue (MB), the fabrication of which is schematically shown in Figure 24. Upon addition of As(III), it specifically binds to SBP DNA, which leads to conformational changes and the dissociation of SBP DNA from the electrode into the solution. As a result, the amount of MB remaining on the modified electrode is reduced, which decreases the peak MB current. Under optimized conditions, As(III) was quantified by measuring the DPV response of MB absorbed by the SBP/CP hybrid at the electrode surface, and the reduction peak current was linearly related to the logarithmic value of As(III) concentration, yielding a linear concentration range of $0.1-200 \mathrm{ppb}$ and a detection limit as low as 75 ppt [200].

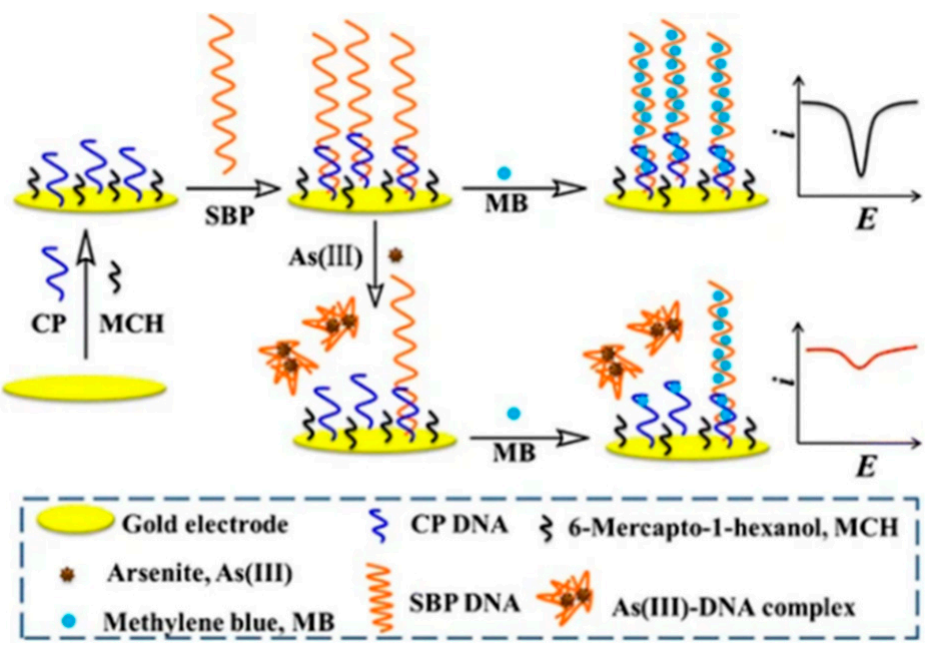

Figure 24. Schematic diagram of the fabrication of an electrochemical method for As(III) detection based on As(III)-induced DNA conformational changes and the electrochemical indicator MB. (Reprinted with permission from [200], Copyright 2017, Springer Nature Switzerland AG.) 


\subsubsection{Aptamer Sensors for Arsenic Detection}

An aptamer-based biosensor is a small device that assembles one or more biomaterials/nanomaterials onto an electrode transducer, and electrochemical impedance spectroscopy (EIS), differential pulse voltammetry (DPV), etc., are often used with aptamer sensors for arsenic detection [201]. For example, Baghbaderani and Noorbakhsh constructed several aptamer sensors based on electrochemical signals for the determination of As(III) [202]. They designed an unlabeled impedance aptamer sensor for highly sensitive As(III) determination using a chitosan-Nafion(Chit-Naf) compound as an excellent conductive surface platform and a novel carbon nanotube based on the signal amplification process. The EIS experimental results show that the glassy carbon electrode (GCE) modified by Chit-Naf has higher electron transfer kinetics compared with bare GCE, GCE/Naf, and GCE/Chit electrodes, which provides great feasibility for an effective platform for biosensor design. In this work, based on a carbon nanotube-bovine serum albumin (CNTBSA) hybrid system, they also used a signal amplification process to achieve an LOD of 74 pM. Lin Cui et al. designed an electrochemical aptamer sensor for the detection of As(III) based on gold-nanocoated screen-printed carbon electrodes (AuNPs/SPCE) [203], and the detection schematic is shown in Figure 25. By immobilizing the Ars-3 aptamer on AuNPs/SPCE, the Ars-3 aptamer is able to adsorb cations through electrostatic interactions with polydiallyldimethylammonium chloride (PDDA) and repel other cations. In the presence of arsenite, the Ars-3 conformation changes due to the formation of Ars-3/As(III) complexes, which reduces the adsorption of more positively charged electrochemically active indicator $\left[\mathrm{Ru}\left(\mathrm{NH}_{3}\right)_{6}\right]^{3+}$ on the surface of the PDDA adsorption electrode as a means to achieve coupling, thus enabling detection.

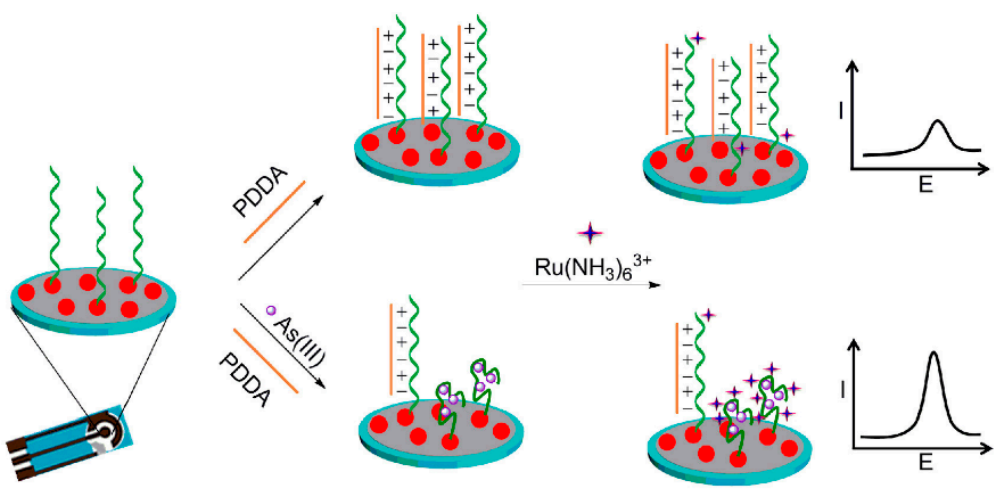

Figure 25. Schematic diagram of AuNPs/SPCE-based detection with Ars-3 aptamer. (Reprinted with permission from [203], Copyright 2016, Elsevier B.V.)

\subsubsection{Arsenic Detection Based on Other Biomolecules}

In addition to DNA with aptamers, certain proteins have been used as materials for the electrochemical detection of arsenic, and most protein-based arsenic detection is based on the inhibition phenomenon. Cytochrome-C (Cyt-C), an important component of the mitochondrial electron transport chain, is sensitive to all toxic compounds and is also used as a biorecognition element [204]. An electrochemical biosensor was constructed using Cyt-C, immobilized on a boron-doped diamond electrode. Square-wave voltammetry (SWV) and electrochemical impedance spectroscopy (EIS) were performed to investigate the interaction of Cyt-C with arsenic and cyanide. Subtractive normalized Fourier transform infrared spectroscopy (SNFTIR) was performed to confirm the effective protein adsorption onto the electrode. UV-vis studies of Cyt-C with the analytes confirmed the correct binding. The results indicate that their interaction was through the amino acids of the basic protein structure rather than through the heme portion of Cyt-C. Jae-Hoon Hwang et al. developed a novel As(III) sensor by depositing iron-chitosan complexes on screen-printed carbon electrodes using electrodeposition [205]. Mine wastewater and soil leachate were tested by square-wave anodic dissolution voltammetry. The detection limits of the Fe-chitosan- 
coated electrode were $1.12 \mathrm{ppb}$ for mine wastewater and $1.01 \mathrm{ppb}$ for soil leachate, both of which were significantly lower than the WHO requirements. The interference of $\mathrm{Cu}^{2+}$ ions had little effect on the detection, indicating that the chitosan-coated iron carbon could improve the stability. The sensor has high sensitivity and selectivity and provides a reliable level of detection of As(III) concentration in leachate from actual wastewater and contaminated sites. Suparna Saha et al. modified glassy carbon electrode with chitosan$\mathrm{Fe}(\mathrm{OH})_{3}$ composite and reducing agent L-cysteine [158], and its detection schematic is shown in Figure 26, under optimal optimized conditions, by differential pulse. The anodic dissolution voltammetry achieved a detection limit of $0.072 \mathrm{ppb}$ in the linear interval of 2-100 ppb and avoided the interference of common co-existing ions. More examples of biomolecule-modified electrodes for the detection of arsenic are given in Table 7.

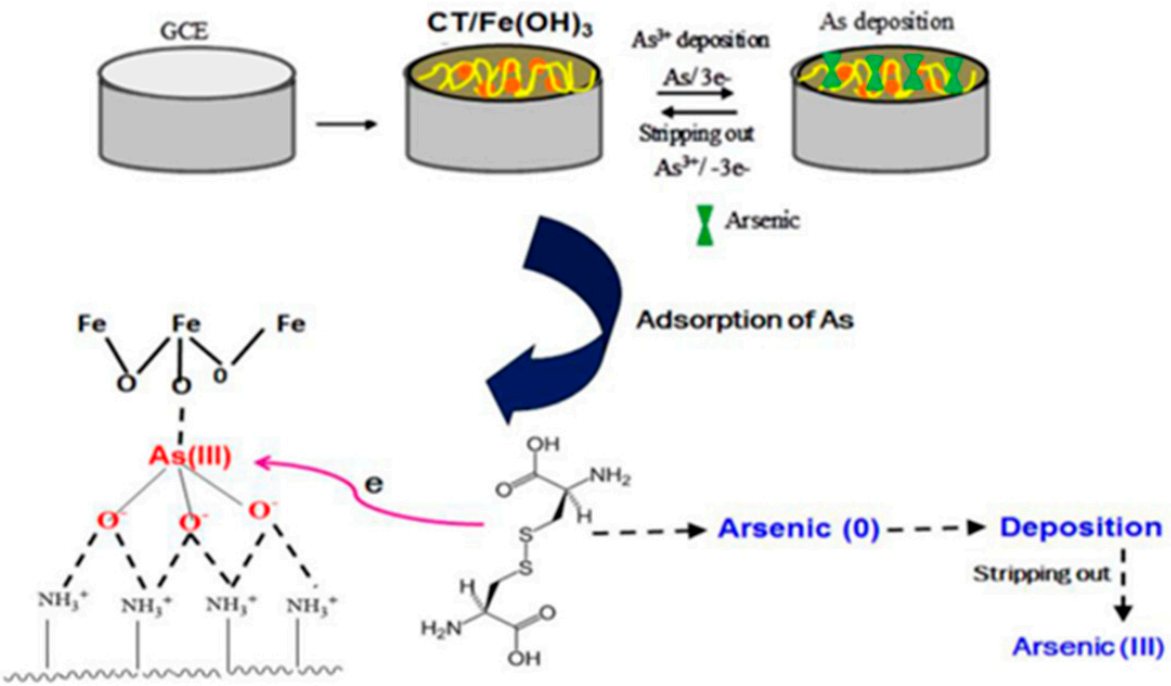

Figure 26. Schematic diagram of the scheme for the detection of arsenic ions by Fe-chitosan composites. (Reprinted with permission from [158], Copyright 2016, Elsevier B.V.)

Table 7. Biomolecule-modified electrodes.

\begin{tabular}{|c|c|c|c|c|c|}
\hline Electrode & Method & Sensitivity $(\mu \mathrm{A} / \mathrm{ppb})$ & Linear Range (ppb) & LOD (ppb) & Reference \\
\hline SBP DNA & DPV & & $0.1-200$ & 0.075 & [200] \\
\hline $\begin{array}{c}(\mathrm{GT})_{21} \text {-ssDNA and } \\
\text { PB@GO }\end{array}$ & DPV & & $0.2-500$ & 0.058 & [206] \\
\hline GH-APTES-Fe ${ }_{3} \mathrm{O}_{4} \mathrm{NP}$ & SWV & $1.92 / 0.12$ & $13.3-65.8 / 117-241$ & 1.6 & [207] \\
\hline SAMs & ASV & & $2-40$ & 0.5 & [208] \\
\hline L-tryptophan & SWASV & & $7.49 \times 10^{-3}-7.49$ & $0.90 \times 10^{-3}$ & [209] \\
\hline AuNP-rLA-Lcyst & SWV-ASV & 0.1 & $3-25$ & 3 & [97] \\
\hline P. cruentum & DPASV & & $2.5-20$ & 1.08 & [210] \\
\hline MTs & ASV & & $5-1000$ & 13 & [211] \\
\hline AgNPs/CT & DPASV & & $10-100$ & 1.20 & [113] \\
\hline Chitosan- $\mathrm{Fe}(\mathrm{OH})_{3}$ & ASV & 8.39 & $2-100$ & 0.072 & [158] \\
\hline $\begin{array}{c}\text { SPE/CNF-CHIT@Au } \\
\text { nano }\end{array}$ & FIA-ECD & 0.2181 & $100-100,000$ & 11.4 & [83] \\
\hline ACh-SPC & chronoamperometry & & & 2689.63 & [212] \\
\hline $\begin{array}{l}\text { HCR and RecJf } \\
\text { exonuclease }\end{array}$ & EIS & & $0.1-500$ & 0.02 & [213] \\
\hline
\end{tabular}


Table 7. Cont.

\begin{tabular}{|c|c|c|c|c|c|}
\hline Electrode & Method & Sensitivity $(\mu \mathrm{A} / \mathrm{ppb})$ & Linear Range (ppb) & LOD (ppb) & Reference \\
\hline AF / AuNPs-SPCE & $\mathrm{CV}$ & & $0.500-1999.61$ & 137.85 & [214] \\
\hline GC-AuNP-ArOx & $\mathrm{CV}$ & 46.05 & $0.75-749.21$ & 0.37 & [101] \\
\hline Escherichia coli & $\mathrm{CV}$ & & $0.94-3.75 / 3.75-30$ & 0.8 & [215] \\
\hline Whole-Cell Biosensors & $\mathrm{CV}$ & & $0-100$ & & [216] \\
\hline E. coli & $\mathrm{CV}$ & 0.122 & & 1.5 & [217] \\
\hline Ars-3 & DPV & & $0.015-7.49$ & 0.011 & [203] \\
\hline $\begin{array}{l}\text { 3D-rGO/Au } \\
\text { NPs/ssDNA }\end{array}$ & EIS & & $3.8 \times 10^{-7}-3.0 \times 10^{-4}$ & $1.4 \times 10^{-7}$ & [82] \\
\hline ArsSApt & EIS & & $50-10,000$ & 59.94 & [218] \\
\hline C-AuNPs & SWV & & $0.5-100$ & 0.092 & [136] \\
\hline Ars-3/AuNPs-GO-MB & DPV & & $0.4-10,000$ & 0.2 & [197] \\
\hline
\end{tabular}

\subsection{Others}

\subsubsection{Silicon and Its Compound-Modified Electrodes}

Suhainie Ismail et al. developed an efficient electrochemical detection method for arsenite using linear scanning anodic solvation voltammetry (LSASV) based on silicon nanoparticles and gold nanoparticles (SiNPs / AuNPs/SPCE) modifying the screen-printed electrode surface [93]. The electrode showed good linearity in the concentration range of $10-100 \mathrm{ppb}$ with a detection limit of $5.6 \mathrm{ppb}$. Multiple co-existing ions- $\mathrm{Pb}^{2+}, \mathrm{Ni}^{2+}, \mathrm{Zn}^{2+}$, $\mathrm{Hg}^{2+}$ and $\mathrm{Cu}^{2+}$-in the water samples did not interfere with the detection of arsenite. The method is highly sensitive and reproducible with a relative standard deviation of $4.52 \%$, which is promising for application. In addition, they also tried to detect As(III) using silicon nanoparticles (SiNPs)-modified screen-printed electrodes (SPCE) and tested the electrochemical response of the electrode to arsenic using cyclic voltammetry $(\mathrm{CV})$ and linear scanning anodic solvation voltammetry (LSASV) [219]. Under the optimized conditions, the peak anode current showed good linearity in the concentration range of 5-30 $\mu \mathrm{g} / \mathrm{L}$ As(III) with a detection limit of $6.2 \mu \mathrm{g} / \mathrm{L}$. This method can effectively detect As (III) in real water samples with low fabrication cost, good reproducibility and stability. In addition to silicon nanoparticles, Feng Sun prepared nano-Au/ $\mathrm{SiO}_{2}$ modified GCE by a one-step method. This nanohybrid material was used for the electrochemical detection of As (III). The calculated LOD was $0.07 \mu \mathrm{g} / \mathrm{L}$, with a linear detection range of $0.1-40 \mu \mathrm{g} / \mathrm{L}$ [80].

\subsubsection{Novel Polymer-Modified Electrodes}

Mohammed M. Rahman synthesized a new class of thermally stable hybrid poly(arylene) (azomethanes) and copoly(arylene)(azomethanes) (PAAP) based on diarylidenecycloalkanes by solution polycondensation, combined with a conductive nafion ( $5 \%$ ) coating agentmodified glassy carbon electrode for the detection of arsenic by the I-V method, which exhibits higher sensitivity and selectivity for $\mathrm{As}^{3+}$ ions. Based on the calibration curve, the sensitivity and detection limits were calculated as $2.714 \mu \mathrm{A} \mu \mathrm{M}^{-1} \mathrm{~cm}^{-2}$ and $6.8 \pm 0.1 \mathrm{nM}$, respectively, and this novel method provides a new route for the electrochemical detection of arsenic ions [220]. Wuwei Ma et al. proposed an electrochemical sensor based on ion-imprinted polymers (IIPs) and nanoporous gold (NPG)-modified gold electrode (IIP/NPG/GE) for the determination of arsenic ions $\left(\mathrm{As}^{3+}\right)$ in different kinds of water, which was prepared by the electrodeposition of nanoporous gold on the gold electrode, and then a layer of IIPs with $\mathrm{As}^{3+}$ as the template ion was synthesized in situ on the NPG surface by electropolymerization. The IIPs/NPG/GE formation process is shown in Figure 27. The linear range of $\mathrm{As}^{3+}$ was obtained from $2.0 \times 10^{-11}$ to $9.0 \times 10^{-9} \mathrm{M}$ by cyclic voltammetry, and the lower limit of detection was $7.1 \times 10^{-12} \mathrm{M}$ after the calibration curve [221]. 


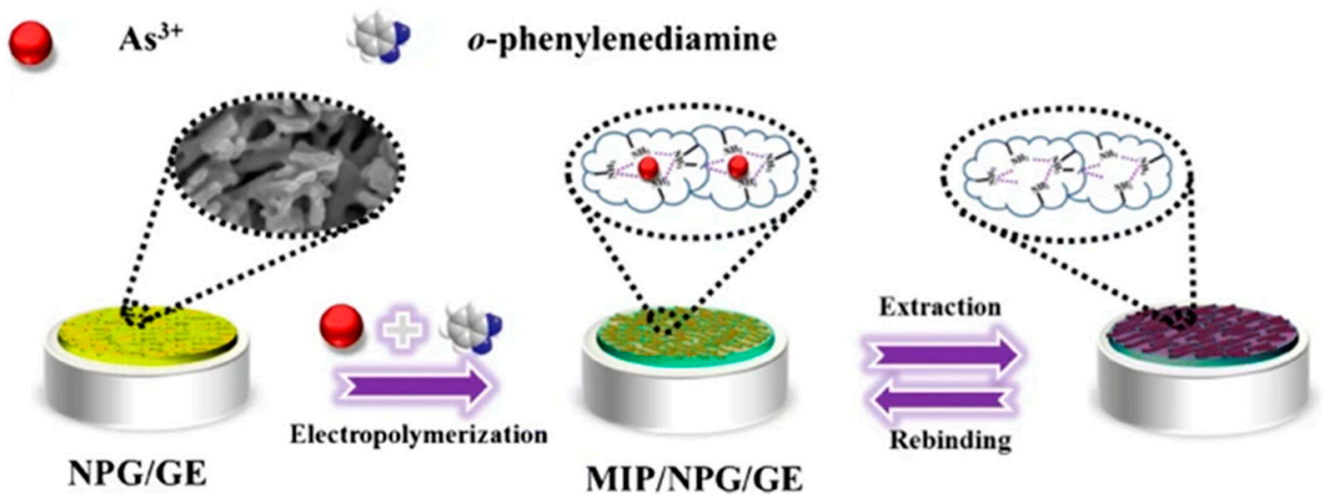

Figure 27. Schematic diagram of IIPs/NPG/GE formation process. (Reprinted with permission from [221], Copyright 2020, Springer Nature Switzerland AG.)

\section{Conclusions}

Arsenic contamination has seriously endangered the living environment and health of human beings, and achieving the efficient and reliable measurement of arsenic ions has gradually become a popular research area in the scientific community. The electrochemical detection method based on a nanomaterial-modified electrode has become a mainstream analytical method for measuring inorganic arsenic, with many advantages, such as simple operation, high sensitivity, good selectivity, low cost, and rapid portability. The working electrode is modified by nanomaterials so as to improve the performance of the electrochemical sensor, as described in this paper. The use of noble metal materials to modify the electrode can increase the mass transfer and reduce the effect of solution resistance; due to the synergistic effect, the bimetallic materials can ensure the detection performance while controlling the detection cost. Although noble metals show excellent performance in the electrochemical detection of arsenic, no noble metal nanomaterials are considered to be mainstream for the electrochemical detection of arsenic. The use of other metals and their compounds can achieve low cost, high sensitivity, and strong interference resistance; secondly, biomolecule-based electrochemical sensors for arsenic have better reproducibility and feasibility, and are increasingly being used in clinical diagnosis, food analysis, and environmental monitoring.

Most electrochemical studies are conducted under acidic conditions (i.e., acidic buffer solutions are used as solvents in sample preparation, along with the more common buffer solutions such as phosphate, acetic acid, hydrochloric acid, nitric acid buffers, etc.). Precious metal nanoparticles, bimetallic nanomaterials, metal oxide nanomaterials, and other modified electrodes show better performance and obtain better sensitivity in acidic environments. However, detection under ambient $\mathrm{pH}$ conditions has several advantages, such as avoiding unexpected changes in As morphology during acidification and simplifying the experimental procedures during field detection. In the operation of electrode preparation, deposition techniques, including electrodeposition and chemical deposition, are mostly used for metal nanoparticles, and drop casting is less frequently used. For metal oxide nanoparticles, the drop-casting method is mostly used directly. In real water samples, there may be interference from co-existing ions, such as $\mathrm{Pb}(\mathrm{II}), \mathrm{Cu}(\mathrm{II}), \mathrm{Ni}(\mathrm{II}), \mathrm{Co}(\mathrm{II}), \mathrm{Cr}(\mathrm{III}), \mathrm{Zn}(\mathrm{II})$, and $\mathrm{NO}_{3}{ }^{-}$. The electrodes in most of the previous studies showed high anti-interference and selectivity, and also performed well when the concentration of interfering ions was much higher than that of arsenic.

A method suitable for field analysis which can achieve a low detection limit (within $10 \mathrm{ppb}$ ) is urgently needed to detect arsenic in drinking water, and the use of a nanomaterialmodified electrode electrochemical system for this purpose represents a great opportunity. Research on new nanomaterials continues to make progress, such as reduced graphene oxide (rGO) and other metal oxide composites, which have been shown to have good detection performance, showing that metals and their compound nanomaterials for the detection of arsenic ions in water have a bright future. 
Author Contributions: Conceptualization, H.H. and B.X.; validation, B.X. and Y.L.; formal analysis, H.H.; investigation, B.X. and Y.L.; resources, H.H.; data curation, B.X.; writing-original draft preparation, B.X. and Y.L.; writing-review and editing, J.Z.; project administration, H.H.; funding acquisition, H.H. All authors have read and agreed to the published version of the manuscript.

Funding: This research was funded by Natural Science Foundation of Anhui Province (1808085QE140) and the project of Research on Sensing Properties of Graphene-Based Composite Materials (W2020JSFW0662).

Institutional Review Board Statement: Not applicable.

Informed Consent Statement: Not applicable.

Data Availability Statement: Not applicable.

Acknowledgments: Thanks for the technical supports that are given by Liu Xingnan and Meng Fancheng.

Conflicts of Interest: The authors declare no conflict of interest.

\section{References}

1. Mandal, B.K.; Suzuki, K.T. Arsenic round the world: A review. Talanta 2002, 58, 201-235. [CrossRef]

2. Walsh, D.F.; Berger, B.L.; Bean, J.R. Mercury, arsenic, lead, cadmium, and selenium residues in fish, 1971-1973-National Pesticide Monitoring Program. Pestic. Monit. J. 1977, 11, 5-34. [PubMed]

3. Waalkes, M.P.; Coogan, T.P.; Barter, R.A. Toxicological principles of metal carcinogenesis with special emphasis on cadmium. Crit. Rev. Toxicol. 1992, 22, 175-201. [CrossRef] [PubMed]

4. Qiao, Y.L.; Taylor, P.R.; Yao, S.X.; Erozan, Y.S.; Luo, X.C.; Barrett, M.J.; Yan, Q.Y.; Giffen, C.A.; Huang, S.Q.; Maher, M.M.; et al. Risk factors and early detection of lung cancer in a cohort of Chinese tin miners. Ann. Epidemiol. 1997, 7, 533-541. [CrossRef]

5. Lu, Y.J.; Sun, S.Q. Study of deposition and translocation of mineral dust in lungs of tin miners in Yunnan by X-ray microanalysis. Chin. J. Pathol. 1992, 21, 103-105.

6. Kabir, R.; Sinha, P.; Mishra, S.; Ebenebe, O.V.; Taube, N.; Oeing, C.U.; Keceli, G.; Chen, R.; Paolocci, N.; Rule, A.; et al. Inorganic arsenic induces sex-dependent pathological hypertrophy in the heart. Am. J. Physiol. Heart Circ. Physiol. 2021, 320, H1321-H1336. [CrossRef]

7. Ozturk, M.; Metin, M.; Altay, V.; Bhat, R.A.; Ejaz, M.; Gul, A.; Unal, B.T.; Hasanuzzaman, M.; Nibir, L.; Nahar, K.; et al. Arsenic and Human Health: Genotoxicity, Epigenomic Effects, and Cancer Signaling. Biol. Trace Elem. Res. 2022, 200, 988-1001. [CrossRef]

8. Argos, M.; Kalra, T.; Rathouz, P.J.; Chen, Y.; Pierce, B.; Parvez, F.; Islam, T.; Ahmed, A.; Rakibuz-Zaman, M.; Hasan, R.; et al. Arsenic exposure from drinking water, and all-cause and chronic-disease mortalities in Bangladesh (HEALS): A prospective cohort study. Lancet 2010, 376, 252-258. [CrossRef]

9. Martinez, V.D.; Vucic, E.A.; Lam, S.; Lam, W.L. Arsenic and Lung Cancer in Never-Smokers: Lessons from Chile. Am. J. Respir. Crit. Care Med. 2012, 185, 1131-1132. [CrossRef]

10. Bostock, J. Observations on the Different Methods Recommended for Detecting Minute Portions of Arsenic. Edinb. Med. Surg. J. 1809, 5, 166-174.

11. Delepine, S. The Detection of Arsenic in Beer and Brewing Material. Br. Med. J. 1901, 1, 81-84. [CrossRef] [PubMed]

12. Scozzari, A. Electrochemical sensing methods: A brief review. In Proceedings of the Conference on NATO-Advanced-StudyInstitute on Sensor Systems for Biological Threats-Algal Toxins Case, Pisa, Italy, 30 September-11 October 2008; pp. 335-351.

13. Bansod, B.; Kumar, T.; Thakur, R.; Rana, S.; Singh, I. A review on various electrochemical techniques for heavy metal ions detection with different sensing platforms. Biosens. Bioelectron. 2017, 94, 443-455. [CrossRef] [PubMed]

14. Aragay, G.; Pons, J.; Merkoci, A. Recent Trends in Macro-, Micro-, and Nanomaterial-Based Tools and Strategies for Heavy-Metal Detection. Chem. Rev. 2011, 111, 3433-3458. [CrossRef] [PubMed]

15. Giacomino, A.; Abollino, O.; Lazzara, M.; Malandrino, M.; Mentasti, E. Determination of As(III) by anodic stripping voltammetry using a lateral gold electrode: Experimental conditions, electron transfer and monitoring of electrode surface. Talanta 2011, 83, 1428-1435. [CrossRef] [PubMed]

16. Rahman, M.R.; Okajima, T.; Ohsaka, T. Selective Detection of As(III) at the Au(III)-like Polycrystalline Gold Electrode. Anal. Chem. 2010, 82, 9169-9176. [CrossRef] [PubMed]

17. Diu, Y.; Zhao, W.; Xu, J.-J.; Chen, H.-Y. Electrochemical determination of arsenite in neutral media on reusable gold nanostructured films. Talanta 2009, 79, 243-248. [CrossRef]

18. Dugo, G.; La Pera, L.; Lo Turco, V.; Di Bella, G. Speciation of inorganic arsenic in alimentary and environmental aqueous samples by using derivative anodic stripping chronopotentiometry (dASCP). Chemosphere 2005, 61, 1093-1101. [CrossRef]

19. Viltchinskaia, E.A.; Zeigman, L.L.; Garcia, D.M.; Santos, P.F. Simultaneous determination of mercury and arsenic by anodic stripping voltammetry. Electroanalysis 1997, 9, 633-640. [CrossRef]

20. HuiliangHuang, K.; Dasgupta, P. A field-deployable instrument for the measurement and speciation of arsenic in potable water. Anal. Chim. Acta 1999, 380, 27-37. [CrossRef] 
21. Alves, G.M.S.; Magalhaes, J.M.C.S.; Salauen, P.; van den Berg, C.M.G.; Soares, H.M.V.M. Simultaneous electrochemical determination of arsenic, copper, lead and mercury in unpolluted fresh waters using a vibrating gold microwire electrode. Anal. Chim. Acta 2011, 703, 1-7. [CrossRef]

22. Bu, L.; Gu, T.; Ma, Y.; Chen, C.; Tan, Y.; Xie, Q.; Yao, S. Enhanced Cathodic Preconcentration of As(0) at Au and Pt Electrodes for Anodic Stripping Voltammetry Analysis of As(III) and As(V). J. Phys. Chem. C 2015, 119, 11400-11409. [CrossRef]

23. Zhou, C.; Yang, M.; Li, S.-S.; Jiang, T.-J.; Liu, J.-H.; Huang, X.-J.; Chen, X. Electrochemically etched gold wire microelectrode for the determination of inorganic arsenic. Electrochim. Acta 2017, 231, 238-246. [CrossRef]

24. Laschi, S.; Bagni, G.; Palchetti, I.; Mascini, M. As(III) voltammetric detection by means of disposable screen-printed gold electrochemical sensors. Anal. Lett. 2007, 40, 3002-3013. [CrossRef]

25. Orellana Jaramillo, D.X.; Sukeri, A.; Saravia, L.P.H.; Espinoza-Montero, P.J.; Bertotti, M. Nanoporous Gold Microelectrode: A Novel Sensing Platform for Highly Sensitive and Selective Determination of Arsenic(III) using Anodic Stripping Voltammetry. Electroanalysis 2017, 29, 2316-2322. [CrossRef]

26. Navratil, T.; Kopanica, M.; Krista, J. Anodic stripping voltammetry for arsenic determination on composite gold electrode. Chem. Anal. 2003, 48, 265-272.

27. Prakash, R.; Srivastava, R.C.; Seth, P.K. Direct estimation of total arsenic using a novel metal side disk rotating electrode Electroanalysis 2003, 15, 1410-1414. [CrossRef]

28. Vandenhecke, J.; Waeles, M.; Riso, R.D.; Le Corre, P. A stripping chronopotentiometric (SCP) method with a gold film electrode for determining inorganic arsenic species in seawater. Anal. Bioanal. Chem. 2007, 388, 929-937. [CrossRef]

29. Jena, B.K.; Raj, C.R. Gold nanoelectrode ensembles for the simultaneous electrochemical detection of ultratrace arsenic, mercury, and copper. Anal. Chem. 2008, 80, 4836-4844. [CrossRef]

30. Li, D.; Li, J.; Jia, X.; Han, Y.; Wang, E. Electrochemical determination of arsenic(III) on mercaptoethylamine modified Au electrode in neutral media. Anal. Chim. Acta 2012, 733, 23-27. [CrossRef]

31. Zakharova, E.A.; Noskova, G.N.; Antonova, S.G.; Kabakaev, A.S. Speciation of arsenic(III) and arsenic(V) by manganese-mediated stripping voltammetry at gold microelectrode ensemble in neutral and basic medium. Int. J. Environ. Anal. Chem. 2014, 94, 1478-1498. [CrossRef]

32. Jiang, J.; Holm, N.; O’Brien, K. Improved Anodic Stripping Voltammetric Detection of Arsenic(III) Using Nanoporous Gold Microelectrode. ECS J. Solid State Sci. Technol. 2015, 4, S3024-S3029. [CrossRef]

33. Korolczuk, M.; Ochab, M.; Rutyna, I. Determination of As(III) by anodic stripping voltammetry following double deposition and stripping steps at two gold working electrodes. Talanta 2015, 144, 517-521. [CrossRef] [PubMed]

34. Jedryczko, D.; Pohl, P.; Welna, M. Inorganic arsenic speciation in natural mineral drinking waters by flow-through anodic stripping chronopotentiometry. Talanta 2016, 150, 265-271. [CrossRef] [PubMed]

35. Kim, J.; Han, S.; Kim, Y. Electrochemical detection of arsenic(III) using porous gold via square wave voltammetry. Korean J. Chem. Eng. 2017, 34, 2096-2098. [CrossRef]

36. Lestarini, D.T.; Ivandini, T.A. Electrochemical detection of $\mathrm{As}^{3+}$ and $\mathrm{As}^{5+}$ by anodic stripping voltammetry at a gold electrode. In Proceedings of the 2nd International Symposium on Current Progress in Functional Materials (ISCPFM)-Functional Materials for Energy and Environment Applications, Bali, Indonesia, 8-9 November 2019.

37. Wang, L.; Lu, W.; Jing, G.; Cui, T. Trace Determination of Arsenite with an Ionophore-Coated Selective Micro Sensor. IEEE Sens. J. 2018, 18, 4364-4371. [CrossRef]

38. Babar, N.-U.-A.; Joya, K.S.; Tayyab, M.A.; Ashiq, M.N.; Sohail, M. Highly Sensitive and Selective Detection of Arsenic Using Electrogenerated Nanotextured Gold Assemblage. ACS Omega 2019, 4, 13645-13657. [CrossRef]

39. Dutta, S.; Strack, G.; Kurup, P. Gold nanostar electrodes for heavy metal detection. Sens. Actuators B Chem. 2019, $281,383-391$. [CrossRef]

40. Majid, E.; Hrapovic, S.; Liu, Y.L.; Male, K.B.; Luong, J.H.T. Electrochemical determination of arsenite using a gold nanoparticle modified glassy carbon electrode and flow analysis. Anal. Chem. 2006, 78, 762-769. [CrossRef]

41. Boonpeng, P.; Sooksamiti, P.; Lapanantnoppakhun, S.; Jakmunee, J. Determination of Inorganic Arsenic by Anodic Stripping Voltammetry with Gold Nanoparticles Modified Screen-printed Carbon Electrode and Anion Exchange Column Preconcentration. Chiang Mai J. Sci. 2019, 46, 106-117.

42. Sakira, A.K.; Some, I.T.; Ziemons, E.; Dejaegher, B.; Mertens, D.; Hubert, P.; Kauffmann, J.-M. Determination of Arsenic(III) at a Nanogold Modified Solid Carbon Paste Electrode. Electroanalysis 2015, 27, 309-316. [CrossRef]

43. Simm, A.O.; Banks, C.E.; Ward-Jones, S.; Davies, T.J.; Lawrence, N.S.; Jones, T.G.J.; Jiang, L.; Compton, R.G. Boron-doped diamond microdisc arrays: Electrochemical characterisation and their use as a substrate for the production of microelectrode arrays of diverse metals (Ag, Au, Cu) via electrodeposition. Analyst 2005, 130, 1303-1311. [CrossRef] [PubMed]

44. Forsberg, G.; O'Laughlin, J.W.; Megargle, R.G.; Koirtyihann, S.R. Determination of arsenic by anodic stripping voltammetry and differential pulse anodic stripping voltammetry. Anal. Chem. 1975, 47, 1586-1592. [CrossRef]

45. Duangthong, S.; Suwanin, A.; Chooto, P.; Innuphat, C. Flow injection-differential pulse anodic stripping voltammetry to measure $\mathrm{As}(\mathrm{III})$ and $\mathrm{As}(\mathrm{V})$ in natural water samples. ScienceAsia 2016, 42, 266-274. [CrossRef]

46. Hassan, S.S.; Sirajuddin; Solangi, A.R.; Kazi, T.G.; Kalhoro, M.S.; Junejo, Y.; Tagar, Z.A.; Kalwar, N.H. Nafion stabilized ibuprofen-gold nanostructures modified screen printed electrode as arsenic(III) sensor. J. Electroanal. Chem. 2012, 682, 77-82. [CrossRef] 
47. Tran Ngoc, H.; Ganesh, T.; Kim, K.S.; Kim, S.; Han, S.-H.; Chung, H. A three-dimensional gold nanodendrite network porous structure and its application for an electrochemical sensing. Biosens. Bioelectron. 2011, 27, 183-186. [CrossRef]

48. Anh Quang, D.; Do Mai, N.; Tran Thanh Tam, T. Determination of arsenic(III) in water using gold nanorods-modified electrode. J. Mater. Sci. Mater. Electron. 2021, 32, 27962-27974. [CrossRef]

49. Lu, D.; Sullivan, C.; Brack, E.M.; Drew, C.P.; Kurup, P. Simultaneous voltammetric detection of cadmium(II), arsenic(III), and selenium(IV) using gold nanostar-modified screen-printed carbon electrodes and modified Britton-Robinson buffer. Anal. Bioanal. Chem. 2020, 412, 4113-4125. [CrossRef]

50. Stankovic, A.; Kajinic, Z.; Turkalj, J.V.; Romic, Z.; Sikiric, M.D.; Asserghine, A.; Nagy, G.; Medvidovic-Kosanovic, M. Voltammetric Determination of Arsenic with Modified Glassy Carbon Electrode. Electroanalysis 2020, 32, 1043-1051. [CrossRef]

51. Sullivan, C.; Lu, D.; Senecal, A.; Kurup, P. Voltammetric detection of Arsenic(III) using gold nanoparticles modified carbon screen printed electrodes: Application for facile and rapid analysis in commercial apple juice. Food Chem. 2021, 352, 129327. [CrossRef]

52. Kamyabi, M.A.; Aghaei, A. Electromembrane extraction coupled to square wave anodic stripping voltammetry for selective preconcentration and determination of trace levels of As(III) in water samples. Electrochim. Acta 2016, 206, 192-198. [CrossRef]

53. Rastogi, P.K.; Yadav, D.K.; Pandey, S.; Ganesan, V.; Sonkar, P.K.; Gupta, R. Synthesis and characterization of gold nanoparticles incorporated bentonite clay for electrocatalytic sensing of arsenic(III). J. Chem. Sci. 2016, 128, 349-356. [CrossRef]

54. Tang, Q.; Zhu, G.; Ge, Y.; Yang, J.; Huang, M.; Liu, J. AuNPs-polyaniline nanosheet array on carbon nanofiber for the determination of As(III). J. Electroanal. Chem. 2020, 873, 114381. [CrossRef]

55. Agir, S.K.; Kundu, M.; IEEE. Detection and Quantification of Arsenic in Water Using Electronic Tongue. In Proceedings of the 1st IEEE International Conference on Control, Measurement and Instrumentation (CMI), Jadavpur University, Kolkata, India, 8-10 January 2016; pp. 424-428.

56. Chowdhury, A.-N.; Ferdousi, S.; Islam, M.M.; Okajima, T.; Ohsaka, T. Arsenic detection by nanogold/conducting-polymermodified glassy carbon electrodes. J. Appl. Polym. Sci. 2007, 104, 1306-1311. [CrossRef]

57. Song, Y.; Swain, G.M. Total inorganic arsenic detection in real water samples using anodic stripping voltammetry and a goldcoated diamond thin-film electrode. Anal. Chim. Acta 2007, 593, 7-12. [CrossRef] [PubMed]

58. Xiao, L.; Wildgoose, G.G.; Compton, R.G. Sensitive electrochemical detection of Arsenic(III) using gold nanoparticle modified carbon nanotubes via anodic stripping voltammetry. Anal. Chim. Acta 2008, 620, 44-49. [CrossRef] [PubMed]

59. Cui, H.; Yang, W.; Li, X.; Zhao, H.; Yuan, Z. An electrochemical sensor based on a magnetic $\mathrm{Fe}_{3} \mathrm{O}_{4}$ nanoparticles and gold nanoparticles modified electrode for sensitive determination of trace amounts of arsenic(III). Anal. Methods 2012, 4, 4176-4181. [CrossRef]

60. Lan, Y.; Luo, H.; Ren, X.; Wang, Y.; Wang, L. Glassy Carbon Electrode Modified with Citrate Stabilized Gold Nanoparticles for Sensitive Arsenic(III) Detection. Anal. Lett. 2012, 45, 1184-1196. [CrossRef]

61. Thotiyl, M.M.O.; Basit, H.; Sanchez, J.A.; Goyer, C.; Coche-Guerente, L.; Dumy, P.; Sampath, S.; Labbe, P.; Moutet, J.-C. Multilayer assemblies of polyelectrolyte-gold nanoparticles for the electrocatalytic oxidation and detection of arsenic(III). J. Colloid Interface Sci. 2012, 383, 130-139. [CrossRef]

62. Huang, J.-F.; Chen, H.-H. Gold-nanoparticle-embedded nafion composite modified on glassy carbon electrode for highly selective detection of arsenic(III). Talanta 2013, 116, 852-859. [CrossRef]

63. Liu, Y.; Huang, Z.; Xie, Q.; Sun, L.; Gu, T.; Li, Z.; Bu, L.; Yao, S.; Tu, X.; Luo, X.; et al. Electrodeposition of electroreduced graphene oxide-Au nanoparticles composite film at glassy carbon electrode for anodic stripping voltammetric analysis of trace arsenic(III) Sens. Actuators B Chem. 2013, 188, 894-901. [CrossRef]

64. Pifferi, V.; Ardizzone, S.; Cappelletti, G.; Falciola, L.; Meroni, D. Ultra-Traces Detection by Gold-Based Electrodes in As(III) Novel Photoremediation. Electrocatalysis 2013, 4, 306-311. [CrossRef]

65. Wang, D.; Zhao, Y.; Jin, H.; Zhuang, J.; Zhang, W.; Wang, S.; Wang, J. Synthesis of Au-Decorated Tripod-Shaped Te Hybrids for Applications in the Ultrasensitive Detection of Arsenic. ACS Appl. Mater. Interfaces 2013, 5, 5733-5740. [CrossRef] [PubMed]

66. Wu, J.; Yang, M.; Xiao, J.; Fu, X.; Jin, J.; Li, L.; Chang, W.; Xie, C. Gold Nanoparticle Dropped Titania Microsphere Hybrids as an Enhanced Sensitive Material for Stripping Voltammetry Determination of As(III). J. Electrochem. Soc. 2013, 160, B225-B230. [CrossRef]

67. Cinti, S.; Politi, S.; Moscone, D.; Palleschi, G.; Arduini, F. Stripping Analysis of As(III) by Means of Screen-Printed Electrodes Modified with Gold Nanoparticles and Carbon Black Nanocomposite. Electroanalysis 2014, 26, 931-939. [CrossRef]

68. Wu, S.; Zhao, Q.; Zhou, L.; Zhang, Z. Stripping Analysis of Trace Arsenic Based on the $\mathrm{MnO}_{\mathrm{x}} /$ AuNPs Composite Film Modified Electrode in Alkaline Media. Electroanalysis 2014, 26, 1840-1849. [CrossRef]

69. Sanghavi, B.J.; Gadhari, N.S.; Kalambate, P.K.; Karna, S.P.; Srivastava, A.K. Potentiometric stripping analysis of arsenic using a graphene paste electrode modified with a thiacrown ether and gold nanoparticles. Microchim. Acta 2015, 182, 1473-1481. [CrossRef]

70. Kato, D.; Kamata, T.; Kato, D.; Yanagisawa, H.; Niwa, O. Au Nanoparticle-Embedded Carbon Films for Electrochemical As ${ }^{3+}$ Detection with High Sensitivity and Stability. Anal. Chem. 2016, 88, 2944-2951. [CrossRef]

71. Mafa, J.P.; Mabuba, N.; Arotiba, O.A. An Exfoliated Graphite Based Electrochemical Sensor for As(III) in Water. Electroanalysis 2016, 28, 1462-1469. [CrossRef]

72. Wei, J.; Li, S.-S.; Guo, Z.; Chen, X.; Liu, J.-H.; Huang, X.-J. Adsorbent Assisted in Situ Electrocatalysis: An Ultra-Sensitive Detection of $\mathrm{As}(\mathrm{III})$ in Water at $\mathrm{Fe}_{3} \mathrm{O}_{4}$ Nanosphere Densely Decorated with Au Nanoparticles. Anal. Chem. 2016, 88, 1154-1161. [CrossRef] 
73. Yang, M.; Chen, X.; Liu, J.-H.; Huang, X.-J. Enhanced anti-interference on electrochemical detection of arsenite with nanoporous gold in mild condition. Sens. Actuators B Chem. 2016, 234, 404-411. [CrossRef]

74. Zhou, S.; Han, X.; Fan, H.; Liu, Y. Electrochemical Sensing toward Trace As(III) Based on Mesoporous $\mathrm{MnFe}_{2} \mathrm{O}_{4} / \mathrm{Au}_{\mathrm{Hybrid}}$ Nanospheres Modified Glass Carbon Electrode. Sensors 2016, 16, 935. [CrossRef]

75. Carrera, P.; Espinoza-Montero, P.J.; Fernandez, L.; Romero, H.; Alvarado, J. Electrochemical determination of arsenic in natural waters using carbon fiber ultra-microelectrodes modified with gold nanoparticles. Talanta 2017, 166, 198-206. [CrossRef] [PubMed]

76. Idris, A.O.; Mabuba, N.; Arotiba, O.A. Electrochemical co-detection of Arsenic and Selenium on a Glassy Carbon Electrode Modified with Gold Nanoparticles. Int. J. Electrochem. Sci. 2017, 12, 10-21. [CrossRef]

77. Nunez-Bajo, E.; Carmen Blanco-Lopez, M.; Costa-Garcia, A.; Teresa Fernandez-Abedule, M. Electrogeneration of Gold Nanoparticles on Porous-Carbon Paper-Based Electrodes and Application to Inorganic Arsenic Analysis in White Wines by Chronoamperometric Stripping. Anal. Chem. 2017, 89, 6415-6423. [CrossRef] [PubMed]

78. Sahoo, S.; Sahoo, P.K.; Satpati, A.K. Gold Nano Particle and Reduced Graphene Oxide Composite Modified Carbon Paste Electrode for the Ultra Trace Detection of Arsenic(III). Electroanalysis 2017, 29, 1400-1409. [CrossRef]

79. Salunke, R.S.; Kasar, C.K.; Bangar, M.A.; Chavan, P.G.; Shirale, D.J. Electrodeposition of gold nanoparticles decorated single polypyrrole nanowire for arsenic detection in potable water: A chemiresistive sensor device. J. Mater. Sci. Mater. Electron. 2017, 28, 14672-14677. [CrossRef]

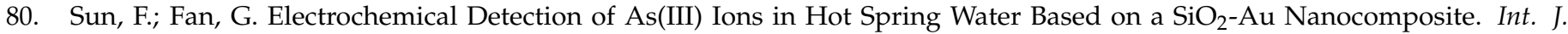
Electrochem. Sci. 2017, 12, 8982-8990. [CrossRef]

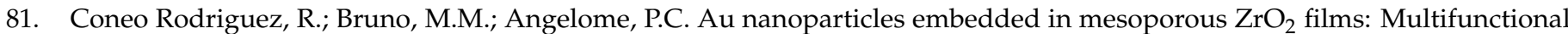
materials for electrochemical detection. Sens. Actuators B Chem. 2018, 254, 603-612. [CrossRef]

82. Ensafi, A.A.; Akbarian, F.; Heydari-Soureshjani, E.; Rezaei, B. A novel aptasensor based on 3D-reduced graphene oxide modified gold nanoparticles for determination of arsenite. Biosens. Bioelectron. 2018, 122, 25-31. [CrossRef]

83. Nellaiappan, S.; Pillai, K.C.; Kumar, A.S. Flow-injection analysis coupled with electrochemical detection of poisonous inorganic arsenic(III) species using a gold nanoparticle/carbon nanofiber/chitosan chemically modified carbon screen printed electrode in neutral pH solution. Anal. Methods 2018, 10, 799-808. [CrossRef]

84. Pungjunun, K.; Chaiyo, S.; Jantrahong, I.; Nantaphol, S.; Siangproh, W.; Chailapakul, O. Anodic stripping voltammetric determination of total arsenic using a gold nanoparticle-modified boron-doped diamond electrode on a paper-based device. Microchim. Acta 2018, 185, 324. [CrossRef] [PubMed]

85. Yang, M.; Li, P.-H.; Xu, W.-H.; Wei, Y.; Li, L.-N.; Huang, Y.-Y.; Sun, Y.-F.; Chen, X.; Liu, J.-H.; Huang, X.-J. Reliable electrochemical sensing arsenic(III) in nearly groundwater $\mathrm{pH}$ based on efficient adsorption and excellent electrocatalytic ability of $\mathrm{AuNPs}_{\mathrm{C}} / \mathrm{CeO}_{2-}$ $\mathrm{ZrO}_{2}$ nanocomposite. Sens. Actuators B Chem. 2018, 255, 226-234. [CrossRef]

86. Buffa, A.; Mandler, D. Arsenic(III) detection in water by flow-through carbon nanotube membrane decorated by gold nanoparticles. Electrochim. Acta 2019, 318, 496-503. [CrossRef]

87. Gimenez-Gomez, P.; Baldi, A.; Ayora, C.; Fernandez-Sanchez, C. Automated Determination of As(III) in Waters with an Electrochemical Sensor Integrated into a Modular Microfluidic System. ACS Sens. 2019, 4, 3156-3165. [CrossRef] [PubMed]

88. Trachioti, M.G.; Karantzalis, A.E.; Hrbac, J.; Prodromidis, M.I. Low-cost screen-printed sensors on-demand: Instantly prepared sparked gold nanoparticles from eutectic Au/Si alloy for the determination of arsenic at the sub-ppb level. Sens. Actuators B Chem. 2019, 281, 273-280. [CrossRef]

89. Wang, W.; Bao, N.; Yuan, W.; Si, N.; Bai, H.; Li, H.; Zhang, Q. Simultaneous determination of lead, arsenic, and mercury in cosmetics using a plastic based disposable electrochemical sensor. Microchem. J. 2019, 148, 240-247. [CrossRef]

90. Zhao, G.; Liu, G. Electrochemical Deposition of Gold Nanoparticles on Reduced Graphene Oxide by Fast Scan Cyclic Voltammetry for the Sensitive Determination of As(III). Nanomaterials 2019, 9, 41. [CrossRef]

91. Bu, L.; Xie, Q.; Ming, H. Gold nanoparticles decorated three-dimensional porous graphitic carbon nitrides for sensitive anodic stripping voltammetric analysis of trace arsenic(III). J. Alloys Compd. 2020, 823, 153723. [CrossRef]

92. Chen, C.; Yu, S.; Jiang, S.; Liu, J.; Wang, Z.; Ye, B.-C. A novel and sensitive electrochemical sensor based on nanoporous gold for determination of As(III). Microchim. Acta 2020, 187, 395. [CrossRef]

93. Ismail, S.; Yusof, N.A.; Abdullah, J.; Abd Rahman, S.F. Development of Electrochemical Sensor Based on Silica/Gold Nanoparticles Modified Electrode for Detection of Arsenite. IEEE Sens. J. 2020, 20, 3406-3414. [CrossRef]

94. Kongor, A.; Panchal, M.; Athar, M.; Vora, M.; Verma, N.; Pandya, A.; Jha, P.C.; Bhadresha, K.; Rawal, R.; Jain, V. Colorimetric and electrochemical sensing of As(III) using calix 4 pyrrole capped gold nanoparticles and evaluation of its cytotoxic activity. J. Incl. Phenom. Macrocycl. Chem. 2020, 98, 29-41. [CrossRef]

95. Sullivan, C.; Lu, D.; Brack, E.; Drew, C.; Kurup, P. Voltammetric codetection of arsenic(III) and copper(II) in alkaline buffering system with gold nanostar modified electrodes. Anal. Chim. Acta 2020, 1107, 63-73. [CrossRef] [PubMed]

96. Udayan, A.P.M.; Kachwala, B.; Karthikeyan, K.G.; Gunasekaran, S. Ultrathin quasi-hexagonal gold nanostructures for sensing arsenic in tap water. RSC Adv. 2020, 10, 20211-20221. [CrossRef]

97. Jijana, A.N.; Mphuthi, N.; Shumbula, P.; Vilakazi, S.; Sikhwivhilu, L. The Ultra-sensitive Electrochemical Detection of As(III) in Ground Water Using Disposable L-cysteine/Lipoic Acid Functionalised Gold Nanoparticle Modified Screen-Printed Electrodes. Electrocatalysis 2021, 12, 310-325. [CrossRef] 
98. Li, C.-Y.; Wei, Y.-Y.; Shen, W.; Dong, X.; Yang, M.; Wei, J. Ultrahigh sensitivity electroanalysis of trace As(III) in water and human serum via gold nanoparticles uniformly anchored to $\mathrm{Co}_{3} \mathrm{O}_{4}$ porous microsheets. Electrochim. Acta 2021, 368, 137605. [CrossRef]

99. Nodehi, M.; Baghayeri, M.; Veisi, H. Preparation of GO/ $\mathrm{Fe}_{3} \mathrm{O}_{4} @ P M D A / A u N P s$ nanocomposite for simultaneous determination of $\mathrm{As}^{3+}$ and $\mathrm{Cu}^{2+}$ by stripping voltammetry. Talanta 2021, 230, 122288. [CrossRef]

100. Zhu, X.; Zhu, G.; Ge, Y.; Zhang, B.; Yang, J.; Hu, B.; Liu, J. AU(nano)/Fe-MOF hybrid electrode for highly sensitive determination of trace As(III). J. Electroanal. Chem. 2021, 899, 115642. [CrossRef]

101. Tabibi, Z.; Massah, J.; Vakilian, K.A. A biosensor for the sensitive and specific measurement of arsenite using gold nanoparticles. Measurement 2022, 187, 110281. [CrossRef]

102. Nguyen, T.S.V.; Huynh, T.M.; Nguyen, L.D.; Doan, T.C.D.; Baptist, R.; Dang, C.M. Sensitive electrochemical measurement of As(III) using Nafion modified platinum electrode via anode stripping voltammetry. Int. J. Nanotechnol. 2020, 17, 659-672. [CrossRef]

103. Xu, H.; Zeng, L.; Xing, S.; Shi, G.; Chen, J.; Man, Y.; Jin, L. Highly ordered platinum-nanotube arrays for oxidative determination of trace arsenic(III). Electrochem. Commun. 2008, 10, 1893-1896. [CrossRef]

104. Xu, H.; Zeng, L.; Xing, S.; Xian, Y.; Jin, L. Microwave-irradiated synthesized platinum nanoparticles/carbon nanotubes for oxidative determination of trace arsenic(III). Electrochem. Commun. 2008, 10, 551-554. [CrossRef]

105. Sitorus, R.; Saefumillah, A.; Ivandini, T.A. Arsenic and arsenate detection with anodic stripping voltammetry technique using boron-doped diamond modified by platinum. IOP Conf. Ser. Mater. Sci. Eng. 2020, 763, 012013. [CrossRef]

106. Kempegowda, R.; Antony, D.; Malingappa, P. Graphene-platinum nanocomposite as a sensitive and selective voltammetric sensor for trace level arsenic quantification. Int. J. Smart Nano Mater. 2014, 5, 17-32. [CrossRef]

107. Hrapovic, S.; Liu, Y.; Luong, J.H.T. Reusable platinum nanoparticle modified boron doped diamond microelectrodes for oxidative determination of arsenite. Anal. Chem. 2007, 79, 500-507. [CrossRef]

108. Dai, X.; Compton, R.G. Detection of As(III) via oxidation to As(V) using platinum nanoparticle modified glassy carbon electrodes: Arsenic detection without interference from copper. Analyst 2006, 131, 516-521. [CrossRef]

109. Li, P.-H.; Yang, M.; Song, Z.-Y.; Chen, S.-H.; Xiao, X.-Y.; Lin, C.-H.; Huang, X.-J. Highly Sensitive and Stable Determination of As(III) under Near-Neutral Conditions: Benefit from the Synergetic Catalysis of Pt Single Atoms and Active S Atoms over Pt-1/MoS2. Anal. Chem. 2021, 93, 15115-15123. [CrossRef]

110. Han, D.-D.; Liu, Z.-G.; Liu, J.-H.; Huang, X.-J. The size effect of Pt nanoparticles: A new route to improve sensitivity in electrochemical detection of As(III). RSC Adv. 2015, 5, 38290-38297. [CrossRef]

111. Aguirre, M.d.C.; Rivas, B.L.; Basaez, L.; Pena-Farfal, C. Electrochemical Detection of Arsenite with Silver Electrodes in Inorganic Electrolyte and Natural System Mixtures. J. Braz. Chem. Soc. 2011, 22, 2362-2370. [CrossRef]

112. Sonkoue, B.M.; Tchekwagep, P.M.S.; Nanseu-Njiki, C.P.; Ngameni, E. Electrochemical Determination of Arsenic Using Silver Nanoparticles. Electroanalysis 2018, 30, 2738-2743. [CrossRef]

113. Prakash, S.; Chakrabarty, T.; Singh, A.K.; Shahi, V.K. Silver nanoparticles built-in chitosan modified glassy carbon electrode for anodic stripping analysis of As(III) and its removal from water. Electrochim. Acta 2012, 72, 157-164. [CrossRef]

114. Dar, R.A.; Khare, N.G.; Cole, D.P.; Karna, S.P.; Srivastava, A.K. Green synthesis of a silver nanoparticle-graphene oxide composite and its application for As(III) detection. RSC Adv. 2014, 4, 14432-14440. [CrossRef]

115. Wen, S.-H.; Liang, R.-P.; Zhang, L.; Qiu, J.-D. Multimodal Assay of Arsenite Contamination in Environmental Samples with Improved Sensitivity through Stimuli-Response of Multiligands Modified Silver Nanoparticles. ACS Sustain. Chem. Eng. 2018, 6 , 6223-6232. [CrossRef]

116. Agustiany, T.; Khalil, M.; Einaga, Y.; Jiwanti, P.K.; Ivandini, T.A. Stable iridium-modified boron-doped diamond electrode for the application in electrochemical detection of Arsenic(III). Mater. Chem. Phys. 2020, 244, 122723. [CrossRef]

117. Mafakheri, E.; Salimi, A.; Hallaj, R.; Ramazani, A.; Kashi, M.A. Synthesis of Iridium Oxide Nanotubes by Electrodeposition into Polycarbonate Template: Fabrication of Chromium(III) and Arsenic(III) Electrochemical Sensor. Electroanalysis 2011, 23, 2429-2437. [CrossRef]

118. Gupta, R.; Gamare, J.S.; Pandey, A.K.; Tyagi, D.; Kamat, J.V. Highly Sensitive Detection of Arsenite Based on Its Affinity Toward Ruthenium Nanoparticles Decorated on Glassy Carbon Electrode. Anal. Chem. 2016, 88, 2459-2465. [CrossRef]

119. Dash, S.; Munichandraiah, N. Electroanalysis of As(III) at nanodendritic Pd on PEDOT. Analyst 2014, 139, 1789-1795. [CrossRef]

120. Alam, M.M.; Rashed, M.A.; Rahman, M.M.; Rahman, M.M.; Nagao, Y.; Hasnat, M.A. Electrochemical oxidation of As(III) on Pd immobilized Pt surface: Kinetics and sensing performance. RSC Adv. 2018, 8, 8071-8079. [CrossRef]

121. Murali Mohan, J.; Amreen, K.; Javed, A.; Dubey, S.K.; Goel, S. Electrochemical Mini-Platform with Thread-Based Electrodes for Interference Free Arsenic Detection. IEEE Trans. Nanobiosci. 1800, 21, 117-124. [CrossRef]

122. Sanllorente-Mendez, S.; Dominguez-Renedo, O.; Arcos-Martinez, M.J. Determination of Arsenic(III) Using Platinum NanoparticleModified Screen-Printed Carbon-Based Electrodes. Electroanalysis 2009, 21, 635-639. [CrossRef]

123. Zhang, Y.; Li, D.; Compton, R.G. Arsenic(III) Detection with Underpotential Deposition and Anodic Stripping Voltammetry. ChemElectroChem 2021, 8, 3707-3715. [CrossRef]

124. Mendez Cortes, S.P.; Andres Galan-Vidal, C.; Rodriguez Avila, J.A.; Alvarez Romero, G.A.; Paez-Hernandez, M.E. Square Wave Anodic Stripping Voltammetry Determination of Arsenic(III) onto Carbon Electrodes by Means of Co-deposition with Silver. J. Mex. Chem. Soc. 2018, 62, 314-322. [CrossRef] 
125. Salimi, A.; Hyde, M.E.; Banks, C.E.; Compton, R.G. Boron doped diamond electrode modified with iridium oxide for amperometic detection of ultra trace amounts of arsenic(III). Analyst 2004, 129, 9-14. [CrossRef]

126. Ivandini, T.A.; Sato, R.; Makide, Y.; Fujishima, A.; Einaga, Y. Electrochemical detection of arsenic(III) using iridium-implanted boron-doped diamond electrodes. Anal. Chem. 2006, 78, 6291-6298. [CrossRef]

127. Touilloux, R.; Tercier-Waeber, M.-L.; Bakker, E. Direct arsenic(III) sensing by a renewable gold plated Ir-based microelectrode. Analyst 2015, 140, 3526-3534. [CrossRef]

128. Gumpu, M.B.; Veerapandian, M.; Krishnan, U.M.; Rayappan, J.B.B. Simultaneous electrochemical detection of Cd(II), Pb(II), As(III) and $\mathrm{Hg}(\mathrm{II})$ ions using ruthenium(II)-textured graphene oxide nanocomposite. Talanta 2017, 162, 574-582. [CrossRef] [PubMed]

129. Gumpu, M.B.; Veerapandian, M.; Krishnan, U.M.; Rayappan, J.B.B. Amperometric determination of As(III) and Cd(II) using a platinum electrode modified with acetylcholinesterase, ruthenium(II)-tris(bipyridine) and graphene oxide. Microchim. Acta 2018, 185, 297. [CrossRef]

130. Moghimi, N.; Mohapatra, M.; Leung, K.T. Bimetallic Nanoparticles for Arsenic Detection. Anal. Chem. 2015, 87, 5546-5552. [CrossRef] [PubMed]

131. Lan, Y.; Luo, H.; Ren, X.; Wang, Y.; Liu, Y. Anodic stripping voltammetric determination of arsenic(III) using a glassy carbon electrode modified with gold-palladium bimetallic nanoparticles. Microchim. Acta 2012, 178, 153-161. [CrossRef]

132. Zhang, Q.-X.; Yin, L.-B. Electrochemical performance of heterostructured Au-Pd bimetallic nanoparticles toward As(III) aqueous media. Electrochem. Commun. 2012, 22, 57-60. [CrossRef]

133. Bu, L.; Liu, J.; Xie, Q.; Yao, S. Anodic stripping voltammetric analysis of trace arsenic(III) enhanced by mild hydrogen-evolution at a bimetallic Au-Pt nanoparticle modified glassy carbon electrode. Electrochem. Commun. 2015, 59, 28-31. [CrossRef]

134. Yang, M.; Guo, Z.; Li, L.-N.; Huang, Y.-Y.; Liu, J.-H.; Zhou, Q.; Chen, X.; Huang, X.-J. Electrochemical determination of arsenic(III) with ultra-high anti-interference performance using Au-Cu bimetallic nanoparticles. Sens. Actuators B Chem. 2016, 231, 70-78. [CrossRef]

135. Melinte, G.; Hosu, O.; Lettieri, M.; Cristea, C.; Marrazza, G. Electrochemical Fingerprint of Arsenic(III) by Using Hybrid Nanocomposite-Based Platforms. Sensors 2019, 19, 2279. [CrossRef] [PubMed]

136. Mushiana, T.; Mabuba, N.; Idris, A.O.; Peleyeju, G.M.; Orimolade, B.O.; Nkosi, D.; Ajayi, R.F.; Arotiba, O.A. An aptasensor for arsenic on a carbon-gold bi-nanoparticle platform. Sens. Bio-Sens. Res. 2019, 24, 8-12. [CrossRef]

137. Yadav, R.; Kushwah, V.; Gaur, M.S.; Bhadauria, S.; Berlina, A.N.; Zherdev, A.V.; Dzantiev, B.B. Electrochemical aptamer biosensor for $\mathrm{As}^{3+}$ based on apta deep trapped Ag-Au alloy nanoparticles-impregnated glassy carbon electrode. Int. J. Environ. Anal. Chem. 2020, 100, 623-634. [CrossRef]

138. Sedki, M.; Zhao, G.; Ma, S.; Jassby, D.; Mulchandani, A. Linker-Free Magnetite-Decorated Gold Nanoparticles (Fe $\left.\mathrm{O}_{4}-\mathrm{Au}\right)$ : Synthesis, Characterization, and Application for Electrochemical Detection of Arsenic(III). Sensors 2021, 21, 883. [CrossRef]

139. Shin, S.-H.; Hong, H.-G. Anodic Stripping Voltammetric Detection of Arsenic(III) at Platinum-Iron(III) Nanoparticle Modified Carbon Nanotube on Glassy Carbon Electrode. Bull. Korean Chem. Soc. 2010, 31, 3077-3083. [CrossRef]

140. Xu, W.-H.; Wang, L.; Wang, J.; Sheng, G.-P.; Liu, J.-H.; Yu, H.-Q.; Huang, X.-J. Superparamagnetic mesoporous ferrite nanocrystal clusters for efficient removal of arsenite from water. CrystEngComm 2013, 15, 7895-7903. [CrossRef]

141. Devi, P.; Sharma, C.; Kumar, P.; Kumar, M.; Bansod, B.K.S.; Nayak, M.K.; Singla, M.L. Selective electrochemical sensing for arsenite using $\mathrm{rGO} / \mathrm{Fe}_{3} \mathrm{O}_{4}$ nanocomposites. J. Hazard. Mater. 2017, 322, 85-94. [CrossRef]

142. Hu, H.; Lu, W.; Liu, X.; Meng, F.; Zhu, J. A High-Response Electrochemical As(III) Sensor Using Fe $\mathrm{O}_{4}$-rGO Nanocomposite Materials. Chemosensors 2021, 9, 150. [CrossRef]

143. Chimezie, A.B.; Hajian, R.; Yusof, N.A.; Woi, P.M.; Shams, N. Fabrication of reduced graphene oxide-magnetic nanocomposite $\left(\mathrm{rGO}-\mathrm{Fe}_{3} \mathrm{O}_{4}\right)$ as an electrochemical sensor for trace determination of $\mathrm{As}(\mathrm{III})$ in water resources. J. Electroanal. Chem. 2017, 796, 33-42. [CrossRef]

144. Gao, C.; Yu, X.-Y.; Xiong, S.-Q.; Liu, J.-H.; Huang, X.-J. Electrochemical Detection of Arsenic(III) Completely Free from Noble Metal: $\mathrm{Fe}_{3} \mathrm{O}_{4}$ Microspheres-Room Temperature Ionic Liquid Composite Showing Better Performance than Gold. Anal. Chem. 2013, 85, 2673-2680. [CrossRef]

145. Huang, H.-Q.; Li, Y.-Y.; Chen, S.-H.; Liu, Z.-G.; Cui, Y.-M.; Li, H.-Q.; Guo, Z.; Huang, X.-J. Noble-metal-free Fe $\mathrm{O}_{4} / \mathrm{Co}_{3} \mathrm{~S}_{4}$ nanosheets with oxygen vacancies as an efficient electrocatalyst for highly sensitive electrochemical detection of As(III). Anal. Chim. Acta 2022, 1189, 339208. [CrossRef] [PubMed]

146. Ren, B.; Sudarsanam, P.; Kandjani, A.E.; Hillary, B.; Amin, M.H.; Bhargava, S.K.; Jones, L.A. Electrochemical Detection of As(III) on a Manganese Oxide-Ceria $\left(\mathrm{Mn}_{2} \mathrm{O}_{3} / \mathrm{CeO}_{2}\right)$ Nanocube Modified Au Electrode. Electroanalysis 2018, 30, 928-936. [CrossRef]

147. Ponnaiah, S.K.; Periakaruppan, P.; Selvam, M.; Muthupandian, S.; Jeyaprabha, B.; Selvanathan, R. Clinically Pertinent Manganese Oxide/Polyoxytyramine/Reduced Graphene Oxide Nanocomposite for Voltammetric Detection of Salivary and Urinary Arsenic J. Clust. Sci. 2020, 31, 877-885. [CrossRef]

148. Salimi, A.; Manikhezri, H.; Hallaj, R.; Soltanian, S. Electrochemical detection of trace amount of arsenic(III) at glassy carbon electrode modified with cobalt oxide nanoparticles. Sens. Actuators B Chem. 2008, 129, 246-254. [CrossRef]

149. Santhosh, C.; Velmurugan, V.; Jacob, G.; Jeong, S.K.; Grace, A.N.; Bhatnagar, A. Role of nanomaterials in water treatment applications: A review. Chem. Eng. J. 2016, 306, 1116-1137. [CrossRef]

150. Jiang, T.-J.; Guo, Z.; Liu, J.-H.; Huang, X.-J. Gold electrode modified with ultrathin $\mathrm{SnO}_{2}$ nanosheets with high reactive exposed surface for electrochemical sensing of As(III). Electrochim. Acta 2016, 191, 142-148. [CrossRef] 
151. Bhanjana, G.; Mehta, N.; Chaudhary, G.R.; Dilbaghi, N.; Kim, K.-H.; Kumar, S. Novel electrochemical sensing of arsenic ions using a simple graphite pencil electrode modified with tin oxide nanoneedles. J. Mol. Liq. 2018, 264, 198-204. [CrossRef]

152. Karthika, A.; Selvarajan, S.; Karuppasamy, P.; Suganthi, A.; Rajarajan, M. A novel highly efficient and accurate electrochemical detection of poisonous inorganic Arsenic(III) ions in water and human blood serum samples based on $\mathrm{SrTiO}_{3} /$ beta-cyclodextrin composite. J. Phys. Chem. Solids 2019, 127, 11-18. [CrossRef]

153. Ndlovu, T.; Mamba, B.B.; Sampath, S.; Krause, R.W.; Arotiba, O.A. Voltammetric detection of arsenic on a bismuth modified exfoliated graphite electrode. Electrochim. Acta 2014, 128, 48-53. [CrossRef]

154. Mafa, P.J.; Idris, A.O.; Mabuba, N.; Arotiba, O.A. Electrochemical co-detection of As(III), $\mathrm{Hg}(\mathrm{II})$ and Pb(II) on a bismuth modified exfoliated graphite electrode. Talanta 2016, 153, 99-106. [CrossRef] [PubMed]

155. Durai, L.; Badhulika, S. Ultra-selective, trace level detection of $\mathrm{As}^{3+}$ ions in blood samples using $\mathrm{PANI}_{\mathrm{coated}} \mathrm{BiVO} \mathrm{m}_{4}$ modified SPCE via differential pulse anode stripping voltammetry. Mater. Sci. Eng. C Mater. Biol. Appl. 2020, 111, 110806. [CrossRef] [PubMed]

156. Bhanjana, G.; Dilbaghi, N.; Chaudhary, S.; Kim, K.-H.; Kumar, S. Robust and direct electrochemical sensing of arsenic using zirconia nanocubes. Analyst 2016, 141, 4211-4218. [CrossRef]

157. Noskova, G.N.; Zakharova, E.A.; Kolpakova, N.A.; Kabakaev, A.S. Electrodeposition and stripping voltammetry of arsenic(III) and arsenic(V) on a carbon black-polyethylene composite electrode in the presence of iron ions. J. Solid State Electrochem. 2012, 16, 2459-2472. [CrossRef]

158. Saha, S.; Sarkar, P. Differential pulse anodic stripping voltammetry for detection of As(III) by Chitosan-Fe(OH $)_{3}$ modified glassy carbon electrode: A new approach towards speciation of arsenic. Talanta 2016, 158, 235-245. [CrossRef]

159. Xie, Z.; Xu, J.; Xie, F.; Xiong, S. Electrochemical Detection of $\mathrm{As}(\mathrm{III})$ by a $\mathrm{rGO} / \mathrm{Fe}_{3} \mathrm{O}_{4}$-modified Screen-Printed Carbon Electrode. Anal. Sci. 2016, 32, 1053-1058. [CrossRef] [PubMed]

160. Zhang, Z.; Ji, H.; Song, Y.; Zhang, S.; Wang, M.; Jia, C.; Tian, J.-Y.; He, L.; Zhang, X.; Liu, C.-S. Fe(III)-based metal-organic framework-derived core-shell nanostructure: Sensitive electrochemical platform for high trace determination of heavy metal ions. Biosens. Bioelectron. 2017, 94, 358-364. [CrossRef]

161. Gounden, D.; Khene, S.; Nombona, N. Electroanalytical detection of heavy metals using metallophthalocyanine and silica-coated iron oxide composites. Chem. Pap. 2018, 72, 3043-3056. [CrossRef]

162. Li, S.-S.; Zhou, W.-Y.; Jiang, M.; Guo, Z.; Liu, J.-H.; Zhang, L.; Huang, X.-J. Surface Fe(II)/Fe(III) Cycle Promoted Ultra-Highly Sensitive Electrochemical Sensing of Arsenic(III) with Dumbbell-Like Au/ $\mathrm{Fe}_{3} \mathrm{O}_{4}$ Nanoparticles. Anal. Chem. 2018, 90, 4569-4577. [CrossRef]

163. Zhang, R.; Hong, S.; Zhang, D.; Li, S.; Zhao, Z.; Bai, H. Nano alpha-FeOOH Modified Carbon Paste Electrode for Arsenic Determination in Natural Waters. Mater. Sci. Medzg. 2018, 24, 355-361. [CrossRef]

164. Yogeeshwari, R.T.; Shreenivasa, L.; Krishna, R.H.; Prashanth, S.A.; Banuprakash, G.; Ashoka, S. Synthesis of acid resistant $\mathrm{Fe}_{2} \mathrm{~V}_{4} \mathrm{O}_{13}$-polypyrrole nanocomposite: Its application towards the fabrication of disposable electrochemical sensor for the detection of As(III). Mater. Res. Express 2019, 6, 126448. [CrossRef]

165. Zhao, Z.; Li, C.; Wu, H. Reduced graphene oxide nanosheets modified with plasmonic gold-based hybrid nanostructures and with magnetite $\left(\mathrm{Fe}_{3} \mathrm{O}_{4}\right)$ nanoparticles for cyclic voltammetric determination of arsenic(III). Microchim. Acta 2019, 186, 226. [CrossRef] [PubMed]

166. Saleemi, A.S.; Hafeez, M.; Munawar, A.; Akhtar, N.; Abbas, W.; Mazhar, M.E.; Shafiq, Z.; Davis, A.P.; Lee, S.-L. Synthesis and sensing efficiency of $\mathrm{CN}$-wrapped $\mathrm{ZnFe}_{2} \mathrm{O}_{4}$ microsphere-ionic liquid composites towards ultra-high sensitive arsenic(iii) monitoring of ground drinking water. J. Mater. Chem. C 2020, 8, 12984-12992. [CrossRef]

167. Zhou, S.-F.; Han, X.-J.; Fan, H.-L.; Zhang, Q.-X.; Liu, Y.-Q. Electrochemical detection of As(III) through mesoporous $\mathrm{MnFe}_{2} \mathrm{O}_{4}$ nanocrystal clusters by square wave stripping voltammetry. Electrochim. Acta 2015, 174, 1160-1166. [CrossRef]

168. Devi, P.; Bansod, B.; Kaur, M.; Bagchi, S.; Nayak, M.K. Co-electrodeposited $\mathrm{rGO} / \mathrm{MnO}_{2}$ nanohybrid for arsenite detection in water by stripping voltammetry. Sens. Actuators B Chem. 2016, 237, 652-659. [CrossRef]

169. Yang, M.; Chen, X.; Jiang, T.-J.; Guo, Z.; Liu, J.-H.; Huang, X.-J. Electrochemical Detection of Trace Arsenic(III) by Nanocomposite of Nanorod-Like alpha- $\mathrm{MnO}_{2}$ Decorated with similar to $5 \mathrm{~nm}$ Au Nanoparticles: Considering the Change of Arsenic Speciation. Anal. Chem. 2016, 88, 9720-9728. [CrossRef] [PubMed]

170. Jiang, T.; Qi, L.; Lu, X.; Hou, C.; Qin, W. Selective determination of Arsenic(III) using a Nafion/alpha-MnO ${ }_{2} @$ polydopamine modified electrode. J. Electroanal. Chem. 2020, 878, 114562. [CrossRef]

171. Gumpu, M.B.; Mani, G.K.; Nesakumar, N.; Kulandaisamy, A.J.; Babu, K.J.; Rayappan, J.B.B. Electrocatalytic nanocauliflower structured fluorine doped CdO thin film as a potential arsenic sensor. Sens. Actuators B Chem. 2016, 234, 426-434. [CrossRef]

172. Jimana, A.; Peleyeju, M.G.; Tshwenya, L.; Pillay, K.; Arotiba, O.A. Voltammetric Analysis of As(III) at a Cobalt Nanoparticles/Reduced Graphene Oxide Modified Exfoliated Graphite Electrode. Int. J. Electrochem. Sci. 2018, 13, 10127-10140. [CrossRef]

173. Kumar, P.; Devi, P.; Jain, R.; Saini, A.; Noetzel, R. Electrochemical Detection of Trace Arsenic(III) by functionalized $\mathrm{In}_{0.38} \mathrm{Ga}_{0.62} \mathrm{~N} / \mathrm{Si}(111)$ electrode. Mater. Lett. 2019, 236, 587-590. [CrossRef]

174. Ramesha, G.K.; Sampath, S. In-situ formation of graphene-lead oxide composite and its use in trace arsenic detection. Sens. Actuators B Chem. 2011, 160, 306-311. [CrossRef]

175. Dai, X.A.; Compton, R.G. Direct electrodeposition of gold nanoparticles onto indium tin oxide film coated glass: Application to the detection of arsenic(III). Anal. Sci. 2006, 22, 567-570. [CrossRef] [PubMed] 
176. El-Said, W.A.; Hajjar, D.; Makki, A.A.; Elshehy, E.A.; Choi, J.-W. A reusable Gemini surfactant-based electrochemical sensor for As(III) detection. Int. J. Environ. Anal. Chem. 2021, 101, 1-12. [CrossRef]

177. Pereira, F.J.; Vazquez, M.D.; Deban, L.; Aller, A.J. Inorganic arsenic speciation by differential pulse anodic stripping voltammetry using thoria nanoparticles-carbon paste electrodes. Talanta 2016, 152, 211-218. [CrossRef]

178. Zhang, X.; Zeng, T.; Hu, C.; Hu, S.; Tian, Q. Studies on fabrication and application of arsenic electrochemical sensors based on titanium dioxide nanoparticle modified gold strip electrodes. Anal. Methods 2016, 8, 1162-1169. [CrossRef]

179. Pourbeyram, S.; Asadi, S. Time Resolved Direct Determination of Arsenate in the Presence of Arsenite on Pencil Graphite Electrode Modified by Graphene Oxide and Zirconium. Electroanalysis 2018, 30, 154-161. [CrossRef]

180. Pandey, S.K.; Singh, P.; Singh, J.; Sachan, S.; Srivastava, S.; Singh, S.K. Nanocarbon-based Electrochemical Detection of Heavy Metals. Electroanalysis 2016, 28, 2472-2488. [CrossRef]

181. Kumar, S.; Bhanjanaa, G.; Dilbaghi, N.; Kumar, R.; Umar, A. Fabrication and characterization of highly sensitive and selective arsenic sensor based on ultra-thin graphene oxide nanosheets. Sens. Actuators B Chem. 2016, 227, 29-34. [CrossRef]

182. Yang, M.; Jiang, T.-J.; Wang, Y.; Liu, J.-H.; Li, L.-N.; Chen, X.; Huang, X.-J. Enhanced electrochemical sensing arsenic(III) with excellent anti-interference using amino-functionalized graphene oxide decorated gold microelectrode: XPS and XANES evidence. Sens. Actuators B Chem. 2017, 245, 230-237. [CrossRef]

183. Gumpu, M.B.; Veerapandian, M.; Krishnan, U.M.; Rayappan, J.B.B. Electrochemical sensing platform for the determination of arsenite and arsenate using electroactive nanocomposite electrode. Chem. Eng. J. 2018, 351, 319-327. [CrossRef]

184. Yuan, Y.-H.; Zhu, X.-H.; Wen, S.-H.; Liang, R.-P.; Zhang, L.; Qiu, J.-D. Electrochemical assay for As(III) by combination of highly thiol-rich trithiocyanuric acid and conductive reduced graphene oxide nanocomposites. J. Electroanal. Chem. 2018, 814, 97-103. [CrossRef]

185. Baghayeri, M.; Ghanei-Motlagh, M.; Tayebee, R.; Fayazi, M.; Narenji, F. Application of graphene/zinc-based metal-organic framework nanocomposite for electrochemical sensing of As(III) in water resources. Anal. Chim. Acta 2020, 1099, 60-67. [CrossRef] [PubMed]

186. Deshmukh, S.; Banerjee, D.; Bhattacharya, G.; Fishlock, S.J.; Barman, A.; McLaughlin, J.; Roy, S.S. Red Mud-Reduced Graphene Oxide Nanocomposites for the Electrochemical Sensing of Arsenic. ACS Appl. Nano Mater. 2020, 3, 4084-4090. [CrossRef]

187. Nunez, C.; Jose Trivino, J.; Segura, R.; Arancibia, V. Development of a fast and sensitive method for the determination of As(III) at trace levels in urine by differential pulse anodic voltammetry using a simple graphene screen-printed electrode. Microchem. J. 2020, 159, 105393. [CrossRef]

188. Liu, Y.; Wei, W. Jointly modified single-walled carbon nanotubes on low resistance monolayer modified electrode for arsenic(III) detection. J. Electroanal. Chem. 2008, 624, 299-304. [CrossRef]

189. Liu, Y.; Wei, W. Layer-by-layer assembled DNA functionalized single-walled carbon nanotube hybrids for arsenic(III) detection. Electrochem. Commun. 2008, 10, 872-875. [CrossRef]

190. Daud, N.; Yusof, N.A.; Tee, T.W.; Abdullah, A.H. Electrochemical Sensor for As(III) Utilizing CNTs/Leucine/Nafion Modified Electrode. Int. J. Electrochem. Sci. 2012, 7, 175-185.

191. Yusof, N.A.; Daud, N.; Tee, T.W.; Abdullah, A.H. Electrocatalytic Characteristic of Carbon Nanotubes/Glutamine/Nafion Modified Platinum Electrode in Development of Sensor for Determination of As(III). Int. J. Electrochem. Sci. $2011,6,2385-2397$.

192. Gamboa, J.C.M.; Cornejo, L.; Squella, J.A. Vibrating screen printed electrode of gold nanoparticle-modified carbon nanotubes for the determination of arsenic(III). J. Appl. Electrochem. 2014, 44, 1255-1260. [CrossRef]

193. Wang, Y.; Wang, P.; Wang, Y.; He, X.; Wang, K. Single strand DNA functionalized single wall carbon nanotubes as sensitive electrochemical labels for arsenite detection. Talanta 2015, 141, 122-127. [CrossRef]

194. Roy, E.; Patra, S.; Madhuri, R.; Sharma, P.K. Europium doped magnetic graphene oxide-MWCNT nanohybrid for estimation and removal of arsenate and arsenite from real water samples. Chem. Eng. J. 2016, 299, 244-254. [CrossRef]

195. RasulKhan, B.; Ponnaiah, S.K.; Periakaruppan, P.; Venkatachalam, G.; Balasubramanian, J. A new CQDs/f-MWCNTs/GO nanocomposite electrode for arsenic $\left(10^{-12} \mathrm{M}\right)$ quantification in bore-well water and industrial effluents. New J. Chem. 2020, 44, 18149-18156. [CrossRef]

196. Baghayeri, M.; Amiri, A.; Karimabadi, F.; Di Masi, S.; Maleki, B.; Adibian, F.; Pourali, A.R.; Malitesta, C. Magnetic MWCNTsdendrimer: A potential modifier for electrochemical evaluation of As(III) ions in real water samples. J. Electroanal. Chem. 2021, 888, 115059. [CrossRef]

197. Zhang, W.; Chen, Z.; Guan, Y.; Liu, C.; Zheng, K.; Zou, X. Aptamer-functionalized screen-printed electrode coupled with graphene oxide and methylene blue nanocomposite as enhanced signal label for total arsenic determination in shellfish. Sens. Actuators $B$ Chem. 2021, 335, 129383. [CrossRef]

198. Arora, K.; Prabhakar, N.; Chand, S.; Malhotra, B.D. Immobilization of single stranded DNA probe onto polypyrrole-polyvinyl sulfonate for application to DNA hybridization biosensor. Sens. Actuators B Chem. 2007, 126, 655-663. [CrossRef]

199. Labuda, J.; Bubnicova, K.; Kovalova, L.; Vanickova, M.; Mattusch, J.; Wennrich, R. Voltammetric detection of damage to DNA by arsenic compounds at a DNA biosensor. Sensors 2005, 5, 411-423. [CrossRef]

200. Wen, S.; Zhang, C.; Liang, R.; Chi, B.; Yuan, Y.; Qiu, J. Highly sensitive voltammetric determination of arsenite by exploiting arsenite-induced conformational change of ssDNA and the electrochemical indicator Methylene Blue. Microchim. Acta 2017, 184, 4047-4054. [CrossRef] 
201. Mao, K.; Zhang, H.; Wang, Z.; Cao, H.; Zhang, K.; Li, X.; Yang, Z. Nanomaterial-based aptamer sensors for arsenic detection. Biosens. Bioelectron. 2020, 148, 111785. [CrossRef]

202. Baghbaderani, S.S.; Noorbakhsh, A. Novel chitosan-Nafion composite for fabrication of highly sensitive impedimetric and colorimetric As(III) aptasensor. Biosens. Bioelectron. 2019, 131, 1-8. [CrossRef]

203. Cui, L.; Wu, J.; Ju, H. Label-free signal-on aptasensor for sensitive electrochemical detection of arsenite. Biosens. Bioelectron. 2016, 79, 861-865. [CrossRef]

204. Fuku, X.; Iftikar, F.; Hess, E.; Iwuoha, E.; Baker, P. Cytochrome c biosensor for determination of trace levels of cyanide and arsenic compounds. Anal. Chim. Acta 2012, 730, 49-59. [CrossRef]

205. Hwang, J.-H.; Pathak, P.; Wang, X.; Rodriguez, K.L.; Park, J.; Cho, H.J.; Lee, W.H. A novel Fe-Chitosan-coated carbon electrode sensor for in situ As(III) detection in mining wastewater and soil leachate. Sens. Actuators B Chem. 2019, 294, 89-97. [CrossRef]

206. Wen, S.-H.; Wang, Y.; Yuan, Y.-H.; Liang, R.-P.; Qiu, J.-D. Electrochemical sensor for arsenite detection using graphene oxide assisted generation of prussian blue nanoparticles as enhanced signal label. Anal. Chim. Acta 2018, 1002, 82-89. [CrossRef] [PubMed]

207. Sawan, S.; Hamze, K.; Youssef, A.; Bouhadir, K.; Errachid, A.; Maalouf, R.; Jaffrezic-Renault, N. The Use of Voltammetry for Sorption Studies of Arsenic(III) Ions by Magnetic Beads Functionalized with Nucleobase Hydrazide Derivatives. Electroanalysis 2021, 33, 1789-1799. [CrossRef]

208. Chen, L.; Zhou, N.; Li, J.; Chen, Z.; Liao, C.; Chen, J. Synergy of glutathione, dithiothreitol and N-acetyl-L-cysteine self-assembled monolayers for electrochemical assay: Sensitive determination of arsenic(III) in environmental and drinking water. Analyst 2011, 136, 4526-4532. [CrossRef] [PubMed]

209. Shah, A. L-tryptophan modified glassy carbon electrode for the picomolar detection of As(III). J. Electrochem. Soc. 2020, 167, 117509. [CrossRef]

210. Zaib, M.; Saeed, A.; Hussain, I.; Athar, M.M.; Iqbal, M. Voltammetric detection of As(III) with Porphyridium cruentum based modified carbon paste electrode biosensor. Biosens. Bioelectron. 2014, 62, 242-248. [CrossRef]

211. Irvine, G.W.; Tan, S.N.; Stillman, M.J. A Simple Metallothionein-Based Biosensor for Enhanced Detection of Arsenic and Mercury. Biosensors 2017, 7, 14. [CrossRef]

212. del Torno-de Roman, L.; Asuncion Alonso-Lomillo, M.; Dominguez-Renedo, O.; Julia Arcos-Martinez, M. Dual Biosensing Device for the Speciation of Arsenic. Electroanalysis 2015, 27, 302-308. [CrossRef]

213. Gu, H.; Yang, Y.; Chen, F.; Liu, T.; Jin, J.; Pan, Y.; Miao, P. Electrochemical detection of arsenic contamination based on hybridization chain reaction and $\operatorname{RecJ}(\mathrm{f})$ exonuclease-mediated amplification. Chem. Eng. J. 2018, 353, 305-310. [CrossRef]

214. Nunez, C.; Jose Trivino, J.; Arancibia, V. A electrochemical biosensor for As(III) detection based on the catalytic activity of Alcaligenes faecalis immobilized on a gold nanoparticle-modified screen-printed carbon electrode. Talanta 2021, 223, 121702. [CrossRef] [PubMed]

215. Cortes-Salazar, F.; Beggah, S.; van der Meer, J.R.; Girault, H.H. Electrochemical As(III) whole-cell based biochip sensor. Biosens. Bioelectron. 2013, 47, 237-242. [CrossRef] [PubMed]

216. Sanchez, S.; McDonald, M.; Silver, D.M.; de Bonnault, S.; Chen, C.; LeBlanc, K.; Hicks, E.C.; Mayall, R.M. The Integration of Whole-Cell Biosensors for the Field-Ready Electrochemical Detection of Arsenic. J. Electrochem. Soc. 2021, 168, 067508. [CrossRef]

217. Sciuto, E.L.; Petralia, S.; van der Meer, J.R.; Conoci, S. Miniaturized electrochemical biosensor based on whole-cell for heavy metal ions detection in water. Biotechnol. Bioeng. 2021, 118, 1456-1465. [CrossRef] [PubMed]

218. Vega-Figueroa, K.; Santillan, J.; Ortiz-Gomez, V.; Ortiz-Quiles, E.O.; Quinones-Colon, B.A.; Castilla-Casadiego, D.A.; Almodovar, J.; Bayro, M.J.; Rodriguez-Martinez, J.A.; Nicolau, E. Aptamer-Based Impedimetric Assay of Arsenite in Water: Interfacial Properties and Performance. ACS Omega 2018, 3, 1437-1444. [CrossRef]

219. Ismail, S.; Yusof, N.A.; Abdullah, J.; Abd Rahman, S.F. Electrochemical Detection of Arsenite Using a Silica Nanoparticles-Modified Screen-Printed Carbon Electrode. Materials 2020, 13, 3168. [CrossRef]

220. Rahman, M.M.; Hussein, M.A.; Aly, K.I.; Asiri, A.M. Thermally stable hybrid polyarylidene(azomethine-ether)s polymers (PAAP): An ultrasensitive arsenic(III) sensor approach. Des. Monomers Polym. 2018, 21, 82-98. [CrossRef]

221. Ma, W.; Chang, Q.; Zhao, J.; Ye, B.-C. Novel electrochemical sensing platform based on ion imprinted polymer with nanoporous gold for ultrasensitive and selective determination of $\mathrm{As}^{3+}$. Microchim. Acta 2020, 187, 571. [CrossRef] 